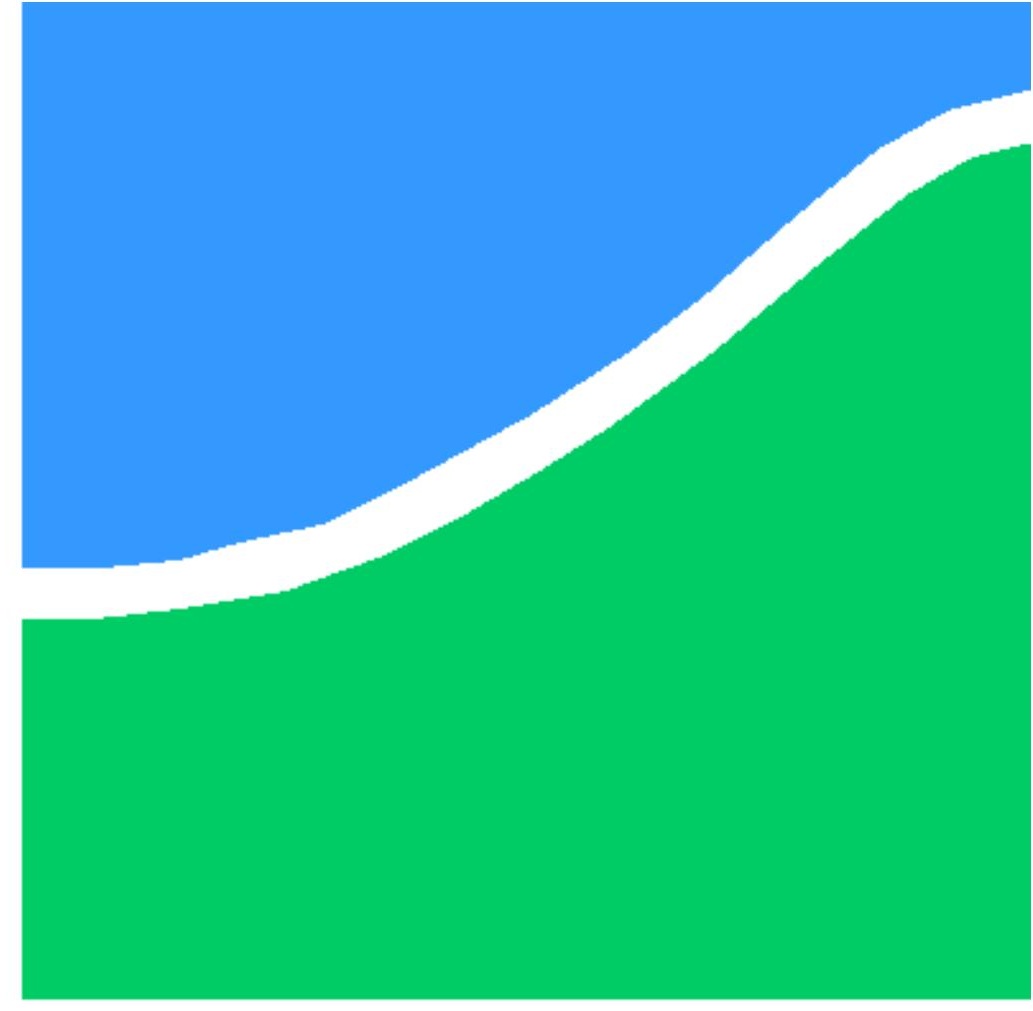

Dissertação de Mestrado

INJEÇÃO DE CARGAS NO POLÍMERO P3HT EM CONDIÇÕES AMBIENTAIS COMO UM CONTROLE DE PROCESSOS DEGRADATIVOS EM MATERIAIS VERDES

Vilany Santana Pereira

Brasília, Julho de 2016

UNIVERSIDADE DE BRASÍLIA 
UNIVERSIDADE DE BRASÍLIA

FACULDADE DE TECNOLOGIA

DEPARTAMENTO DE ENGENHARIA ELÉTRICA

\section{INJEÇÃO DE CARGAS NO POLÍMERO P3HT EM CONDIÇÕES AMBIENTAIS COMO UM CONTROLE DE PROCESSOS DEGRADATIVOS EM MATERIAIS VERDES}

VILANY SANTANA PEREIRA

ORIENTADOR: STEFAN BLAWID

DISSERTAÇÃO DE MESTRADO EM ENGENHARIA DE SISTEMAS ELETRÔNICOS E AUTOMAÇÃO

PUBLICAÇÃO: DMPGEA - 630/2016

BRASÍLIA/DF: JULHO - 2016 


\section{UNIVERSIDADE DE BRASÍLIA \\ FACULDADE DE TECNOLOGIA \\ DEPARTAMENTO DE ENGENHARIA ELÉTRICA}

\section{INJEÇÃO DE CARGAS NO POLÍMERO P3HT EM CONDIÇÕES AMBIENTAIS COMO UM CONTROLE DE PROCESSOS DEGRADATIVOS EM MATERIAIS VERDES}

\section{VILANY SANTANA PEREIRA}

DISSERTAÇÃO DE MESTRADO SUBMETIDA AO DEPARTAMENTO DE ENGENHARIA ELÉTRICA DA FACULDADE DE TECNOLOGIA DA UNIVERSIDADE DE BRASÍLIA, COMO PARTE DOS REQUISITOS NECESSÁRIOS PARA A OBTENÇÃO DO GRAU DE MESTRE.

APROVADA POR:

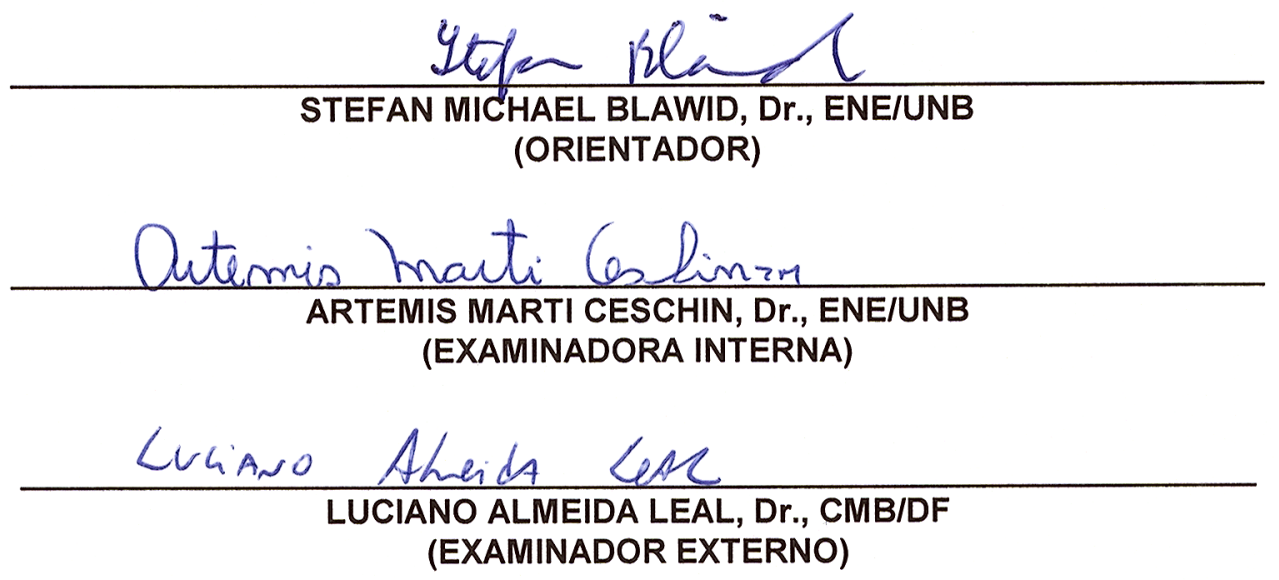

Brasília, 08 de julho de 2016. 


\section{FICHA CATALOGRÁFICA}

PEREIRA, VILANY SANTANA

Injeção de cargas no polímero P3HT em condições ambientais como um controle de processos degradativos em materiais verdes [Distrito Federal] 2016.

xiii, 115p., 210 x 297 mm (ENE/FT/UnB, Mestre, Dissertação de Mestrado - Universidade de Brasília. Faculdade de Tecnologia.

Departamento de Engenharia Elétrica

1.Eletrônica orgânica

2.Polímeros semicondutores

3.Materiais verdes

4.Degradação em dispositivos orgânicos

I. ENE/FT/UnB

II. Título (série)

\section{REFERÊNCIA BIBLIOGRÁFICA}

PEREIRA., V. S. (2016). Injeção de cargas no polímero P3HT em condições ambientais como um controle de processos degradativos em materiais verdes. Dissertação de Mestrado em Engenharia de Sistemas Eletrônicos e de Automação, Publicação DMPGEA - 630/2016, Departamento de Engenharia Elétrica, Universidade de Brasília, Brasília, DF, 115p.

\section{CESSÃO DE DIREITOS}

AUTOR: Vilany Santana Pereira.

TÍTULO: Injeção de cargas no polímero P3HT em condições ambientais como um controle de processos degradativos em materiais verdes.

GRAU: Mestre

ANO: 2016

É concedida à Universidade de Brasília permissão para reproduzir cópias desta dissertação de mestrado e para emprestar ou vender tais cópias somente para propósitos acadêmicos e científicos. $\mathrm{O}$ autor reserva outros direitos de publicação e nenhuma parte dessa dissertação de mestrado pode ser reproduzida sem autorização por escrito do autor.

Vilany Santama Pereina

Vilany Santana Pereira

CLN 407, bloco E, Asa Norte.

70.855-550 Brasília - DF - Brasil. 


\section{Dedicatória}

À meus pais Francisca e Vergniaud por serem minha base, suporte e motivação na vida.

Vilany Santana Pereira 


\section{Agradecimentos}

À Deus pelas oportunidades que fez surgir no meu caminho, guiando minha trajetória até aqui.

À minha família por todo apoio emocional que, inesgotavelmente, me concedem.

Ao meu orientador Stefan Blawid, pela maneira generosa e paciente com que me transmitiu seus conhecimentos, pela dedicação e entusiasmo com que abraça a pesquisa, tornando-se para mim exemplo de profissional.

À professora Artemis Ceschin pela disponibilidade em estar sempre colaborando no que for preciso no LDCI.

Aos amigos Patrick Brito e Marienne Narvaez pela amizade, conhecimentos trocados, pelo apoio psicológico e pelas horas de descontração.

Ao aluno de iniciação científica Filipe Lima pela valiosa ajuda no tratamento dos dados obtidos. Aos demais alunos Caio, Miguel, Pedro e Júlia pelas contribuições ao longo do trabalho.

Aos professores da microeletrônica pelo aprendizado e aos colegas pelas trocas de experiências e compartilhamento de êxitos e desafios da área.

À CAPES pelo apoio financeiro durante o curso.

Vilany Santana Pereira 


\section{RESUMO}

A descoberta de polímeros condutores há 40 anos abriu o caminho para a eletrônica orgânica com a promessa de novas aplicações. Desde então, uma gama considerável de dispositivos eletrônicos contendo polímeros condutores (semi) tem sido desenvolvidos, como diodos emissores de luz, dispositivos ópticos não lineares, músculos artificiais, transístores de filmes finos, dispositivos fotovoltaicos, dentre outros. Incorporando compostos orgânicos extraídos de plantas (os chamados materiais "verdes") nestes dispositivos é possível melhorar estabilidade, sustentabilidade e os custos de manufatura. Materiais verdes são processados sob atmosfera ambiente, utilizando técnicas de deposição simples como spin, dip coating ou drop casting. Mesmo os semicondutores orgânicos bem conhecidos comportam-se de maneira diferente nestas condições. Como um sistema de modelo e referência para materiais verdes, foi reinvestigada a injeção de lacunas no polímero semicondutor regiorregular poly(3-hexylthiophene-2,5-diyl) (P3HT). Este por sua vez, é conhecido por ser sensível aos contaminantes ambientais, como humidade, oxigênio ou solventes remanescentes. No presente trabalho, é dada especial ênfase para a compreensão da resposta elétrica dos semicondutores orgânicos sob ação de processos degradativos, que afetam tanto o filme quanto as interfaces. Para promover a injeção de carga no P3HT vários cenários de secagem foram monitorados após tratamento térmico (annealing) e envelhecimento. Comparou-se a injeção de carga através de uma interface metal-semicondutor com uma heterojunção orgânica na mesma amostra para distinguir efeitos do filme e de interfaces. Fenômenos de dopagem não intencional, presença de impurezas carregadas, degradação por armadilhas de lacunas profundas e camadas interfaciais não uniformes foram identificados através da análise cuidadosa das características de corrente-tensão, parcialmente com a ajuda de simulações numéricas que resolveram as equações diferenciais não-linear de Poisson e de deriva-difusão. Além disso, a injeção de cargas em materiais verdes como filmes plastificados com base em Buriti e óleo de Urucum revelou diferenças marcantes em relação ao material de referência P3HT, provavelmente relacionado a modificações de interface. O exemplo dado demonstra a utilidade da criação de injeção de carga em filme P3HT por casting como controle para desenvolver materiais verdes com aplicações eletrônicas. 


\begin{abstract}
The discovery of conducting polymers 40 years ago paved the way for organic electronics promising exciting new applications. Already a considerable range of electronic devices containing (semi) conducting polymers has been developed like light emitting diodes, non-linear optical devices, artificial muscles, thin film transistors and large area photovoltaic devices. Incorporating organic compounds extracted from plants (so called 'green' materials) in these devices may improve stability, sustainability and manufacturing costs. Green materials are processed under ambient atmosphere using simple deposition techniques like spin and dip coating or drop casting. Even well known organic semiconductors behave differently under these conditions. As a model system and reference for green materials, we reinvestigated the injection of holes into the regioregular semiconducting polymer poly(3-hexylthiophene-2,5-diyl) (P3HT). P3HT is known to be sensitive to ambient dopants, like moisture, oxygen or reminiscent solvents. In the present work, special emphasis is given to understanding the electrical signature of degrading processes, which affect both the bulk and the interfaces of the organic semiconductor. To this extend the charge injection into P3HT was monitored after various drying scenarios, heat treatment (annealing) and aging. Especially fruitful proved the comparison of charge injection across a metal-semiconductor interface and an organic heterojunction in the same sample to distinguish bulk and interface effects. Unintentional doping, the presence of charged impurities, degradation by deep hole traps and non-uniform interfacial layers could be all identified by carefully analysing current-voltage characteristics, partially with the help of numerical simulations solving the coupled nonlinear Poisson and drift-diffusion differential equations. Moreover, charge injection into selected green materials like plasticised films based on Buriti and Annatto oil revealed striking differences compared to the reference material P3HT, most likely related to interface modifications. The given example proves the usefulness of establishing charge injection into casted P3HT film as control when developing green materials for electronic applications.
\end{abstract}




\section{SUMÁRIO}

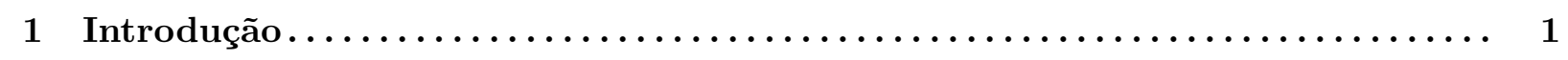

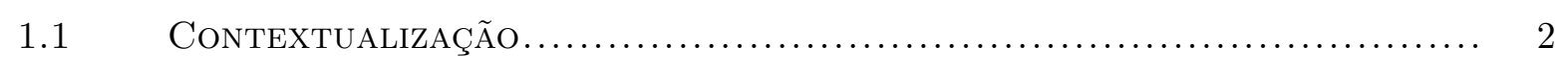

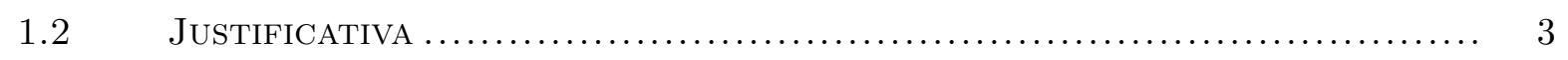

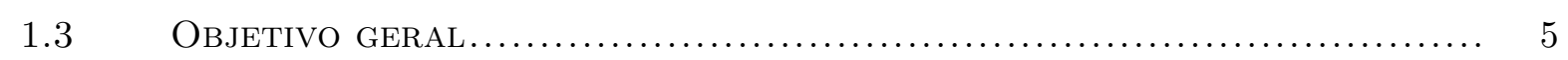

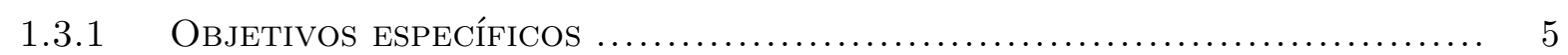

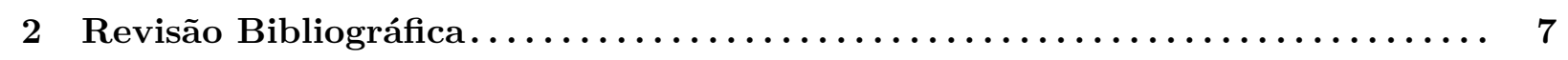

$2.1 \quad$ TRANSPORTE ElETRÔNICO EM POLÍMEROS CONDUTORES $\ldots \ldots \ldots \ldots \ldots \ldots \ldots \ldots \ldots \ldots$

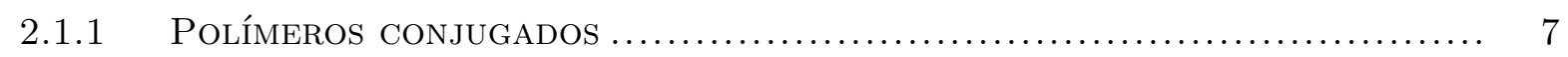

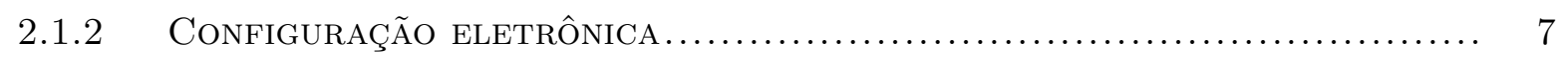

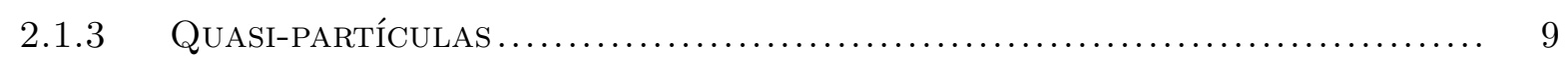

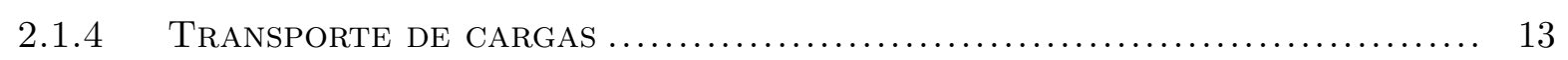

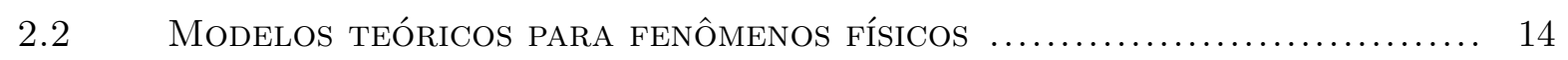

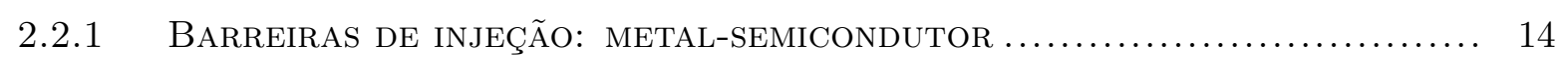

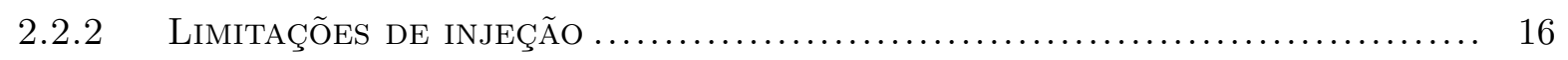

2.2 .3 CORRENTE LIMITADA POR CARGAS ESPACIAIS (SCLC) E ARMADILHAS (TLC) 16

$\begin{array}{lll}2.3 & \text { P3HT (POLY(3-HEXYLTHIOPHENE)) } \ldots \ldots \ldots \ldots \ldots \ldots \ldots \ldots \ldots \ldots \ldots \ldots \ldots \ldots \ldots \ldots \ldots \ldots \ldots \ldots \ldots \ldots \ldots \ldots \ldots \ldots \ldots\end{array}$

2.4 PEDOT:PSS (POLY(3,4-ETHYLENEDIOXYTHIOPHENE)-POLY(STYRENESULFONATE)) 22

$2.5 \quad$ FTO (ÓXIdO DE EstanHO DOPADO COM FLÚOR) $\ldots \ldots \ldots \ldots \ldots \ldots \ldots \ldots \ldots \ldots \ldots \ldots \ldots \ldots$

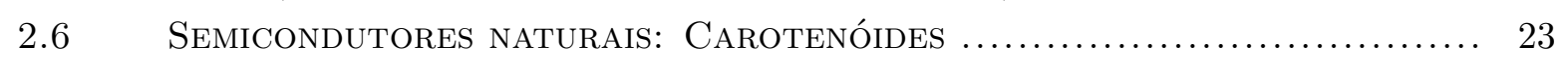

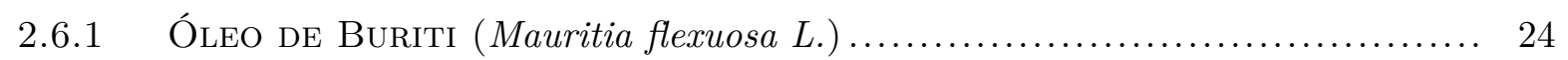

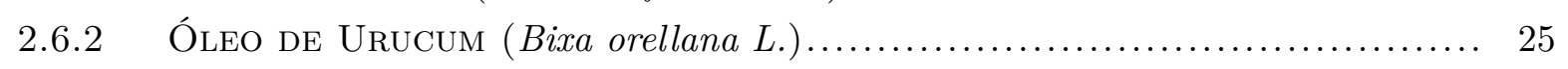

2.7 MECANISMOS DE DEGRADAÇ̃̃O DE UM DISPOSITIVO ORGÂNICO, ............... 26

3 Desenvolvimento $. . \ldots \ldots \ldots \ldots \ldots \ldots \ldots \ldots \ldots \ldots \ldots \ldots \ldots \ldots \ldots \ldots \ldots, \quad 30$

$3.1 \quad$ CONFECÇ̃̃O DE DISPOSITIVOS ORGÂNICOS: ASPECTOS RELEVANTES ............ 30

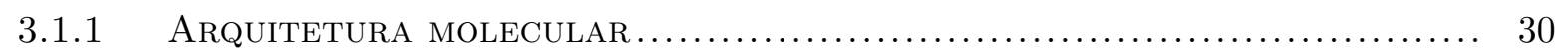

3.1 .2 TÉCNICAS DE PROCESSAMENTO ............................................ 31

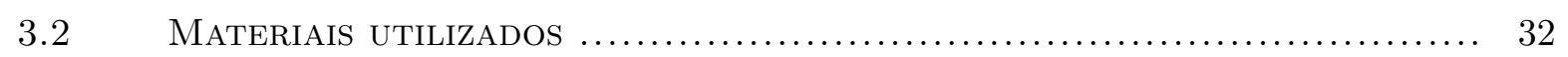

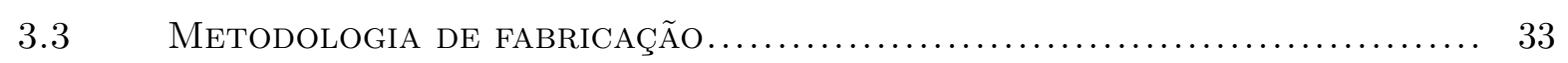

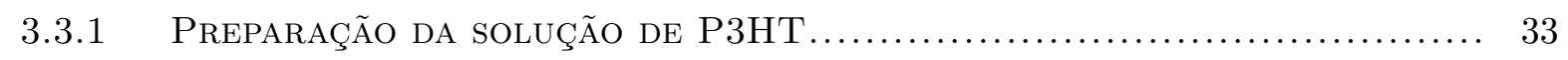

3.3 .2 PREPARAÇÃo DAS SOLUÇÕES DE ÓLEO DE BURITI E ÓLEO DE URCUM ......... 33

$3.3 .3 \quad$ PROCEDIMENTO PARA CONFECÇÃO DOS DISPOSITIVOS $\ldots \ldots \ldots \ldots \ldots \ldots \ldots \ldots \ldots \ldots \ldots \ldots \ldots$ 
$3.3 .4 \quad$ REALIZAÇÃO DE TRATAMENTO TÉRMICO (annealing) $\ldots \ldots \ldots \ldots \ldots \ldots \ldots \ldots \ldots \ldots \ldots \ldots$

3.3 .5 MiCROSCOPIA DE FORÇA ATÔMICA (AFM) E MEDIDAS DA GEOMETRIA ........ 35

3.4 MEDIDA DE RESISTÊNCIA POR QUADRADO: SONDA DE QUATRO PONTAS ....... 36

3.5 CARACTERIZAÇÃO ELÉTRICA DOS DISPOSITIVOS DESENVOLVIDOS ............ 36

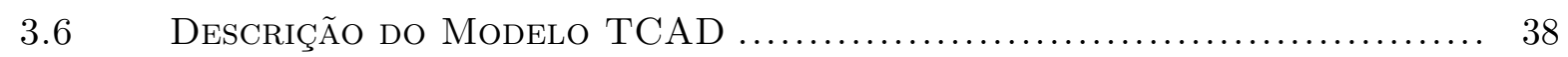

4 Resultados e Discussões.$\ldots \ldots \ldots \ldots \ldots \ldots \ldots \ldots \ldots \ldots \ldots \ldots \ldots \ldots \ldots \ldots \ldots \ldots$

4.1 MiCROSCOPIA DE FORÇA ATÔMICA (AFM) E MEDIDAS DA GEOMETRIA ........ 41

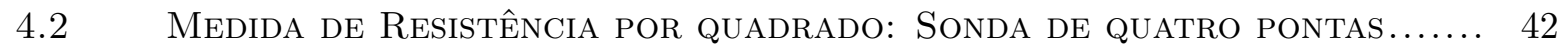

4.3 CARACTERIZAÇÃO ELÉTRICA DO GRUPO 1 DE AMOSTRAS .................... 43

4.3 .1 InVESTIGAÇÃO DE SUBSTRATOS CONDUTIVOS: DO-1 (FTO/P3HT/AG) .... 43

4.3.2 InVESTIGAÇÃo DE SUBSTRATOS CONDUTIVOS: DO-2 (FTO/P3HT/PEDOT:PSS $/ \mathrm{AG})$

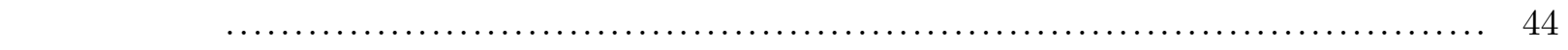

4.3 .3 DETALHAMENTO DO DISPOSITIVO AG/P3HT/PEDOT:PSS/FTO ............ 46

$4.4 \quad$ EFEITOS DE HISTERESE E CAPACITÂNCIA PARASÍTICA $\ldots \ldots \ldots \ldots \ldots \ldots \ldots \ldots \ldots \ldots \ldots$

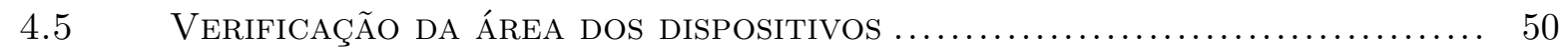

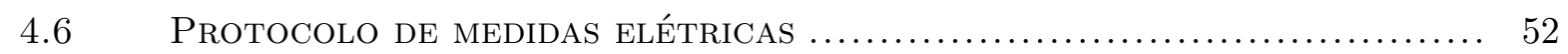

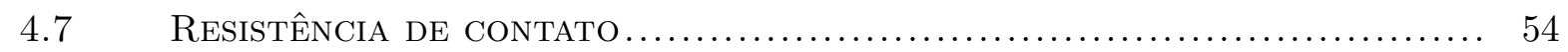

4.8 Estudo DA InJEÇÃO DE CARGA: GRUPO 2 DE AMOSTRAS $\ldots \ldots \ldots \ldots \ldots \ldots \ldots \ldots$

4.8 .1 REGIME DE POLARIZAÇÃO 1: Prata $(+) / \mathrm{FTO}(0) \ldots \ldots \ldots \ldots \ldots \ldots \ldots \ldots \ldots \ldots \ldots$

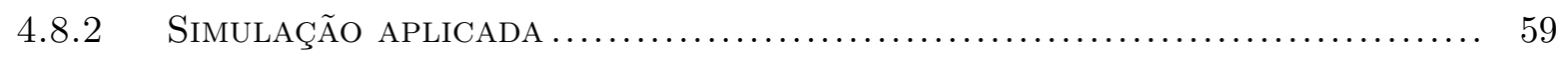

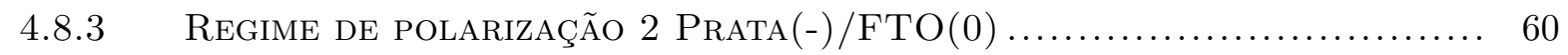

4.8 .4 COMPORTAMENTO SUBLINEAR EM BAIXAS TENSÕES $\ldots \ldots \ldots \ldots \ldots \ldots \ldots \ldots \ldots \ldots \ldots \ldots$

$4.9 \quad$ TRATAMENTO TÉRMICO: ANÁLISE QUALITATIVA $\ldots \ldots \ldots \ldots \ldots \ldots \ldots \ldots \ldots \ldots \ldots \ldots \ldots \ldots \ldots$

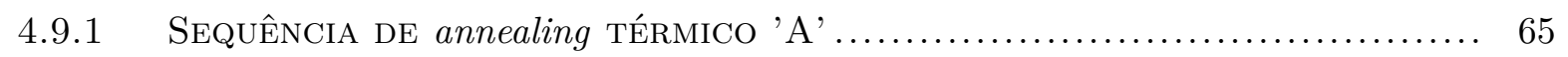

4.9 .2 SEQUÊNCIA DE annealing TÉRMICO 'B' ................................... 67

$4.10 \quad$ TRATAMENTO TÉRMICO: ANÁLISE QUANTITATIVA .......................... 68

4.10 .1 DEPOSIÇÃO DO PEDOT:PSS POR DIP COATER E SPIN COATER ............... 69

4.11 SOB EFEITO DO ENVELHECIMENTO ..................................... 71

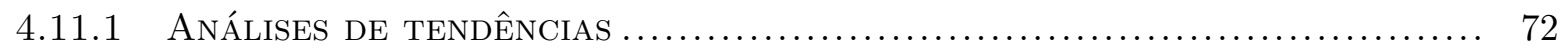

4.12 DISPOSITIVOS OBTIDOS A PARTIR DE OB E OU, ............................. 75

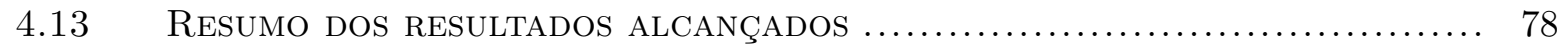

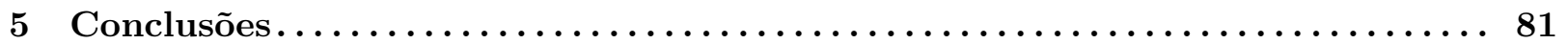

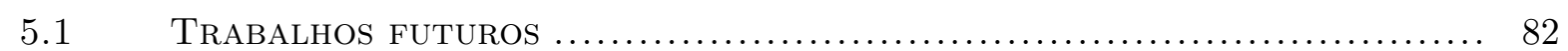

REFERÊNCIAS BIBLIOGRÁFICAS $\ldots \ldots \ldots \ldots \ldots \ldots \ldots \ldots \ldots \ldots \ldots \ldots$

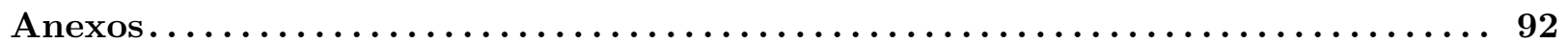

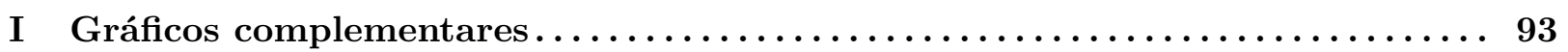

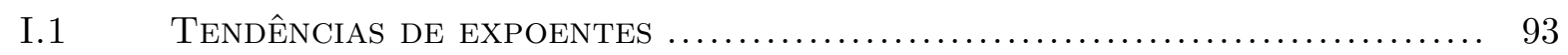

I.2 TÉCNICAS DE DEPOSIÇÃO PEDOT-PSS: TENSÕES NEGATIVAS. ............... 93 


\section{LISTA DE FIGURAS}

2.1 Polímeros conjugados mais significativos na área da eletrônica orgânica $[1][\ldots \ldots \ldots . \quad 8$

2.2 (a) Formação das ligações $\sigma$ e $\pi$ a partir da hibridização $s p^{2}$ do carbono (b) Superposição dos orbitais $p z$ num anel benzênico, resultando em um sistema de elétrons

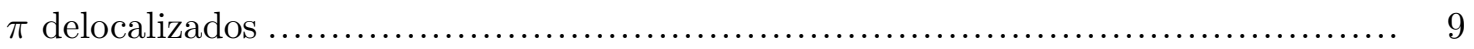

2.3 (a) Transição de Peierls para o trans-poliacetileno: a diferença de $0,1 \AA$ entre os comprimentos das ligações $\mathrm{C}-\mathrm{C}$ e $\mathrm{C}=\mathrm{C}$ dá origem a um gap de $1,5 \mathrm{eV}$ no polímero (b) Diagrama de energia para a molécula de benzeno (⿳亠丷 esquerda) com a interação entre orbitais $\pi$ produzindo uma distribuição de estados eletrônicos que se assemelham à uma estrutura de banda: HOMO e LUMO; representação de orbitais $\pi$ para uma

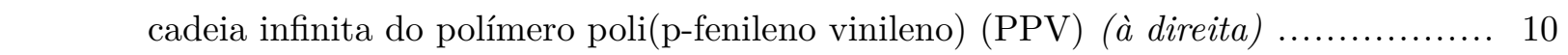

2.4 (a) Cadeia polimérica com diferentes comprimentos de conjugação efetiva $|2|$ (b) Esquemático do transporte eletrônico por saltos por entre estados localizados, cuja distribuição de níveis energéticos é do tipo gaussiana para diferentes densidades de \begin{tabular}{|c|}
\hline estados $\mathrm{D}(\mathrm{E})$. A linha vermelha destaca o nível de transporte com maior probabi- \\
\hline
\end{tabular}

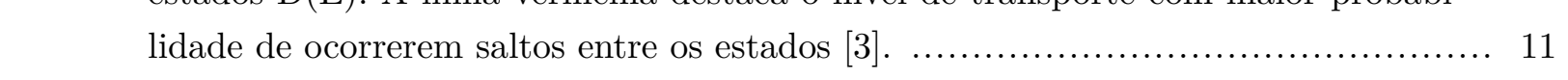

2.5 Processos de dopagem por oxidação/redução dando origem a pôlarons e bipolarons. 12

2.6 Transporte de cargas em polímeros condutores: intracadeia (1-2), intercadeia (2-3),

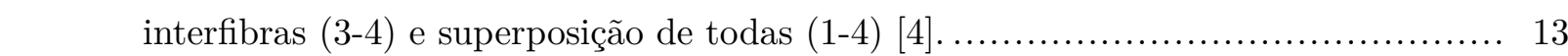

2.7 Tipos de contatos metal/semicondutor em função dos alinhamentos de funções trabalho (a) Contato de acumulação (b) Contato de depleção (c) formação de dipolos

\begin{tabular}{|c|c|}
\hline & los \\
\hline & rface em decorrência da desordem entre os materiais $|5|$ (d) Estrutur \\
\hline & trônica típica de uma interface metal-semicondutor orgânico, exibindo os níveis \\
\hline & energéticos em ambos os lados, a afinidade eletrônica (EA, do inglês, electron af- \\
\hline & finity) e energia de ionização (IE, do inglês, ionization energy) do semicondutor, \\
\hline & o dipolo de interface $\delta$, a densidade de estados gap na interface e o nível de neu- \\
\hline & tralidade de carga ECNL, e a barreira de injeção para lacunas $\phi_{B p}$ e para elétrons \\
\hline & $\phi_{B n}[6] . \ldots$ \\
\hline 2.8 & Curvas J(V) simuladas para um dispositivo contendo elevada densidade de armadi- \\
\hline & lhas $\mathrm{N}_{T}=10^{7} \mathrm{~cm}^{-3}$ e outro com tensão intrínseca $\left(\mathrm{V}_{b} i\right)$ de $1 \mathrm{~V}$. A linha tracejada \\
\hline & separa tais efeitos atuantes em baixas tensões e as limitações do filme semicondutor \\
\hline & em si para moderadas tensões. O contato passa a ser limitado em mais altas tensões \\
\hline & licadas. Adaptado de Kirchartz $|7|$. \\
\hline & lecular do P3HT \\
\hline
\end{tabular}


2.10 Configuração head-to-tail (HT), head-to-head (HH), e tail-to-tail (TT) encontrados

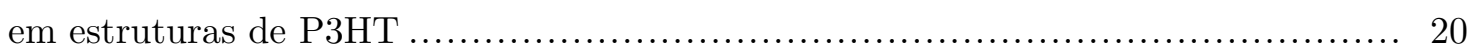

2.11 Orientações possíveis do P3HT ao ser depositado com filme (a) edge-on (b) face-on

(c) Mobilidade preferencial no filme polimérico. Adaptado de Lim $\mid 8] \ldots \ldots \ldots \ldots \ldots \ldots . . \ldots 21$

2.12 Estrutura química do PEDOT:PSS, evidenciando a localização de ambos na forma-

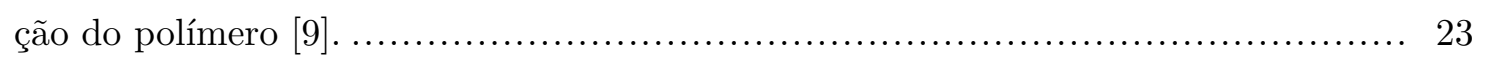

2.13 (a) Fruto do Buriti (b) Estrutura molecular do $\beta$-caroteno ............................ 25

2.14 (a) Semente de Urucum (b) Bixina (c) Norbixina................................. 26

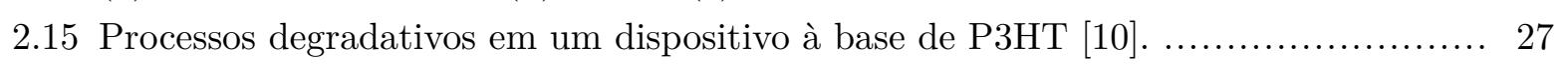

2.16 Energia de banda do filme PEDOT:PSS antes e após ser removida um película de

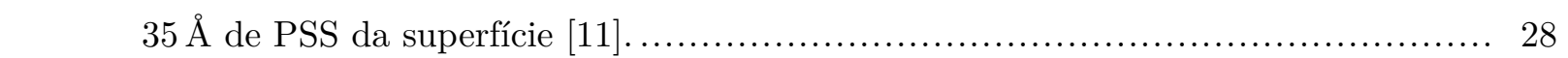

3.1 (a) Técnicas de processamento utilizadas (b) Arquiteturas desenvolvidas para os dispositivos Ag/P3HT/FTO (DO-1) e (b) Ag/P3HT/PEDOT:PSS/FTO (DO-2) (c) fotografia de uma amostra real fabricada .......................................... 34

3.2 Ilustração representativa de funcionamento de AFMs (a) Microscópio de Força atômica Innova ${ }^{\mathrm{TM}}$ (Veeco Instruments) (b) Perfilômetro Dektak150 (Veeco Instru-

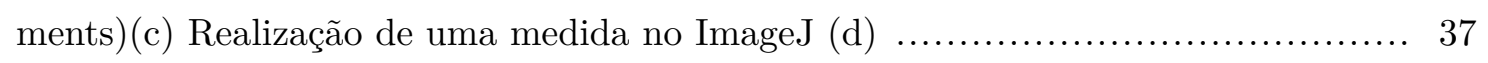

$3.3 \quad$ Equipamento Jandel RM3000 para medidas de sondas de quatro pontos. .............. 37

3.4 Sistema de medição Keysight B2901A (a) Micromanipuladores e sondas metálicas

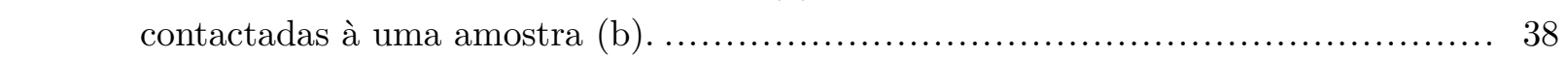

4.1 Microscopia de força atômica (a) FTO (b) PEDOT:PSS (c) P3HT (d) Seção transversal de amostra PET/P3HT evidenciando a espessura do filme. ................... 42

4.2 Características elétricas de DO-1 obtidos por casting para ambas polarizações e com

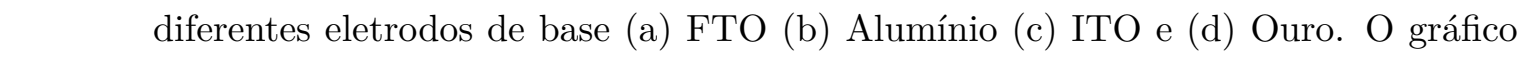
interno refere-se a escala linear e à esquerda uma analogia as bandas de energia dos

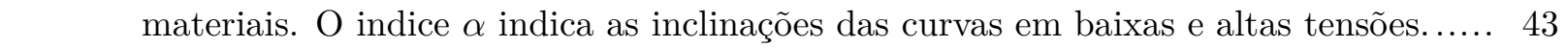

4.3 Características elétricas de DO-2 obtidos por casting para ambas polarizações e com diferentes eletrodos de base (a) FTO (b) Alumínio e (c) ITO. .................... 45

4.4 Bandas de energias dos materiais antes do contato, apenas para indicar o fluxo majoritário de lacunas em ambas polarização, devido a elevada altura de barreira

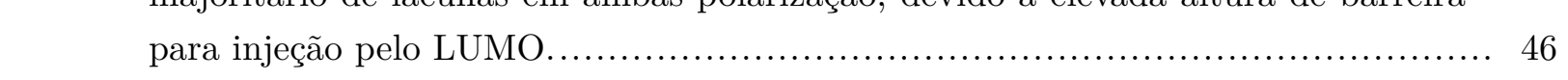

4.5 Três perfis de histereses visualizados para amostras DO-1(FTO/P3HT/PEDOT:PSS/Ag)

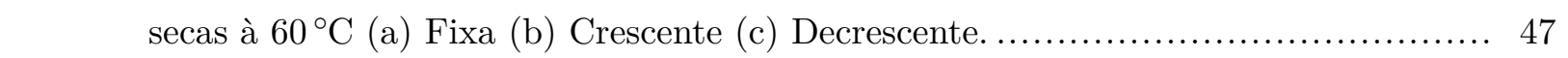

4.6 Correntes negativas em baixas tensões para 8 rampas de tensões aplicadas, evidenciadas pelo pico nas curvas que na escala logarítmica representa valor zero. ........... 49

4.7 Aplicação do protocolo para descarregamento da capacitância (a) Dez aplicações a uma amostra (b) Valor médio para 3 medidas com o erro associado. .................. 49

4.8 Estrutura de dispositivo montado para a verificação do experimento (a) Fluxo 1 de corrente: Ag1 ou Ag2-P3HT-PEDOT:PSS-FTO e Fluxo 2 de corrente: Ag1 ou Ag2P3HT-PEDOT:PSS-Ag3. Obs.: as setas indicam apenas o caminho representativo

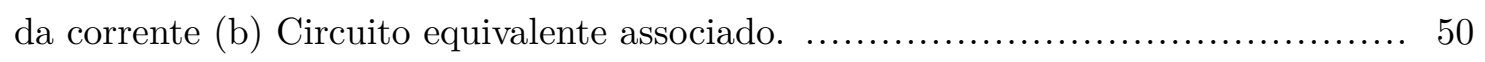


4.9 Comparativos entre os contatos Ag1 e Ag2 (a) Fluxo 1 (b) Fluxo 2 e comparativos entre os fluxos 1 e 2 (c) Ag1 (d) Ag2 ............................................ 51

4.10 Resposta elétrica das velocidades: short, medium, normal e long aplicadas a uma

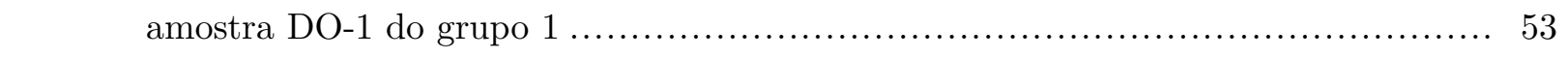

4.11 Comportamento distinto entre aplicação de primeira rampa (1app) e as subsequentes. 53

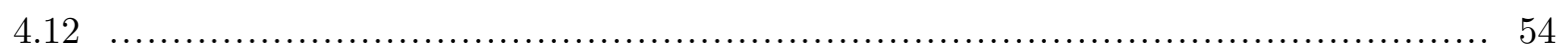

4.13 Esquemáticos (a) resistor de comprimento L, conectado a dois contatos metálicos

\begin{tabular}{|c|}
\hline (b) região de distância $\Delta_{\mathrm{x}}$ abaixo do contato (c) Fluxo de corrente em uma porção \\
\hline
\end{tabular}

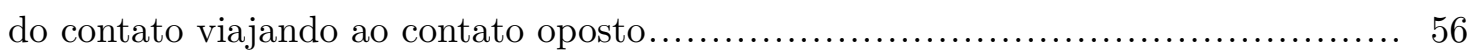

4.14 Experimento realizado para extração da resistência do contato dos filmes polimé-

\begin{tabular}{|c|}
\hline ricos (a) esboço do experimento (b) Circuito equivalente (c) Curva resistência em \\
\hline
\end{tabular}

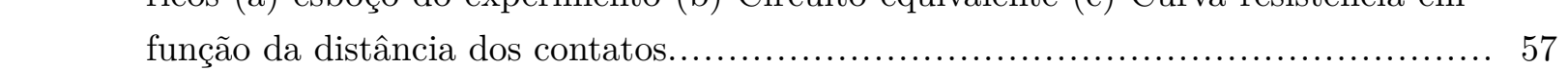

4.15 Curvas $I(V)$ de um dos dispositivos obtidos com secagem de $120^{\circ} \mathrm{C}$, mostrando as

inclinações $\alpha$ em baixas e altas tensões, para tensões positivas e negativas. ............ 58

4.16 Curvas $I(V)$ de amostras de segundo grupo (a) TT3A-Ag2 (b) TT3A-Ag3 (c)

\begin{tabular}{|c|}
\hline TT5A-Ag1. A linha preenchida representa a curva simulada difusão-deriva (DD) e \\
\hline
\end{tabular}

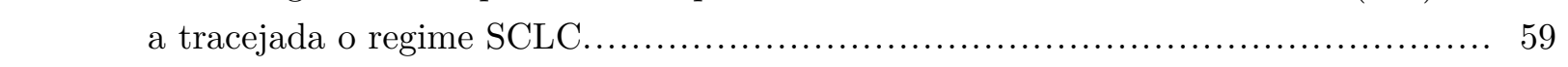

4.17 Relação entre expoentes para baixas e elevadas tensões (a) polarização 1 e (b)

polarização 2, indicando a tendência de ocorrer inclinações sublineares para algumas

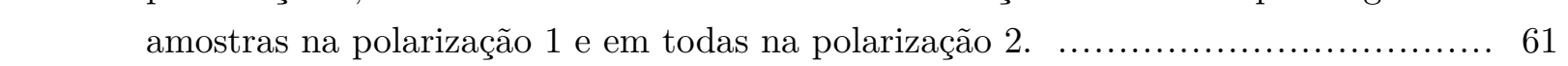

4.18 Ilustrações para elucidação do fenômeno (a) 3 diferentes explicações do filme de PE-

DOT:PSS (b) Sentido das cargas com base nos campos elétricos internos e externos

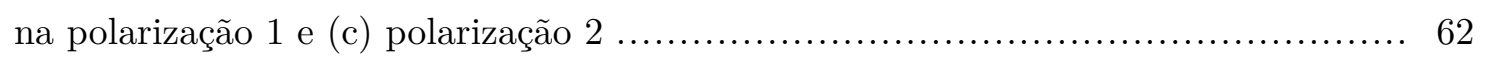

4.19 Curvas $I(V)$ da amostra nomeada TTB-Ag4 (a) Resultado experimental (b) Simu-

lação incluindo a existência de dois canais. A linha preenchida representa a curva

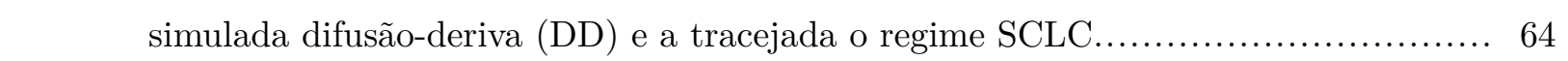

4.20 Caracterização elétrica dos dispositivos submetidos à sequência A de annealing (a)

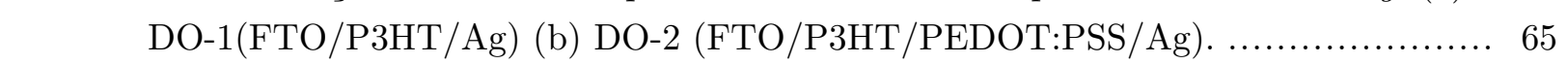

4.21 Caracterização elétrica de DO-2 (FTO/P3HT/PEDOT:PSS/Ag) para sequência de

annealing $\mathrm{B}$ (a) 80 (10 minutos) $+150{ }^{\circ} \mathrm{C}(2$ horas $)$ (b) $100(10$ minutos $)+150{ }^{\circ} \mathrm{C}(2$

horas) (c) $120(10$ minutos $)+150{ }^{\circ} \mathrm{C}(2$ horas $)(\mathrm{d}) 140(10$ minutos $)+150{ }^{\circ} \mathrm{C}(2$ horas $) . .67$

4.22 Caracterização elétrica de amostra DO-2 (FTO/P3HT/PEDOT:PSS/Ag), subme-

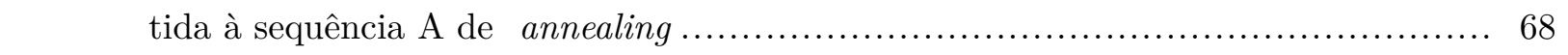

4.23 Caracterização elétrica de dispositivos submetidos à sequência de annealing A, onde

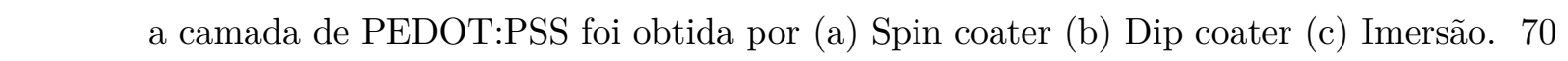

4.24 Curvas IV de amostras submetidas ao envelhecimento por 1, 2 e 3 dias ............... 71

4.25 Gráficos de tendências de todas as amostras de grupo 1, 2 e annealing, relacionando

expoentes obtidos para baixas e altas tensões em ambas polarizações, para amostras

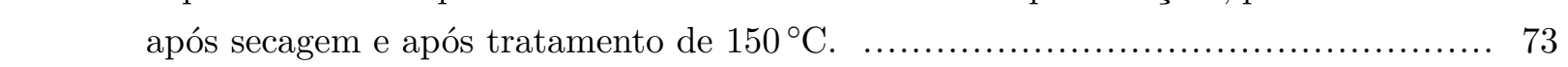

4.26 Gráficos de tendências de todas as amostras após envelhecimento, relacionando

expoentes obtidos para baixas e altas tensões em ambas polarizações, para amostras

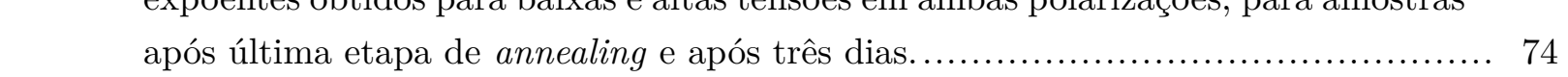


4.27 Características elétricas dos dispositivos à base de OB e OU (a) Na configuração de dispositivo tipo 1 (b) Na configuração de dispositivo tipo 2. A curva interna dos gráficos representa a resposta elétrica para a mesma configuração contendo P3HT, a título de comparação.

4.28 Curvas IV de amostras com diferentes proporções de OU na configuração tipo 2

(a) $28 \%$ (b) $34 \%$ (c) $47 \%$ (d) Comparativo entre amostras 28, 34 e $47 \%$ em escala

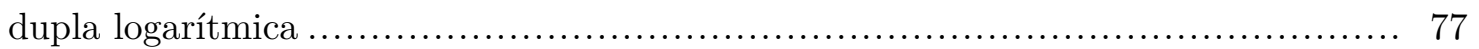

I.1 Amostras de grupo 1, 2 e annealing, relacionando expoentes obtidos para baixas e altas tensões em ambas polarizações.

I.2 Amostras após envelhecimento, relacionando expoentes obtidos para baixas e altas tensões em ambas polarizações.

I.3 Curvas para tensões negativas de dispositivos submetidos à sequência de annealing A, onde a camada de PEDOT:PSS foi obtida por (a) Spin coater (b) Dip coater (c) Imersão. 


\section{LISTA DE TABELAS}

3.1 Concentrações dos compósitos Óleo vegetal/Polímero ................................ 33

3.2 Parâmetros dos materiais usados nas simulações TCAD. Os valores em [colchetes] podem ser modificados para ilustrar fenômenos principais ou para adaptar as medições. Multiplicadores Gaussianos podem ser aplicados para armadilhas e distribuição de dopagem a fim de se modelar os fenômenos de interface. .................. 39

3.3 Condições de contorno aplicadas a portadores de corrente em contatos Schottky. .... 39

$4.1 \quad$ Valores de rugosidade e espessura dos materiais utilizados. $\ldots \ldots \ldots \ldots \ldots \ldots \ldots \ldots \ldots \ldots \ldots \ldots \ldots \ldots \ldots$

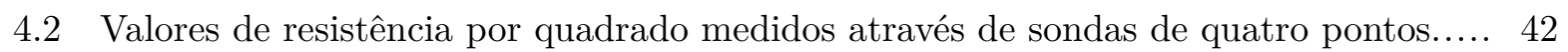

4.3 Distâncias a serem percorridas pelos fluxos 1 e 2, além das resistências calculadas para um contato com relação aos dois caminhos estabelecidos, resultando em $\mathrm{R}_{A g 3}$. $\quad 52$

4.4 Tempos necessários para aplicação das rampas nos modos short, medium, normal

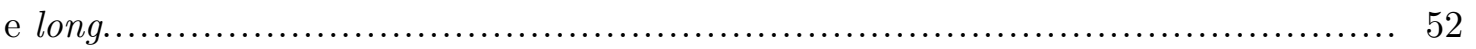

$4.5 \quad$ Parâmetros extraídos da curva Resistência vs Comprimento, obtida no experimento

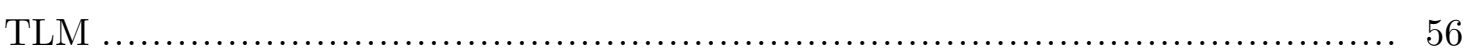

4.6 Valores de mobilidade $\mu$ e densidade de dopagem não intencional $N_{\mathrm{a}}$ extraídos das amostras experimentais a partir da simulação realizada. ............................. 60

4.7 Variações das curvas $I(V)$ durante sequência A de annealing........................... 69

4.8 Evolução nas características IV durante envelhecimento da amostra TT2A-Ag2 . . ... 72

4.9 Níveis energéticos, mobilidade e permitividade do composto $\beta$ - Caroteno, obtidos

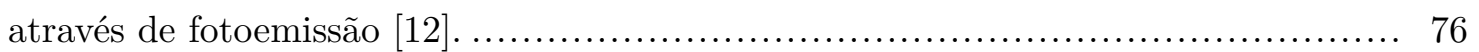




\section{LISTA DE SIMBOLOS}

\section{Símbolos Latinos}

$\begin{array}{llr}A & \text { Área } & {\left[\mathrm{cm}^{2}\right]} \\ J & \text { Densidade de Corrente } & {[\mathrm{I} / \mathrm{A}]} \\ E & \text { Campo elétrico } & {[\mathrm{V} / \mathrm{d}]} \\ I & \text { Corrente elétrica } & {[\text { Ámper }]} \\ L & \text { Espessura do filme } & {[\mu \mathrm{m}]} \\ V & \text { Tensão elétrica } & {[\mathrm{Volts}]} \\ T & \text { Temperatura } & {\left[\mathrm{K} \mathrm{ou}\left[{ }^{\circ} \mathrm{C}\right]\right.} \\ N & \text { Densidade de estados } & {\left[\mathrm{cm}^{-3}\right]} \\ M 1 & \text { Anôdo } & \\ M 2 & \text { Cátodo } & \\ k T & \text { Fator de Boltzmann } & \\ \pi & \text { Orbital ligante } & {\left[\mathrm{cm}^{2} / \mathrm{V} . \mathrm{s}\right]} \\ \pi^{*} & \text { Orbital antiligante } & {\left[\mathrm{cm}^{2} / \mathrm{V} . \mathrm{s}\right]} \\ \sigma & \text { Ligação simples } & \\ \mu & \text { Mobilidade } & {\left[\Omega \mathrm{cm}^{2}\right]} \\ \Phi & \text { Potencial eletrostático } & \\ \epsilon & \text { Permissividade do material } & \\ \phi & \text { Função trabalho dos eletrodos } & \\ \rho & \text { Resistividade } & \text { Afinidade eletrônica (LUMO) }\end{array}$




\section{Subscritos}

$N_{v} \quad$ Densidade de estados banda de valência

$N_{c} \quad$ Densidade de estados banda de condução

$N_{\text {trap }} \quad$ Densidade estados de armadilhas

$N_{a} \quad$ Densidade estados de aceitadores

$p_{t} \quad$ Portadores de cargas capturadas

$p_{f} \quad$ Portadores de cargas livres

$N_{v / c} \quad$ Densidade estados efetiva na banda de condução e valência

$E_{g} \quad$ Energia de gap

$E_{\text {trap }} \quad$ Largura da distribuição exponencial

$L_{\text {eff }} \quad$ Espessura efetiva

$T_{g} \quad$ Temperatura de transição vítrea

$\phi_{n}(\mathrm{x}) \quad$ Potencial quasi-Fermi para elétrons

$\phi_{p}(\mathrm{x}) \quad$ Potencial quasi-Fermi para lacunas

$E_{F, n} \quad$ Estatísticas de Fermi para elétrons

$E_{F, p} \quad$ Estatísticas de Fermi para lacunas

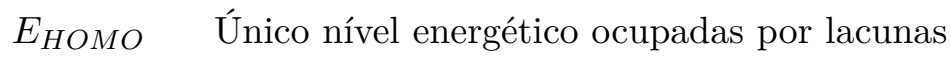

$T_{A n} \quad$ Temperatura de annealing

$\alpha_{h b^{+}} \quad$ Expoente em altas tensões positivas

$\alpha_{l b^{+}} \quad$ Expoente em baixas tensões positivas

$\alpha_{h b^{-}} \quad$ Expoente em altas tensões negativas

$\alpha_{l b^{-}} \quad$ Expoente em baixas tensões negativas

$I_{\min } \quad$ Corrente mínima

$I_{\max } \quad$ Corrente máxima 


\section{Siglas}

\begin{tabular}{|c|c|}
\hline$B C$ & Banda de condução \\
\hline$B V$ & Banda de valência \\
\hline$H H$ & Head-to-Head \\
\hline$H T$ & Head-to-Tail \\
\hline$T T$ & Tail-to-Tail \\
\hline$U V$ & Ultravioleta \\
\hline$L U M O$ & Lowest Unoccupied Molecular Orbital \\
\hline HOMO & Highest Occupied Molecular Orbital \\
\hline$S C L C$ & Corrente limitada por cargas espaciais \\
\hline$T L C$ & Corrente limitada por armadilhas \\
\hline$D(E)$ & Densidade de estados \\
\hline$P L E D$ & Diodo polimérico emissor de luz \\
\hline$P P V$ & Poli(p-fenileno vinileno) \\
\hline$P A T$ & Poli(alquil-tiofenos) \\
\hline$P 3 H T$ & Poly(3-hexylthiophene) \\
\hline PEDOT & Poly(3,4-ethylenedioxythiophene) \\
\hline$P S S$ & Poly(styrenesulfonate) \\
\hline$P S$ & Poliestireno \\
\hline$P E T$ & Politeraftalato de etileno \\
\hline$O P V$ & Células orgânicas fotovoltaicas \\
\hline OFET & Transistores de efeito de campo \\
\hline$T C O$ & Óxidos condutores transparentes \\
\hline FTO & Óxido de Estanho dopado com Flúor \\
\hline ITO & Óxido de Estanho dopado com Indío \\
\hline$C T C$ & Complexo reversível de transferência de carga \\
\hline$H T L$ & Camada transportadora de lacunas \\
\hline$C A R$ & Carotenóide no estado excitado \\
\hline$R O O$ & Radical peroxil \\
\hline$O B$ & Óleo de Buriti \\
\hline$O U$ & Óleo de Urucum \\
\hline$D O$ & Dispositivo Orgânico \\
\hline$R M N$ & Ressonância magnética nuclear \\
\hline$M E V$ & Microscopia eletrônica de varredura \\
\hline$A F M$ & Microscopia de força atômica \\
\hline$D S C$ & Calorimetria exploratória diferencial \\
\hline$M S M$ & Metal-semicondutor-metal \\
\hline$M I M$ & Metal-isolante-metal \\
\hline$O S C$ & Material orgânico semicondutor \\
\hline$C U$ & Unidades de conjugação \\
\hline
\end{tabular}




$\begin{array}{ll}M O P & \text { Metal sobre polímero } \\ P O M & \text { Polímero sobre metal } \\ P L C & \text { Power Line Cycle } \\ S M U & \text { Unidade de Sistema de medição } \\ M T & \text { Measurement time } \\ O T & \text { Overhead time } \\ T L M & \text { Transmission line model } \\ L T & \text { Comprimento de transferência } \\ D D & \text { difusão-deriva } \\ T C A D & \text { Technology Computer Aided Design }\end{array}$




\section{Capítulo 1}

\section{Introdução}

"Devem-se lembrar dos rascunhos porque, se muito importa chegar, importa mais ainda todo o caminho"

Há cerca de 40 anos, a supremacia do Silício havia sido estremecida. Os professores Heeger, MacDiarmid e Shirakawa descobriram uma maneira de atribuir condutividade elétrica aos polímeros, que até ali eram somente isolantes. Desde então, a eletrônica do carbono tem participação cada vez mais ascendente no mercado mundial de eletrônicos.

O início deste século trouxe com ele imensos novos desafios, de um ângulo otimista, oportunidades. Para tanto, faz-se necessário uma mudança nos paradigmas atuais na forma em que utilizamos e descartamos recursos naturais. Além disso, os avanços em campos como a nanomedicina, a bioeletrônica, e a revolução iminente da chamada internet das coisas (IoT), exigem novos materiais funcionais biodegradáveis, baratos, com baixa energia de fabricação, flexíveis para integração com as mais diversas superfícies de tecidos.

No cenário atual, a nova geração tecnológica é conquista da eletrônica flexível, a qual tem recebido notória atenção. Os polímeros conjugados são os principais responsáveis por essa revolução por possuírem uma importante classe de semicondutores orgânicos frequentemente utilizados nos dispositivos optoeletrônicos [13, como diodos poliméricos emissores de luz (PLEDs), células solares [14, sensores, transistores de efeito de campo (OFETs) 15, 16, dentre muitos outros. As significativas vantagens desses dispositivos são baixo custo, baixo peso, flexibilidade, fabricados a partir de soluções [14,17, peso molecular elevado, facilidade de adição de grupo funcional [18, características essas, amigáveis para o meio ambiente [19], além disso podem ser processados por técnicas simples como sping coating e impressão por jato de tinta, facilitando a produção em larga escala 20,21. Porém, um dos principais desafios a serem vencidos para a produção comercial de dispositivos orgânicos tem sido o aumento no tempo de vida dos materiais, que em termos de uso comercial deve atingir no mínimo 10000 horas. Uma maneira de contornar essa problemática é o desenvolvimento de tecnologias de encapsulamento dos dispositivos, garantindo bloqueio satisfatório de efeitos ambientais como oxigênio, umidade, os quais, na presença de luz, induzem à degradação (perda da conjugação) do polímero e, dessa forma, afetando o desempenho dos dispositivos [22]. Outra maneira mais sustentável e barata, seria o emprego de materiais verdes 
na confecção dos mesmos, que por sua ação antioxidante inibe a atuação do oxigênio singleto e interage com radicais livres aumentando o tempo de vida dos dispositivos que os contem.

Os uso de materiais naturais na eletrônica orgânica ainda está na sua infância, há dez anos atrás surgiu essa nova linha de tecnologias com potencial para várias aplicações como fotônica, engenharia biomédica e biomimética. Os materiais naturais extraídos da natureza permitem tecnologias 'verdes' que demonstram ser adequadas para alcançar a tão desafiadora sustentabilidade no campo da eletrônica, tendo em vista que, incorporam baixo consumo de energia aliada a biodegradabilidade e biocompatibilidade [23].

Para facilitar a obtenção de dispositivos à base de óleos vegetais, é necessário investigar os processos físico-químicos envolvendo polímeros já empregados nessa área. Porém, faz-se importante ainda, aliar simplicidade de arquitetura no processo de fabricação à condições ambientais de temperatura e pressão, visando redução de custos e métodos ambientalmente mais amigáveis. Alguns trabalhos já vem apresentando resultados de dispositivos à base de carotenóides como camada ativa, no entanto, poucos investigam o transporte de cargas em óleos vegetais, o que motiva a realização desse trabalho. O caráter inovador se dá pelo estabelecimento de um guia baseado no P3HT- para confecção, injeção de carga e observação de fenômenos degradativos em atmosfera ambiente de dispositivos a partir de óleos vegetais como camada ativa. Adquirindo-se, assim, informações relevantes para construção e otimização de dispositivos confeccionados com esses materiais verdes.

\subsection{Contextualização}

O desenvolvimento econômico aliado a sustentabilidade ambiental é um dos maiores desafios da humanidade neste século. A necessidade de reformular os processos de fabricação, as tecnologias de design e caráter dos produtos, tem se tornado imediata. Para tanto, devem ser promovidas alterações nos padrões de comercialização, distribuição, utilização e reciclagem. A iniciativa da reciclagem por sua vez, requer políticas regulamentadoras de resíduos adequadas para isso, o que não ocorre em muitos países. Além disso, a energia empregada no processo de reciclagem de materiais inorgânicos faz-se dispendiosa e com eliminação de gases poluentes. Desta forma, o desenvolvimento de dispositivos eletrônicos orgânicos não-tóxicos, de baixo custo, biodegradável, de fácil processamento, torna-se um passo à frente na resolução da problemática.

Uma nova eletrônica se descortinou com o surgimento de novos materiais orgânicos semicondutores, a eletrônica orgânica. Para fins de comparação, a mesma está atualmente no estágio de desenvolvimento tecnológico equivalente ao que a eletrônica tradicional baseada no silício estava há quarenta anos. Mesmo assim, já é realidade: os displays a partir de dispositivos orgânicos emissores de luz (OLED, do inglês, Organic Light-Emitting Devices) embarcados em smartphones premium representam a primeira aplicação em massa dessa nova tecnologia. Estados Unidos da América (EUA), Europa, Japão, Coreia e China já posicionaram seus institutos de pesquisa, empresas e governos para aproveitarem o novo mercado a ser formado pelos dispositivos flexíveis, transparentes, finos, biodegradáveis e com possibilidade de serem produzidos a baixo custo, com 
uso até mesmo, de técnicas de impressão. Grandes empresas já fazem uso de materiais orgânicos em seus equipamentos, como a Cambridge Displays Technology, Universal Displays, eMagin, MicroEmissive Displays, Konarka Technologies, Nanosolar, Plextronics, Nanoident, Novaled, Thin-film Electronics, Elam-T, PolyIC, Polymer Vision, Plastic Logic, OrganicID, Orfid, bem como a participação decisiva de grandes corporações como Samsung, Kodak, Basf, Osram/Siemens e DuPont, entre outras.

A eletrônica 'verde' vem surgindo não apenas como um novo termo científico, mas também como uma área de pesquisa ascendente que se baseia na investigação de compostos de origem natural a fim de estabelecer vias economicamente eficientes para a produção de dispositivos biodegradáveis [24].

Um requisito dos semicondutores orgânicos é a existência de uma cadeia de carbono conjugada, permitindo o deslocamento de elétrons, muitos deles ainda possuem moléculas capazes de absorver luz dependendo da extensão dessas cadeias conjugadas. Por esse motivo, existe uma gama de corantes naturais que se encaixam nesse perfil, tais como polienos (à exemplo dos carotenos), quinonas, antraquinonas, indole, pirano e corantes oligopyrrol, bem como pteridinas, isoquinolinas e fenoxazina. A maioria deles compreendem várias estruturas aromáticas e grupos funcionais, para citar: hidroxilo, aminas, imina, grupos halogeneto.

Por esta razão, o foco de inúmeras pesquisas tem se voltado para carotenóides como materiais semicondutores aplicáveis. Em uma revisão recente sobre corantes utilizados na área eletrônica, Muhl [25] constatou que, dentre os polienos de pequenas moléculas, os mais relatados são bixina e $\beta$-caroteno. Irmia-Vladu [26] estudou a adequação dos materiais biodegradáveis no que diz respeito a sua utilização na eletrônica orgânica, mas especificamente OFETs, onde os semicondutores são incorporados como camada ativa. Alguns compostos como clorofíla natural, hemina, fenazina, moléculas terpenoides, indígo e púrpura tíria são descritos como semicondutores naturais tipo-p e n 24 .

\subsection{Justificativa}

A gigantesca demanda mundial por eletrônicos está guiando a população mundial para um desequilíbrio energético, com uma série de consequências desastrosas, como elevada quantidade de resíduos eletrônicos e esgotamento dos elementos naturais já escassos (gálio, índio, por exemplo). Os EUA, a União Européia e o Japão geram 50 milhões de toneladas de rejeito eletrônico por ano. China, Índia, Paquistão, Nigéria e Gana importam a maior quantidade de lixo eletrônico do planeta, em torno de $30 \%$ 24.

É imprescindível que haja uma mudança de paradigma da nossa maneira de controlar, sustentavelmente, tanto a exploração de recursos naturais quanto à eliminação dos resíduos gerados, de maneira a minimizar o impacto negativo de nossas gerações presentes e futuras sobre o ambiente.

O Brasil é o país com a maior biodiversidade do planeta. Das 250 mil espécies existentes, aproximadamente 55 mil estão no país, e destas apenas 14\% são conhecidas [27]. Algumas possuem 
óleos com propriedades interessantes. A exploração e o entendimento de propriedades físicas e químicas de materiais naturais extraídos de plantas, tem se tornado um desafio para pesquisadores nos últimos anos 28 .

Uma variedade de carotenóides podem ser transformados em solução para dispositivos de filmes finos, incluindo $\beta$-caroteno, bixina, astaceno, torularrodina, e isorenieratene. Muscovich $[29]$ e Burch [30 experimentaram $\beta$-caroteno e bixina como camada ativa, quanto à mobilidade de efeito de campo. Com mobilidade de lacuna de $10^{-7} \mathrm{~cm}^{2} / \mathrm{Vs}$ e $10^{-6} \mathrm{~cm}^{2} / \mathrm{Vs}$, respectivamente. Resultado também observado por Glowacki [12] para o $\beta$-caroteno. O autor relata que em estruturas MIM (metal-isolante-metal) o $\beta$ - caroteno se comporta como polímeros conjugados e quando misturado com [6,6]-phenyl-C61-butyric (PCBM) pode agir como um doador de elétrons. Mais recentemente, Haryanto 31], fabricou células solares com diferentes teores de bixina extraído por solução de etanol, observado eficiência de 0.00799-0,05696\%. Por mais que estes não sejam valores atrativos comercialmente, ainda assim a observação de respostas de efeito de campo em moléculas semicondutores naturais é intrigante $[32]$.

Em um estudo pioneiro a cerca de propriedades elétricas de óleos vegetais, Durães [33] ao desenvolver dispositivos contendo o compósito Óleo de Buriti/poliestireno (com diferentes teores do óleo) sanduichado entre um eletrodo de prata e outro de PEDOT:PSS, observou a presença de histerese e resistência diferencial negativa. Seu resultado mais expressivo corresponde a amostras contendo $47 \%$ do óleo de Buriti. Porém, a autora relata a necessidade de se aperfeiçoar a produção dos dispositivos eletrônicos baseados no óleo vegetal, bem como caracterizá-los da maneira mais abrangente. Para tanto é fundamental criar protocolos que permitam um maior controle a cerca da morfologia das camadas envolvidas aliada a uma avaliação mais precisa das interfaces entre os componentes.

Um conceito recente que tem chamado atenção de diversas áreas é a Internet das coisas (Internet of Things - IoT). Trata-se de uma inovação no campo da comunicação, no qual são integrados uma série de objetos físicos e virtuais em redes conectadas à Internet, permitindo que 'coisas' coletem, troquem e armazenem grande quantidade de dados numa nuvem, em que uma vez processados e analisados esses dados, gerem informações e serviços em escala inimaginável [34].

Para muitos, trata-se de uma revolução tecnológica iminente, pois os números são gigantescos. Estima-se que em 2020 seu mercado mundial irá atingir 1.7 bilhões de dólares, com mais de 40 bilhões de dispositivos conectados [35]. Apesar do impacto positivo em diversas áreas, incluindo indústria, eletrônica de consumo, saúde, a quantidade de resíduo eletrônico gerado pode ser preocupante. Além disso, algumas aplicações como dispositivos acoplados ao tecido vivo precisam ser flexíveis e biocompatíveis. Características essas alcançadas por materiais verdes.

O estudo de óleos extraídos de plantas brasileiras se faz importante do ponto de vista da sustentabilidade ambiental oferecida por tais produtos, bem como pelo interesse em investigar materiais inexplorados até então, porém em abundância no nosso país. A indústria tem feito uso de tais materiais como corantes têxteis, tintas, cosméticos, ou aditivos alimentares. A proposta do presente trabalho é a incorporação de óleos vegetais em dispositivos optoeletrônicos, tendo em vista que, pesquisas promissoras vem sendo realizadas sobre o uso de materias biodegradáveis na 
fabricação de dispositivos eletrônicos orgânicos, na forma de materiais para substratos, camadas dielétricas e semicondutores, alcançando dispositivos, até mesmo, totalmente biodegradáveis.

\subsection{Objetivo geral}

O presente trabalho tem o intuito de estabelecer um monitoramento - por meio de injeção de carga - dos mecanismos de degradação em dispositivos contendo P3HT, a fim de se desenvolver dispositivos à base de materiais verdes extraídos de plantas brasileiras. Para tanto, pretende-se, inicialmente, fabricar e analisar dispositivos com polímeros comerciais condutores/semicondutores nas condições mais aproximadas possíveis daquelas cujos óleos são manipulados. Ao final, esperase obter um guia padrão onde a compreensão do perfil degradativo em função das características elétricas de tais dispositivos, possam facilitar o desenvolvimento de amostras à base de materiais verdes e desenvolver estratégias para minimizar tais degradações.

\subsubsection{Objetivos específicos}

Para alcançar o objetivo principal do trabalho, o mesmo foi subdividido nos seguintes tópicos:

1. Fabricar e medir características elétricas de filmes de P3HT em atmosfera ambiente no intuito de estudar mecanismos de degradação, como a dopagem não-intencional.

2. Caracterizar todas as camadas que compõem os dispositivos de teste quanto a espessura, topografia da superfície e área de contato de topo;

3. Investigar a influência da temperatura de secagem.

4. Investigar a influência de diferentes substratos condutivos.

5. Estabelecer um protocolo de medições elétricas.

6. Identificar e caracterizar os elementos parasíticos presentes nos dispositivos, tais como, resistência de contato, resistência shunt, capacitâncias, dentre outros.

7. Tratar termicamente as amostras para eliminação de impurezas decorrentes da fabricação e beneficiamento da injeção de carga. Análise qualitativa e quantitaviva dos resultados alcançados com embasamento em simulações numéricas.

8. Estudo de envelhecimento das amostras;

9. Otimizar processamento da camada transportadora de lacunas (PEDOT:PSS).

10. Confeccionar e caracterizar eletricamente dispositivos incorporando óleo de Buriti e Urucum em diferentes concentrações, como camada ativa.

A dissertação segue a seguinte estrutura: 
No capítulo 2 encontra-se a revisão bibliográfica abordando os tópicos necessários para a compreensão do trabalho. A condutividade polimérica aliada aos modelos teóricos que descrevem o funcionamento de dispositivos orgânicos são imprescindíveis para a discussão do tema tratado. O detalhamento dos materiais empregados na fabricação dos mesmos e os fenômenos degradativos que atuam sobre estes em condições normais de pressão e atmosfera, fazem-se presentes no capítulo.

O capítulo 3 contem os materiais e métodos experimentais utilizados na caracterização morfológica e elétrica das amostras. Este capítulo aborda os procedimentos desde preparação das amostras até confecção dos dispositivos.

Os resultados obtidos e as análises dos mesmos encontram-se no capítulo 4. As conclusões do trabalho estão no capítulo 5 . 


\section{Capítulo 2}

\section{Revisão Bibliográfica}

\subsection{Transporte Eletrônico em Polímeros Condutores}

\subsubsection{Polímeros conjugados}

A descoberta da condutividade polimérica no final dos anos 70, impulsionou a eletrônica orgânica de maneira crucial até os dias atuais. Shirakawa e colaboradores ganharam o prêmio Nobel de 2000, por provarem que a condutividade elétrica do polímero poliacetileno poderia ser 10 vezes maior se sofresse oxidação por cloro, bromo ou vapor de iodo. Tal processo foi chamado mais tarde de 'dopagem' fazendo-se uma analogia aos semicondutores extrínsecos [4,36]. A condutividade em polímeros está restrita a classe dos polímeros conjugados, cuja estrutura da cadeia possui alternância de ligação simples e dupla entre os átomos de carbono. A figura 2.1 mostra os principais polímeros conjugados utilizados atualmente.

A vasta aplicação dos polímeros na área eletrônica atualmente, se deve a intensa pesquisa sobre diversos aspectos e processamento destes, dos quais envolvem estudos combinatórias de proporções de misturas, evolução da estrutura em função de tratamentos térmicos e por solventes, síntese e design de polímeros, e otimização para maximizar a absorção de luz do espectro solar. Todavia, o estudo de degradação e estabilidade não tem a mesma atenção [16].

\subsubsection{Configuração eletrônica}

A razão pela qual os polímeros com ligações conjugadas formam a base dos polímeros condutores é justificada pela hibridização de elétrons do carbono. Os átomos de carbono podem assumir três estados de hibridização: $s p^{3}, s p^{2}$ e $s p$. Em polímeros conjugados ocorre a hibridização $s p^{2}$, resultando em três orbitais $s p^{2}$ hibridos co-planares e um orbital $p z$ puro perpendicular ao plano. A sobreposição dos orbitais $p z$ dá origem a ligação $\pi$, e a sobreposição dos orbitais $s p^{2}$ vizinhos a ligação $\sigma 2,22,37,41$, como mostra a figura 2.2(a).

Os orbitais que participam de uma ligação possuem funções de ondas que, quando apresentam interação construtiva, geram um novo conjunto de orbitais moleculares. A superposição constru- 


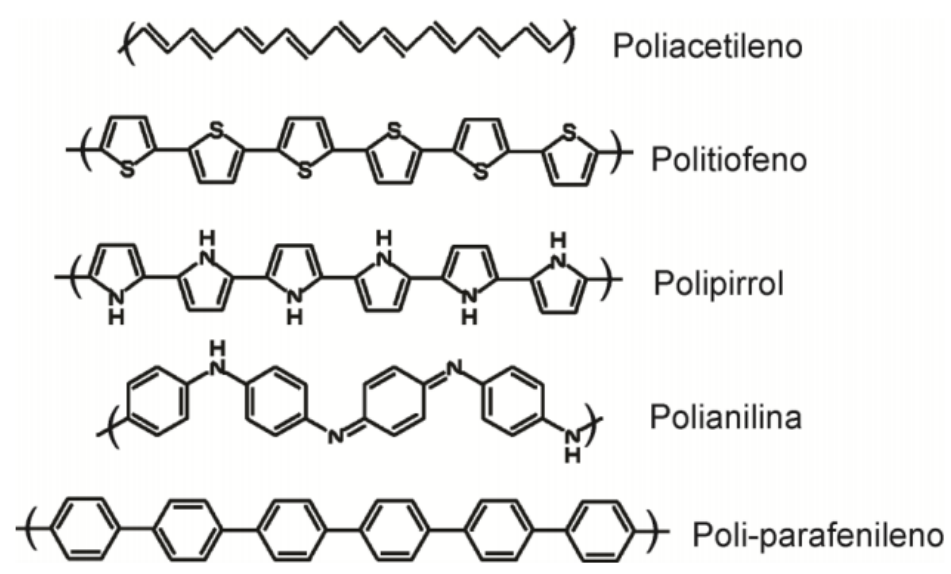

(a)

Figura 2.1: Polímeros conjugados mais significativos na área da eletrônica orgânica |1]

tiva produz um orbital ligante $(\pi)$ contendo dois elétrons e a destrutiva um orbital antiligante $\left(\pi^{*}\right)$ vazio. Tais orbitais possuem menor energia que aqueles gerados pelas ligações $\sigma$, portanto, são responsáveis pela condutividade do material. Se imaginarmos uma cadeia polimérica infinita, as interações entre orbitais $p z$ resulta na delocalização do elétron, que torna-se livre para participar de qualquer parte da cadeia.

A figura 2.2(b) mostra orbitais $p z$ no anel benzênico onde seis deles se sobrepoem dando origem a orbitais ocupados $\pi$ e vazios $\pi^{*}$, com funções de onda molecular delocalizadas e distribuidas por todos os carbonos, desta forma o elétron pode fazer parte do sistema ou não, ao contrário dos elétrons da ligação $\sigma$ que encontram-se entre os átomos de carbono [37]. Em outras palavras as ligações $\pi$ estão relacionadas a características elétricas e ópticas do material e as $\sigma$ pelas características mecânicas 42 .

O surgimento das bandas energéticas nos polímeros condutores, se deve a diferença de comprimento entre ligações $\sigma$ (mais longas) e $\pi$ (mais curtas) explicada pela transição de Peierls 4, 39. Tendo em vista que, as cadeias poliméricas alternam entre ligações simples e duplas para sua equalização energética e que a alternância nas distâncias entre os átomos forma um orbital ligante e outro antiligante, distingue-se então, o nível de energia mais baixo dos orbitais antiligantes chamado LUMO (Lowest Unoccupied Molecular Orbital) - resultante dos orbitais desocupados $\pi^{*}$ e HOMO (Highest Occupied Molecular Orbital) - dos orbitais ocupados $\pi$. A diferença entre o HOMO e o LUMO fornece a energia de banda proibida do material (Eg), a qual situa-se entre 1,5 e 4,0 eV [43], fornecendo a esses materiais propriedades eletrônicas importantes. A figura 2.3 (a) representa a transição de Peierls para a molécula do poliacetileno.

Geralmente, faz-se uma analogia de HOMO e LUMO aos termos: banda de valência e banda de condução, respectivamente, associados a semicondutores inorgânicos. No entanto, é importante que se faça uma ressalva a respeito dessas denominações. O diagrama de bandas contínuas para esses polímeros só poderia ser aplicado para uma cadeia unidimensional, de comprimento infinito e isolada. Como não se tem esse caso na prática, pois polímeros possuem distribuição de cadeias 


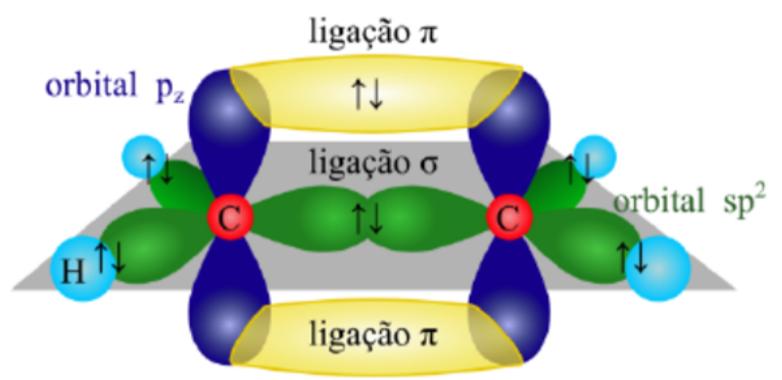

(a)

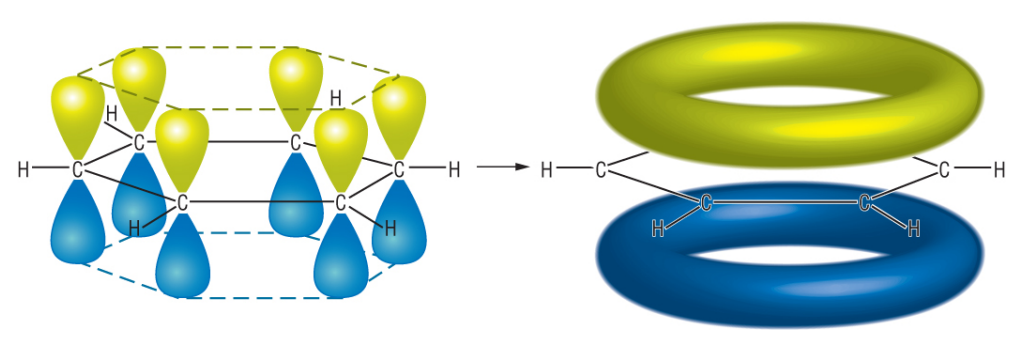

(b)

Figura 2.2: (a) Formação das ligações $\sigma$ e $\pi$ a partir da hibridização $s p^{2}$ do carbono (b) Superposição dos orbitais $p z$ num anel benzênico, resultando em um sistema de elétrons $\pi$ delocalizados

de tamanhos aleatórios, diferentes extensões de conjugação efetiva e morfologia desordenada, alterações nos níveis energéticos podem ocorrer em função da interação dos elétrons $\pi$ em regiões distintas da cadeia. Assim, para regiões com maior comprimento de conjugação efetiva, os níveis energéticos estão mais próximos, ou seja, o gap é reduzido. Desta forma, o polímero em si possui um band gap que representa um valor médio obtido mediante os diferentes tamanhos de conjugação, normalmente atingem de 2 a 10 monômeros. As porções não conjugadas podem ser resultado de torções ou acomodações de cadeia [39].

A figura 2.4 (a) representa os diferentes comprimentos de conjugação efetiva e seu reflexo no band gap. Ao contrário dos semicondutores inorgânicos, os polímeros não apresentam banda de valência e condução bem definidas em virtude dessa desordem estrutural, por esse motivo, faz-se conveniente empregar uma distribuição gaussiana em torno dos níveis energéticos como na figura 2.4 (b), onde o HUMO e LUMO são regiões de transporte de cargas de valores contínuos e entre eles, locais de armadilhas [2]. Coutinho [3] afirma que, atualmente considera-se a distribuição gaussiana de densidade de estados a mais provável na descrição da estrutura eletrônica de filmes de polímeros conjugados.

\subsubsection{Quasi-partículas}

Um fator importante na condutividade polimérica diz respeito a presença de defeitos, tendo em vista que, geram cargas nas cadeias poliméricas ocasionando distorções eletrônicas e reticulares 


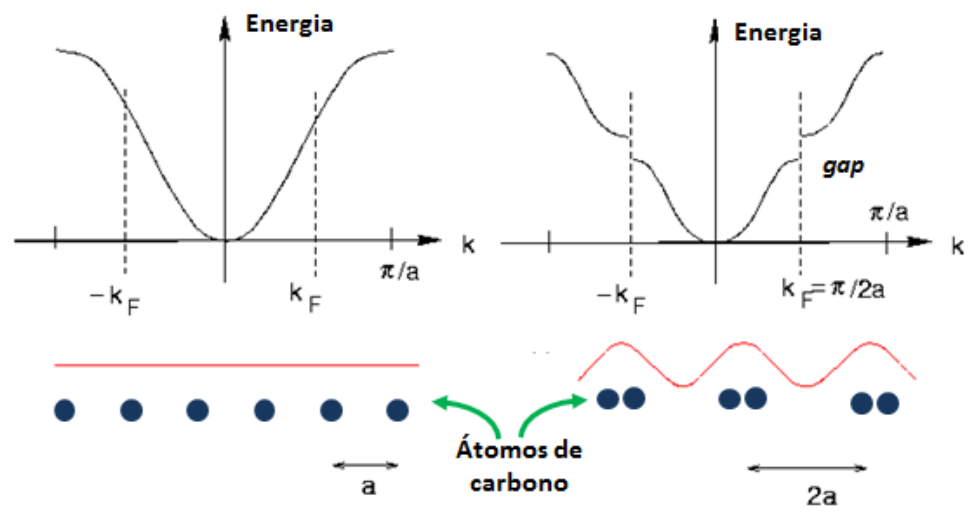

(a)
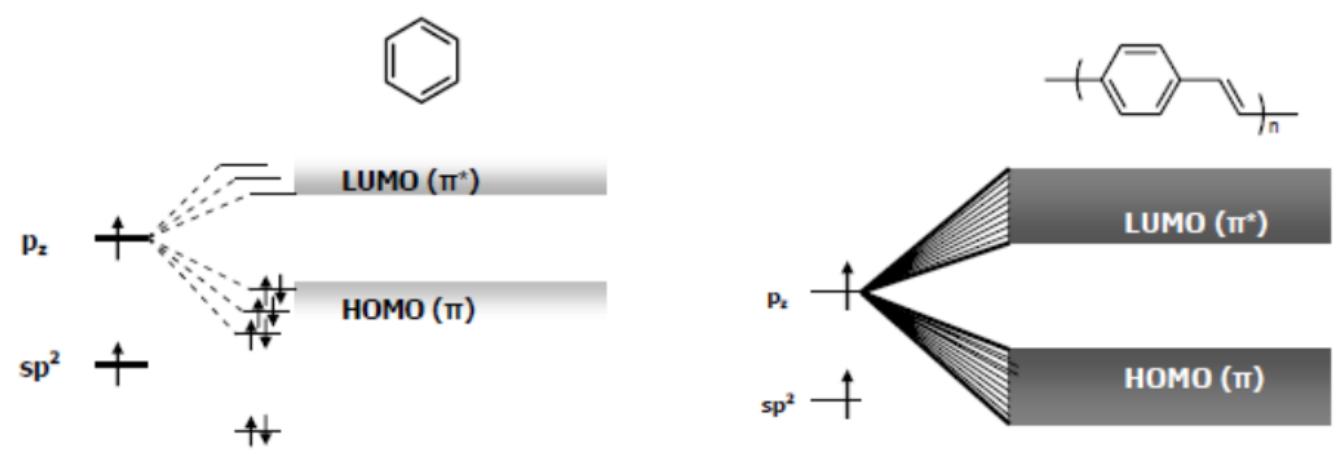

(b)

Figura 2.3: (a) Transição de Peierls para o trans-poliacetileno: a diferença de $0,1 \AA$ entre os comprimentos das ligações $\mathrm{C}-\mathrm{C}$ e $\mathrm{C}=\mathrm{C}$ dá origem a um gap de 1,5 eV no polímero (b) Diagrama de energia para a molécula de benzeno (à esquerda) com a interação entre orbitais $\pi$ produzindo uma distribuição de estados eletrônicos que se assemelham à uma estrutura de banda: HOMO e LUMO; representação de orbitais $\pi$ para uma cadeia infinita do polímero poli(p-fenileno vinileno) (PPV) (à direita) 


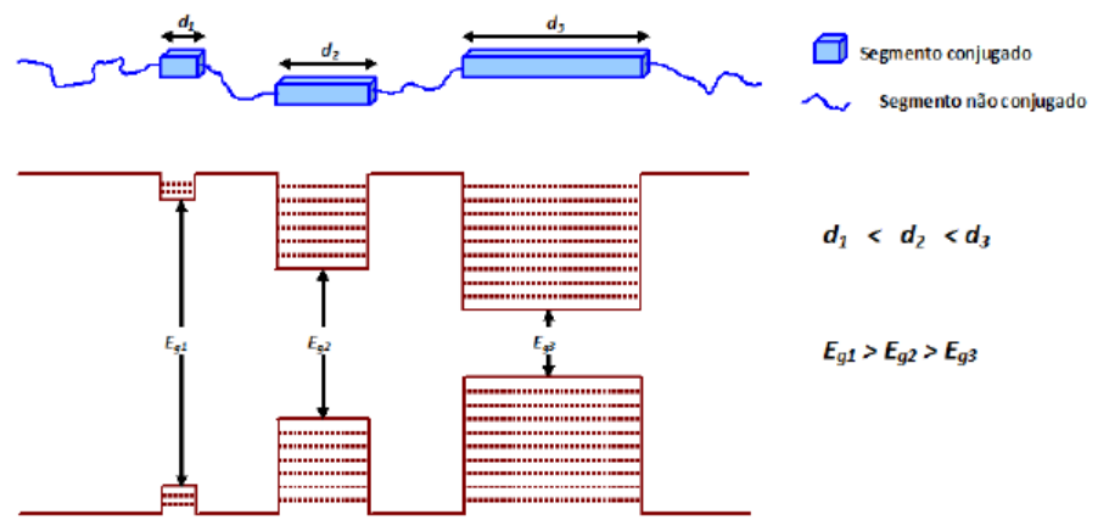

(a)

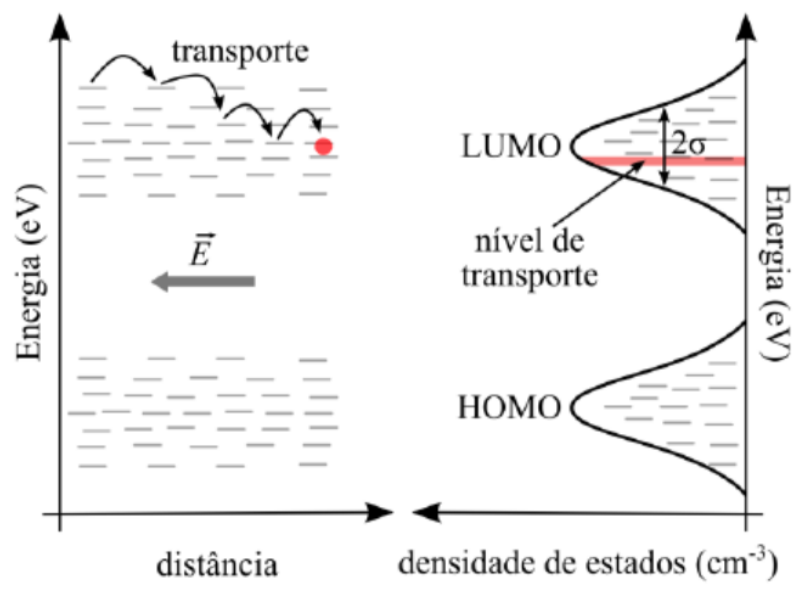

(b)

Figura 2.4: (a) Cadeia polimérica com diferentes comprimentos de conjugação efetiva [2] (b) Esquemático do transporte eletrônico por saltos por entre estados localizados, cuja distribuição de níveis energéticos é do tipo gaussiana para diferentes densidades de estados $\mathrm{D}(\mathrm{E})$. A linha vermelha destaca o nível de transporte com maior probabilidade de ocorrerem saltos entre os estados $[3]$. 


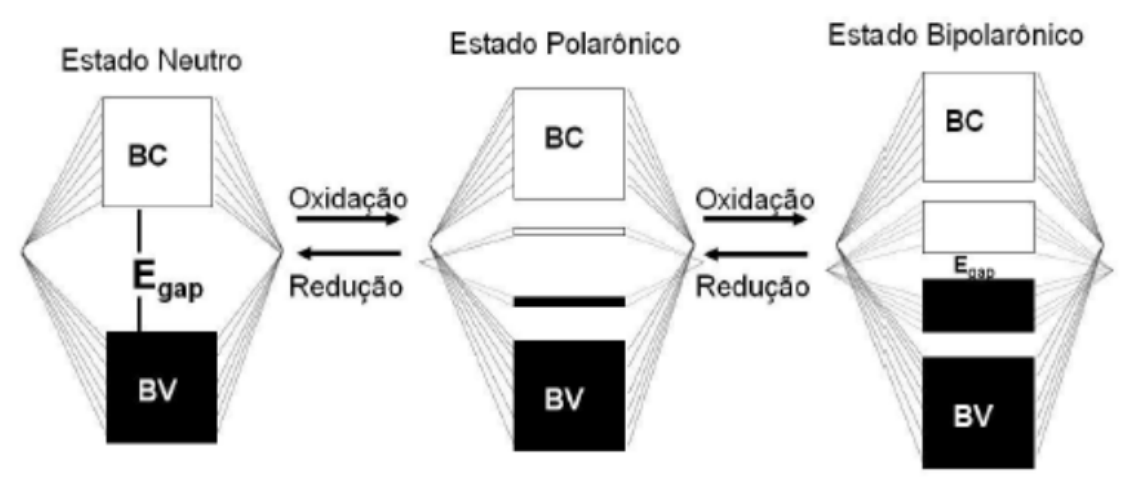

Figura 2.5: Processos de dopagem por oxidação/redução dando origem a pôlarons e bipolarons

associadas.

A distorção eletrônica é consequência da retirada (ou inserção) de uma carga negativa perturbando os orbitais de fronteira (HOMO). Ao passo que, a distorção reticular resulta da formação de uma carga localizada, o que distorce distâncias entre ligações em volta da carga. Na física do estado sólido, as quasi-partículas associadas a estas distorções são denominadas pôlaron, bipôlaron e sóliton 39, cuja descrição se insere a seguir.

Um dos defeitos estruturais oriundos de modificações químicas das ligações da cadeia de poliacetileno, pode dar origem a uma quasi-partícula denominada sóliton neutro, com mobilidade bidirecional ao longo da cadeia. Sólitons representam descontinuidades no padrão de ligações duplas e simples em uma cadeia, pois geram níveis energéticos no gap do material agindo como armadilhas de carga. Sua origem pode ser devido a impurezas durante processamento ou síntese do polímero, fatores configuracionais, etc. Os mesmos são criados apenas aos pares, a menos que já estejam presentes no processo de síntese. Sua inserção adicional pode ser realizada das seguintes maneiras (i) dopagem química (ii ) fotogeração e (iii ) injeção de cargas [2].

Porém, polímeros condutores diferentes do poliacetileno, contêm distintas energias para diferentes estados solitônicos, portanto, mecanismos realizados por essa entidade não acontecem [1] 42 . Contudo, ocorre a formação de pôlarons, que são elétrons localizados provenientes de deformações na rede, pelo acoplamento elétron-fônon, e que geram estados energéticos no gap podendo contribuir para o transporte de carga [1].

No caso dos tiofenos, empregado no presente trabalho na forma de P3HT, a formação do pôlaron ocorre sob dopagem. Ao se promover a oxidação da cadeia (remoção de um elétron), por exemplo, esta é convertida entre as formas benzóide e quinóide produzindo um pôlaron. O bipolaron é formado da retirada de mais um elétron.

Antoni [44] explica que ao sofrer oxidação, uma cadeia conjugada passa a conter um pôlaron. Em consequência, estados eletrônicos no banda de gap são formados gerando uma carga localizada, que por sua vez, promovem um deslocamento energético acima do HOMO e abaixo do LUMO. A extensão desse gap determina as propriedades intrínsecas do material. Dessa forma se, um segundo elétron é retirado da cadeia polimérica, ocorre a formação de um bipolaron (figura 2.5. 


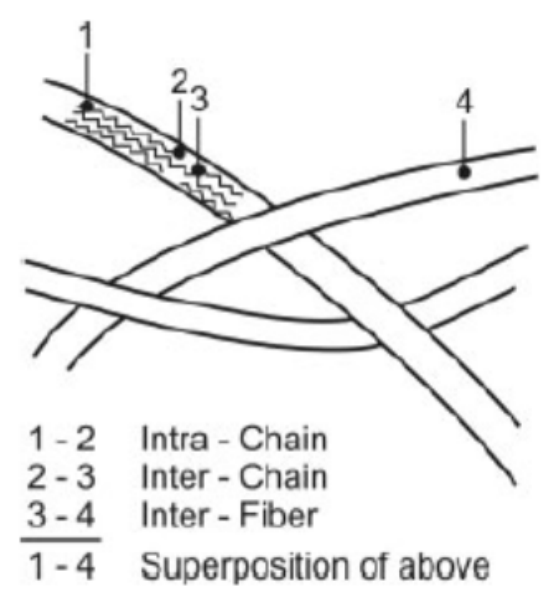

Figura 2.6: Transporte de cargas em polímeros condutores: intracadeia (1-2), intercadeia (2-3), interfibras (3-4) e superposição de todas (1-4) [4].

De uma forma geral, os defeitos estruturais agem como armadilhas dos portadores de carga, podendo assumir diferentes distribuições. Àqueles gerados devido a defeitos químicos e estruturais promovem baixos valores de mobilidade nos polímeros. Por esse motivo, faz-se importante conhecer os processos responsáveis pelo transporte de cargas e a densidade de armadilhas distribuídas no material.

\subsubsection{Transporte de cargas}

A condutividade polimérica depende de três contribuições distintas: condutividade intracadeia, intercadeia e intrafibras. O transporte de cargas pode se dar na própria cadeia: situação 12 da figura ??. Domínios cristalinos coexistem com amorfos e neles cadeias adjacentes podem transferir elétrons de uma para outra, via dopagem (transferência de pôlarons) ou por sobreposição de orbitais moleculares, situação 2-3. No entanto, entre uma região cristalina e outra existem domínios amorfos, então outro mecanismo de transporte faz-se necessário: efeito hopping, situação 3-4. Nesse caso, o transporte é feito por tunelamento quântico assistido por fônon entre regiões cristalinas e estados localizados, presentes na região amorfa. O portador de carga se move de uma molécula para outra saltando ou tunelando as barreiras de energia entre os estados localizados no interior do polímero. O tempo de permanência da carga em cada sítio energético limitará seu fluxo pelo material. Sofre efeito da temperatura, pois temperaturas altas aumentam as possibilidades de fônons guiarem o mecanismo e a condutividade também aumenta. Qu 19 reforça que para a maioria dos polímeros condutores, o transporte de cargas é primariamente controlado por processos intercadeia e hopping. 


\subsection{Modelos teóricos para fenômenos físicos}

\subsubsection{Barreiras de injeção: metal-semicondutor}

Os modelos teóricos Corrente limitada por cargas espaciais (SCLC, do inglês, Space Charge Limit Current) e condução limitada por carga espacial com distribuição exponencial de armadilhas (TLC, do inglês, Trapped Limit Current) que explicam o mecanismo de transporte em semicondutores orgânicos, consideram os contatos formados entre eletrodo-semicondutor intrínseco-eletrodo como sendo ôhmicos. Porém, o tipo de contato formado depende da função trabalho do metal, do nível de Fermi do semicondutor e da barreira de injeção de cargas. Em uma representação ideal e considerando transporte majoritário de lacunas, como mostrado na figura 2.7 (a), quando a função trabalho do metal é maior que função trabalho do semicondutor intrínseco, haverá a transferência de elétrons deste para o metal, promovendo aumento de portadores positivos no polímero próximo à interface de contato. Essa região é chamada de acumulação, sem barreira para injeção de cargas por parte do metal. E o contato de depleção (figura 2.7 (b)) ocorre quando a função trabalho do metal é menor que o nível de Fermi do polímero, havendo transferência de elétrons do metal para o semicondutor para se alcançar o equilíbrio, criando um acúmulo de cargas negativas no polímero e cargas positivas no metal próximo à interface, com barreira para injeção por parte do metal mas não do polímero [3, 38].

Em uma análise mais realista, deve-se levar em consideração a presença de estados eletrônicos interfaciais, pois, trata-se de uma região com maior grau de desordem devido as interações entre metal-polímero (figura 2.7 (c)). Nesse caso, surge desordem energética ali, a qual é caracterizada por uma distribuição gaussiana de estados formados por dipolos induzidos. Em virtude dessa desordem, a curva de distribuição gaussiana de estados do semicondutor mostra-se mais larga, resultando em dipolos que promove rebaixamento do nível de vácuo naquela interface. Sendo assim, o processo de injeção das interfaces metal/polímero é facilitado quando se conhece a distribuição energética, as origens da formação de dipolos e a largura espacial da distribuição de estados [5].

O contato ôhmico pode ser alcançado das seguintes formas: por dopagem do semicondutor orgânico, de maneira a se diminuir a espessura da barreira de injeção em um contato de depleção, ou ainda reduzindo a altura da barreira em um contato de acumulação. Este caso é mais difícil, uma vez que, a interface não está caracterizada apenas pela função trabalho do metal e a afinidade eletrônica do semicondutor, mas também pelos fatores S e ECNL, como sugere a teoria de barreira, indicando quanto o contato metálico pode interferir na altura da barreira, como mostra a figura 2.7 (d) e a equação 2.1 .

$$
\phi_{B n}=S\left(\phi_{M}-E A\right)+(1-S) E C N L ;
$$

Em condições de fabricação muito limpa, a barreira de injeção seria constante e independente do metal, $\mathrm{S}=0$. Ao passo que, superfícies com impurezas permitem que o metal atue sobre a altura da barreira, $\mathrm{S}=1$. Em outras palavras, trata-se de uma equação que promove uma interpolação entre os casos de nenhuma dependência do metal e total dependência deste. 
ACUMULAÇÃo

DEPLEÇÃO
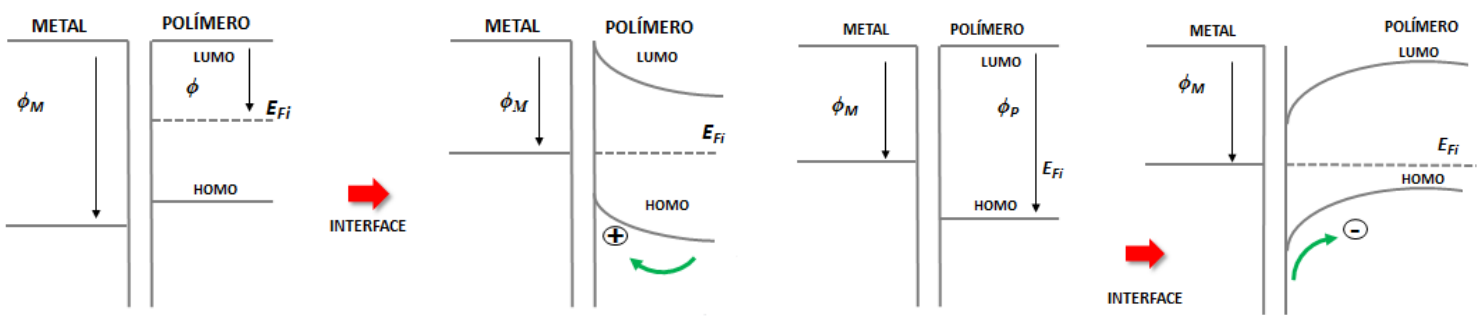

(a)

(b)

(a)

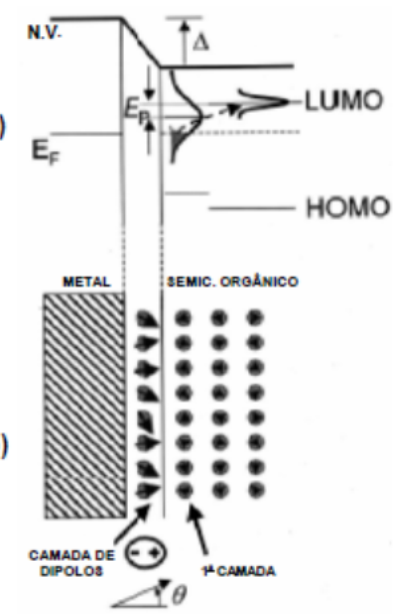

(c)

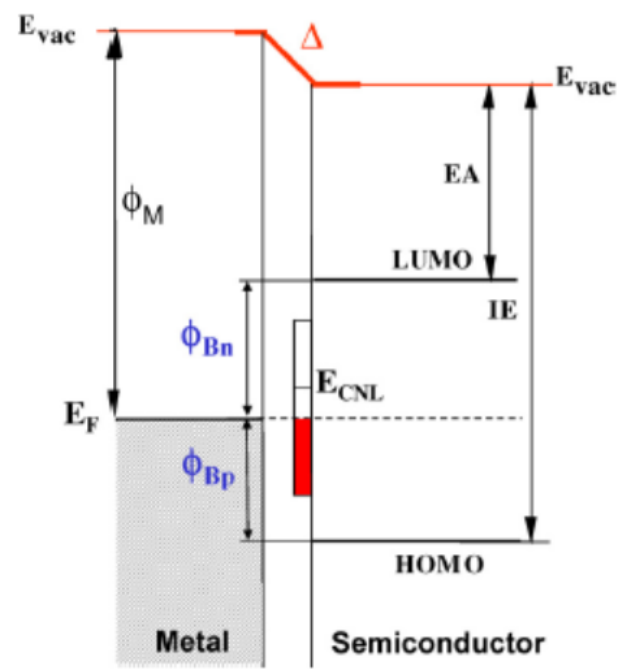

(d)

Figura 2.7: Tipos de contatos metal/semicondutor em função dos alinhamentos de funções trabalho (a) Contato de acumulação (b) Contato de depleção (c) formação de dipolos na interface em decorrência da desordem entre os materiais [5] (d) Estrutura eletrônica típica de uma interface metal-semicondutor orgânico, exibindo os níveis energéticos em ambos os lados, a afinidade eletrônica (EA, do inglês, electron affinity) e energia de ionização (IE, do inglês, ionization energy) do semicondutor, o dipolo de interface $\delta$, a densidade de estados gap na interface e o nível de neutralidade de carga ECNL, e a barreira de injeção para lacunas $\phi_{B p}$ e para elétrons $\phi_{B n}[6$. 


\subsubsection{Limitações de injeção}

Outros fatores limitantes da injeção de portadores atuam sobre baixas tensões em situações práticas, como por exemplo, elevada densidade de armadilhas do filme e tensão intrínseca $\mathrm{V}_{b} i$ (do inglês, voltage build in) a ser vencida. A figura 2.8 resume esses efeitos.

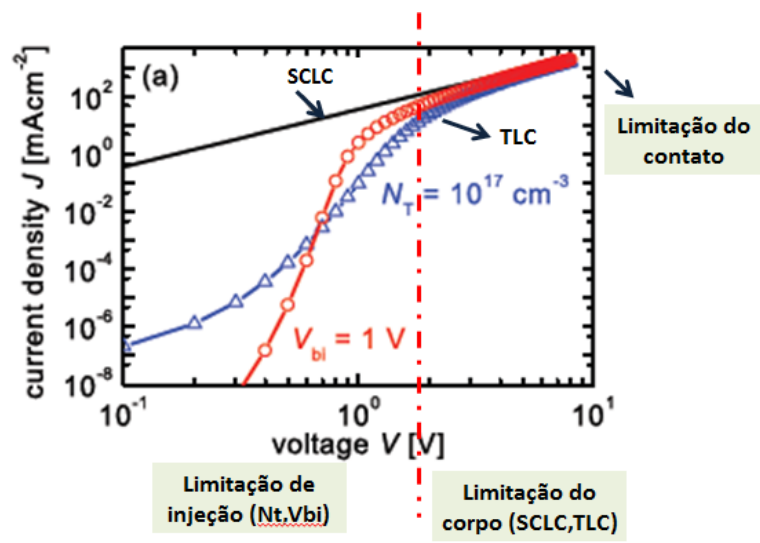

Figura 2.8: Curvas $\mathrm{J}(\mathrm{V})$ simuladas para um dispositivo contendo elevada densidade de armadilhas $\mathrm{N}_{T}=10^{7} \mathrm{~cm}^{-3}$ e outro com tensão intrínseca $\left(\mathrm{V}_{b} i\right)$ de $1 \mathrm{~V}$. A linha tracejada separa tais efeitos atuantes em baixas tensões e as limitações do filme semicondutor em si para moderadas tensões. O contato passa a ser limitado em mais altas tensões aplicadas. Adaptado de Kirchartz 7 .

Considerando-se desprezíveis as concentrações de estados superficiais nas interfaces e a atividade elétrica de impurezas no semicondutor, uma amostra contendo eletrodos de funções trabalho diferentes uma da outra, após entrarem em contato, ocorre migração de elétrons dos níveis de energias mais altos para os níveis mais baixos, no intuito de alcançar o equilíbrio dentro do dispositivo. Como consequência, o dispositivo apresenta uma diferença de potencial intrínseca $V_{b} i$ entre os contatos, como representado pela curva vermelha na figura 2.8 . A tensão de $1 \mathrm{~V}$ indica o ponto onde a resultante entre campo elétrico externo e interno tem o mesmo sentido, com aumento notório da corrente. Por outro lado, em uma amostra sem $\mathrm{V}_{b} i$ mas com densidade de armadilhas considerável (curva azul na figura 2.8) ocorrem o preenchimento dessas armadilhas, reduzindo o número de cargas livres. Em tensões moderadas, os mecanismos de condução controlados pela camada ativa envolvem tipicamente condução ôhmica, SCLC e TLC. Tais teorias afirmam que para um campo elétrico constante, existe uma dependência da densidade de corrente $\mathrm{J}$ com a espessura da camada ativa. Aumentando-se ainda mais a tensão aplicada, o contato não consegue fornecer a quantidade de cargas exigida e passa a ser limitante de injeção.

\subsubsection{Corrente limitada por cargas espaciais (SCLC) e armadilhas (TLC)}

Quando o processo de injeção de cargas ocorre do metal para o semicondutor, em baixas tensões a corrente de deriva é descrita pela lei ôhmica: $\mathrm{J}=q \mathrm{p} \mu \mathrm{E}$, onde o número de cargas p é constante, visto que em baixos campos, a densidade de portadores gerados é maior que a densidade de portadores armadilhados, assim o campo elétrico interno é uniforme e os portadores constantes. 
Por outro lado, em certo momento, forma-se um acumulo de cargas distribuídas no volume do polímero, já que este tem baixa mobilidade. O eletrodo, por sua vez, continua fornecendo corrente, mas o semicondutor não consegue transportar e a corrente passa a ser limitada por carga espacial. Nesse caso, a corrente aumenta com o quadrado da tensão aplicada, para correntes limitadas por carga espacial livre de armadilhas.

A corrente limitada por cargas espaciais é causada pela injeção das cargas em um semicondutor praticamente livre destas (intrínseco). Os portadores injetados derivam entre dois eletrodos de acordo com o campo elétrico aplicado. Uma vez que ambas, a densidade de portadores de carga injetados e o campo elétrico, são proporcionais à tensão externa $V$, uma densidade de corrente $J=I / A \sim V^{2}$ é esperada. Além disso, uma vez que o número das cargas originalmente presentes podem ser negligenciadas se comparada com as injetadas, medidas de densidade de carga adicionais não são necessárias para extrair a mobilidade $\mu$ do portador diretamente a partir da característica $I V$ descrita pela lei Mott-Gurney:

$$
J=\frac{9}{8} \mu \epsilon \frac{V^{2}}{L^{3}},
$$

Se a espessura do filme $L$, área de contato $A$ e a permissividade do material $\epsilon$, são conhecidos [45. Devido à simplicidade da medição, mobilidades SCLC são atraentes para uma primeira análise de materiais naturais, especialmente para laboratórios de baixo orçamento. No entanto, a lei de Mott-Gurney é baseada em várias suposições que levam a deficiências conhecidas. Em primeiro lugar, o elétrodo de injeção tem que ser um contato ôhmico para lacunas (quando injetar no HOMO do semicondutor) ou para os elétrons (quando injetar no LUMO).

Inicialmente, para medições de mobilidade, de preferência, a energia de Fermi do contato de injeção de carga deve estar alinhado com o nível HOMO (LUMO) do material sob investigação e a energia Fermi do contato extrator de carga alinhado na metade do gap. Uma vez que, os níveis HOMO/LUMO de materiais naturais são frequentemente desconhecidos e, possivelmente, distribuídos ao longo de um vasto leque energético (misturas de polímeros), a melhor aposta é a utilização de uma alta (ou baixa) função trabalho do metal injetor de carga e uma moderada função trabalho do metal extrator de carga. No entanto, uma injeção de carga limitada a voltagens mais elevadas, visível como uma reta horizontal na curva $I V$ [46], é esperada, o que pode ser facilmente confundida com uma resistência em série parasitária.

Em segundo lugar, a presença de armadilhas de carga é ignorada na determinação da lei de Mott-Gurney. No entanto, os portadores de deriva em materiais orgânicos e, especialmente, naturais podem ser severamente prejudicados pela presença de armadilhas de carga e é a principal razão para uma inferior corrente de deriva de elétrons em relação a corrente de deriva por lacunas [47. Os elétrons são capturados por complexos hidratados de oxigênio presentes em todos os semicondutores orgânicos com uma densidade estimada de $N_{\text {trap }}=3 \times 10^{17} \mathrm{~cm}^{-3}$. Na presença de armadilhas o campo elétrico é originado a partir de ambos, portadores de carga capturados e móveis (livre) ( $\left(p_{\mathrm{f}}\right.$ e $p_{\mathrm{t}}$, respectivamente), enquanto a corrente é realizada apenas por aqueles não capturados. Para se obter uma injeção de carga alta o suficiente, a energia de Fermi do semicondutor intrínseco é removido do meio do band gap e, no caso de uma distribuição exponencial de 
armadilha espectral, uma lei de potência simples relacionada entre $p_{\mathrm{t}}$ e $p_{\mathrm{f}}$ contém:

$$
p_{\mathrm{t}}=N_{\text {trap }}\left(\frac{p_{\mathrm{f}}}{N_{v / c}}\right)^{1 / l}
$$

Onde o expoente $l=\Delta E_{\text {trap }} / k T$ é determinado pela largura da distribuição exponencial $E_{\text {trap }}$ comparado ao fator de Boltzmann $k T(T=300 \mathrm{~K}) . N_{v / c}$ denota os estados de densidade efetiva (DOS) na banda de condução e valência quando considerando transporte de lacunas e elétrons, respectivamente. Partindo do princípio de que apenas as cargas espaciais determinam o campo elétrico, isto é, $p_{\mathrm{f}} \gg p_{\mathrm{t}}$, e restringindo apenas ao transporte de lacunas, a corrente limitada por armadilha (TLC) também é dada por uma lei de potência [45, 48]:

$$
J=\mu q N_{v}\left(\frac{2 l+1}{l+1}\right)^{l+1}\left(\frac{l}{l+1} \frac{\epsilon}{q N_{\text {trap }}}\right)^{l} \frac{V^{l+1}}{L^{2 l+1}} .
$$

Portanto, um expoente medido $l>1$ é interpretado como prova de um TLC. Para extrair a mobilidade a partir da curva $I V$ no caso TLC, valores conhecidos ou calculáveis de $N_{v}$ e $N_{\text {trap }}$ são obrigatórios. Note-se que $l$ só depende da distribuição espectral das armadilhas mas não da sua densidade no espaço. A distribuição não uniforme de armadilhas ainda leva a um TLC descrito pela Eq. 2.4, no entanto, empregando uma espessura efetiva $L_{\mathrm{eff}}$ [4].

Em terceiro lugar, a análise SCLC/TLC pode falhar quando se considera a injeção de carga em filmes semicondutores espessos. A lei de potência (2.4) apenas funciona para uma energia de Fermi removida do nível de neutralidade de carga, ou seja, quando as cargas injetadas dominam completamente os intrínsecos. Isto deve ser verdade perto do contato de injeção em que um grande número de cargas injetadas são localizadas. No entanto, o interior do filme semicondutor se torna novamente intrínseco, uma vez que, não há portadores de carga suficiente para alterar significativamente a energia de Fermi. Campos elétricos previstos de um diodo de portadores únicos $L=5 \mu \mathrm{m}$ e um valor de tensão de $V=40 \mathrm{~V}$ são da ordem de $E \approx 10^{5} \mathrm{~V} \mathrm{~cm}^{-1}$ e a densidade estimada de lacunas injetados da ordem de $p=1 \times 10^{14} \mathrm{~cm}^{-3}$. Apenas a uma distância de $100 \mathrm{~nm}$ os contatos injetáveis alcançam valores significativamente esperados. Portanto, para filmes espessos e tensões moderadas o potencial eletrostático longe do contato de injecção pode ser determinado principalmente pela distribuição de cargas adicionais causadas por dopagem não intencional ou defeitos carregados (quasi) imóveis. Como consequência, o movimento de deriva de portadores de cargas livres pode ser significativamente alterado e/ou o movimento difusivo não pode, necessariamente, ser ignorado. Um argumento simples pode ilustrar o ponto: Para diodos de portadores únicos de comprimento relativamente alto e considerável tensão que pode assumir uma densidade constante (imóvel) $p_{\mathrm{t}}(x)=$ const ao longo da maioria do diodo, a resolução da equação de Poisson resulta no potencial eletrostático:

$$
\psi(x)=\left(1-\frac{x}{L}\right)\left(V+\frac{V_{0}}{2} \frac{x}{L}\right)
$$

com $V_{0}=\left(q p_{\mathrm{t}} L^{2}\right) / \epsilon$. Então, as lacunas injetadas tem que difundir através da região atrativa 
do potencial do canal para a posição $x_{\max }=L\left(1 / 2-V / V_{0}\right)$ antes de estar à deriva em um campo elétrico apontando para o contato de extração. O potencial máximo $\psi_{\max }=V_{0} / 8 \times(1+$ $\left.4 V / V_{0}+4 V^{2} / V_{0}^{2}\right)$, não é determinado apenas pela diferença da função trabalho (ignorada no exemplo simplificado) dos metais de contato mas também pela espessura do filme. Em outras palavras, TLC é na verdade um fenômeno próximo do contato e desvios da teoria TLC (efeitos de dimensionamento) têm de ser esperado para uma espessura relativamente elevada como em filmes orgânicos para simulações numéricas difusão-deriva.

\subsection{P3HT (poly(3-hexylthiophene))}

O advento dos polímeros conjugados à base de Tiofeno, chamou atenção e o interesse de pesquisadores por materiais poliméricos condutivos e suas aplicações [19]. O Tiofeno mais amplamente estudado atualmente é o poli(3-hexiltiofeno)(P3HT) 49, sendo um dos mais utilizados como camada ativa em dispositivos orgânicos de alta performance como transistores de efeito de campo (OFETs), células orgânicas fotovoltaicas (OPV) [19,49 55], sensores químicos orgânicos voláteis (VOC) [56], OLEDs, dispositivos ópticos não lineares, músculos artificias, entre muitas outras [53]. Seu sucesso se deve ao fato de possuírem favorável processabilidade, relativa estabilidade química [57, boa solubilidade em vários solventes [51, elevado transporte de carga (0.2 $\mathrm{cm}^{2} / \mathrm{V} . \mathrm{s}$ ), propriedades de alteração eletrônica por processos químicos [56], uma vez que possuem baixos bandgaps $(\mathrm{Eg}=1.9 \mathrm{eV})[50,58$, dentre outras.

A figura 2.9 representa a estrutura molecular do P3HT. As primeiras reações de polimerização com alto rendimento e pequenas concentrações de impurezas de síntese foi relatada em 1980. No entanto, não foram processados, pois ocorreu uma forte interação entre as ligações conjugadas da cadeia principal. Em 1986, Elsenbaumer [59] relatou a síntese de poli (alquil-tiofenos) (PAT), facilmente processáveis. As soluções quando transformadas em filmes finos, exibiam uma condutividade razoavelmente limitada em virtude da desordem no acoplamento dos grupos laterais ao monômero de tiofeno. Só após a síntese de P3ATs regioregulares (rr) abriram-se os caminhos para aplicações em dispositivos orgânicos [60].

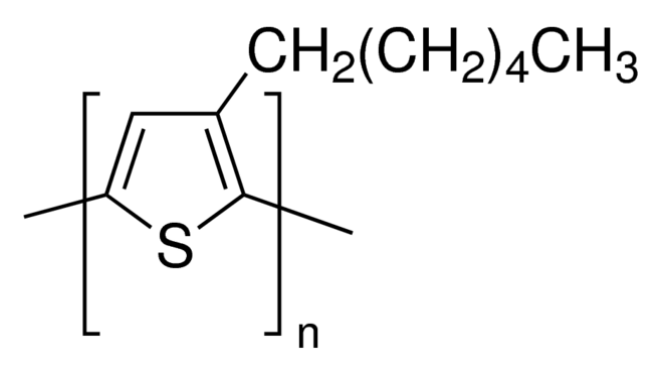

Figura 2.9: Estrutura molecular do P3HT

Alguns fatores são determinantes no desempenho desse polímero, dentre eles destaca-se a regiorregularidade 58,60,61.

Durante a polimerização do P3HT três diferentes configurações podem ocorrer - dependendo 
do método de polimerização empregado - as quais afetam fortemente suas propriedades, a saber: cabeça-cabeça (HH) ( termo do inglês, head-to-head), cabeça-cauda (HT) (head-to-tail) e caudacauda (tail-to-tail), indicados na figura 2.10. A quantidade de conexões HT definem o grau de regiorreguilaridade $(r r-\mathrm{P} 3 \mathrm{HT})$ 62].

Além de definir a regioregularidade do polímero, o percentual de conexões HT reflete em propriedades como mobilidade e cristalização. Mcpherson [62 relata uma forte dependência da regiorregularidade e peso molecular com a orientação molecular e a absorção de luz, pois os grupos alquil ligados a cadeia principal causam impedimento estérico entre as cadeias de P3HT, o que limita o empilhamento $\pi-\pi$ entre cadeias vizinhas. Como o $r r$-P3HT (HT) tem cadeias laterais alinhadas para o mesmo lado de forma alternada entre os anéis de tiofeno, esse efeito é reduzido e a cristalização é facilitada, imprimindo maior mobilidade ao material [63].

$\mathrm{Qu}$ [19] salienta que, as cadeias ordenadas de maneira HT melhoram a mobilidade de portadores e contribuem na produção de mais portadores, aumentando a condutividade elétrica, cujo valor pode ser duas ordens de grandeza maior que a estrutura regioirregular. Elsenbaumer et al. [59] foi pioneiro na observação da regiorregularidade em detrimento das propriedade dos politiofenos. Polímeros processados randômicamente tinham condutividade de $50 \mathrm{~S} / \mathrm{cm}$, em contrapartida, aqueles mais regioregulares com proporção de 2:1 (HT:HH) exibiam $140 \mathrm{~S} / \mathrm{cm}$.

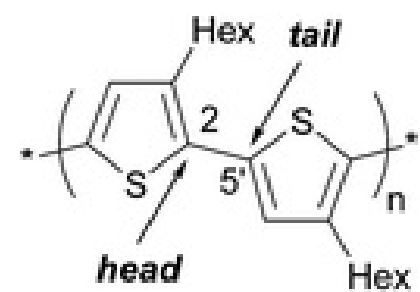

Head-to-Tail (HT)

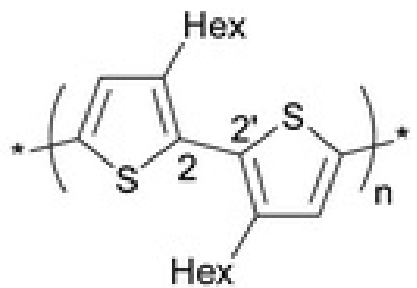

Head-to-Head $(\mathrm{HH})$

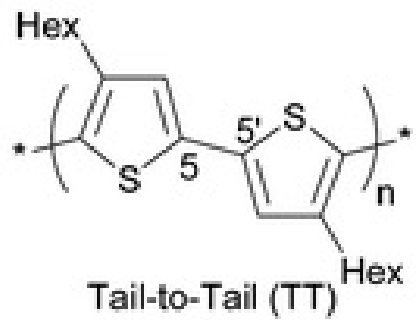

Figura 2.10: Configuração head-to-tail (HT), head-to-head (HH), e tail-to-tail (TT) encontrados em estruturas de P3HT

Com relação à síntese, o método mais amplamente utilizado para síntese de politiofenos, é o descrito por Sugimoto e Yoshino em 1986, o qual promove oxidação do tiofeno por meio de $\mathrm{FeCl}_{3}$. Este método produz amostras com melhor regiorregularidade que os demais métodos, em virtude do mecanismo de polimerização oxidativa que ocorre no tiofeno mediante orbitais livres na superfície de cristais de $\mathrm{FeCl}_{3}[39]$.

A excelente mobilidade evidenciada no P3HT, é atribuída a estrutura conformacional gerada por cadeias alinhadas e empilhadas umas sobre as outras, com anel de tiofeno formando uma con- 
formação planar alternada $[52,64$ onde as cadeias laterais de alquil apontam perpendicularmente à direção de empilhamento, o que confere fortes interações entre cadeias [58].

A direção que o filme semicondutor assume após sua deposição em filme pode ocorrer de duas maneiras em relação ao substrato: bordas (termo em inglês, edge-on)(figura 2.11(a)) ou face (termo em inglês, face-on)(figura 2.11(b)). Esta orientação é importante para determinar a quantidade relativa do material em diferentes maneiras, já que o P3HT é anisotrópico.

Bao 65 acrescenta que, a facilidade de transporte de cargas é oriunda do empilhamento do aromático $\pi-\pi$ na mesma direção do fluxo de corrente - como indicado na figura 2.11 (c) - para tanto a molécula precisa ser relativamente alinhada por deposição ou vapor de solvente, além disso, é importante que os filmes possuam grãos densamente empacotados e bem interligados. No caso de semicondutores processados a partir de solução, as cadeias de alquil segregam preferencialmente para o ar e para a interface com o substrato (de maneira a diminuir a energia interfacial), resultando em orientação borda edge-on.

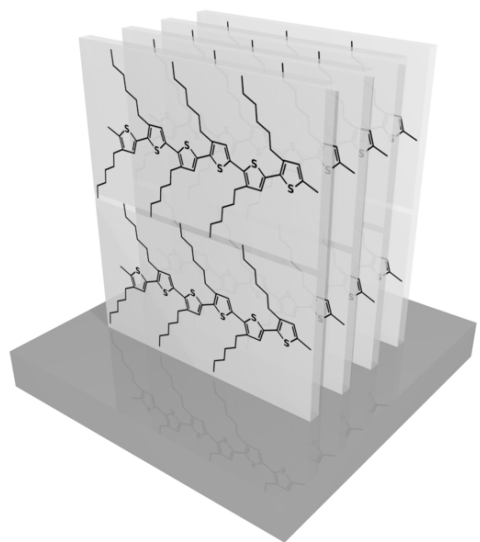

(a)

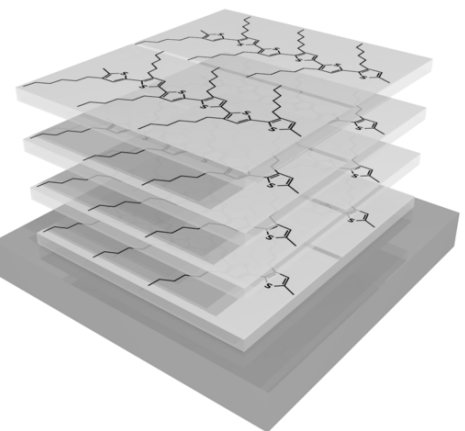

(b)

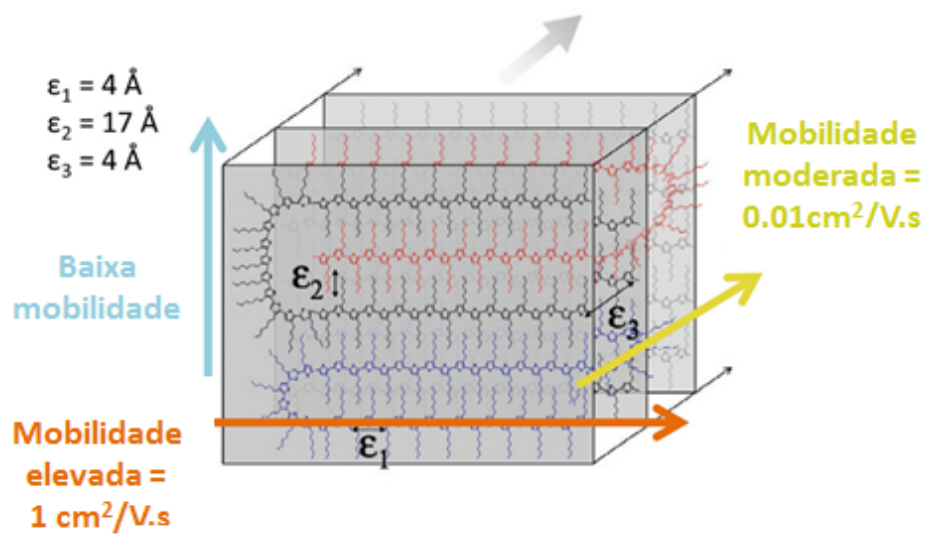

(c)

Figura 2.11: Orientações possíveis do P3HT ao ser depositado com filme (a) edge-on (b) face-on (c) Mobilidade preferencial no filme polimérico. Adaptado de Lim 8 


\subsection{PEDOT:PSS (Poly(3,4-ethylenedioxythiophene)-poly(styrenesulfonate))}

O PEDOT:PSS é um polímero conjugado altamente utilizado na optoeletrônica orgânica, sendo parte essencial do eletrodo de base em dispositivos, pois promove um contato com alta seletividade de carga 14, 66, 67. Desde a sua descoberta no final dos anos 70, tem sido altamente utilizado como camada portadora de lacunas 68 . Na sua forma pura, o PEDOT não é solúvel em solventes comuns e não se funde a temperaturas consideráveis. Para contornar este problema faz-se a polimerização do mesmo na presença do poly(styrenesulfonic acid)(PSS) que é solúvel em água, funcionando como um dopante de balanceamento de carga, uma vez que, promove a ionomerização do PEDOT permanecendo ligado a este por atração Coulombiana e formando partículas coloidais, visto que o PSS age como um íon compensador de carga estabilizando o PEDOT [11]. Após ser dopado, o PEDOT:PSS (figura 2.12) apresenta elevada condutividade de até $130 \mathrm{~S} / \mathrm{cm}$ no plano [69], fácil processabilidade, durabilidade [68, boa transparência óptica em filmes finos, elevada estabilidade, função de trabalho bem definida em torno de $5.1 \mathrm{eV}$, o que auxilia no transporte de lacunas [66, 70], tornando-o muito atrativo como um material de eletrodo, por exemplo, em OLEDs e OPVs 71 .

A primeira função do PEDOT:PSS foi como camada antiestática em filme fotográfico, seguido pela utilização como camada condutora transparente em dispositivos eletroluminescentes, capacitores e transistores, e atualmente é amplamente utilizado como camada transportadora de lacunas em diodos orgânicos, pois possui função trabalho mais elevada que os óxidos condutivos, resultando em um melhor alinhamento dos níveis energéticos. Além disso, promove a suavização da superfície não homogênea daqueles, melhorando a interface com o material fotoativo 72 .

A função trabalho do filme de PEDOT:PSS tem sido estudada por diferentes métodos de preparação como ambiente de tratamento térmico annealing ou raio entre PSS/PEDOT. A espectroscopia revela que o annealing no alto vácuo aumenta a função trabalho, mas é instável quando expostas ao ar. Ying-Jie [67] analisou o efeito da irradiação UV na função trabalho dos filmes PEDOT: PSS por meio de PYS (do inglês, photoelectron yields pectroscopy) e emissão de campo no vácuo. O aumento no raio de PSS/PEDOT aumentou a função trabalho do filme quando tratados com UV, bem como modificou a altura da barreira de injeção 67.

O PEDOT:PSS tem sido empregado em uma gama de aplicações de biosensores e até mesmo em estudos in vivo, evidenciando sua baixa toxicidade. Trabalhos recentes empregaram o polímero como eletrodo cerebrais mostrando raio de sinal/ruído superior aos tradicionais eletrodos [26].

A utilização do PEDOT:PSS recebeu considerável interesse em OLEDs em virtude de dois aspectos: boa condutividade para substituição de óxidos condutores transparentes (TCOs) ou suavizando a superfície áspera destes e por possuir a capacidade de elevado transporte de lacunas 73. Unsworth 72 corrobora que por suas ótimas características como polímero condutor, além de fácil processabilidade por meio de spray ou impressão, por exemplo, constitui-se com um material com potencial para utilização como eletrodo substituto dos TCOs, tendo em vista que mantêm a boa performance dos dispositivos 72 . 


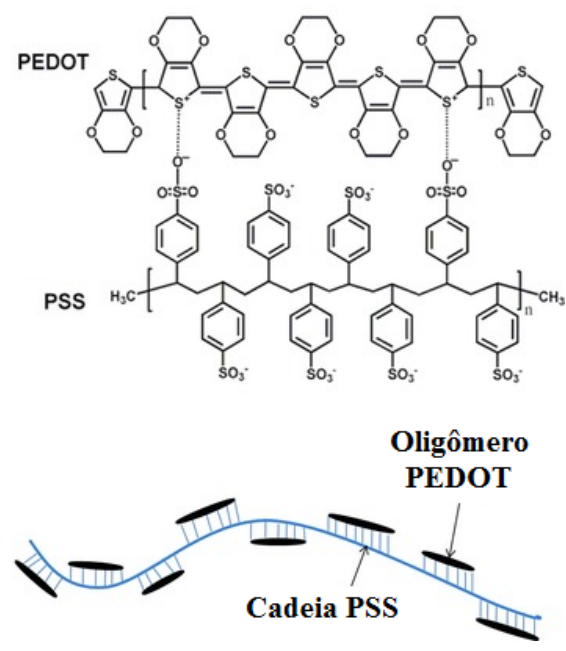

Figura 2.12: Estrutura química do PEDOT:PSS, evidenciando a localização de ambos na formação do polímero [9].

\subsection{FTO (Óxido de Estanho dopado com Flúor)}

Os TCOs tem sido muitos empregados em dispositivos optoeletrônicos em função das diversas vantagens por eles oferecidas, tais como: baixo custo, condutividade elétrica [74], estabilidade térmica, química e mecânica, baixa absorção de luz [23, [75] [76]. Sua elevada condutividade elétrica e ao mesmo tempo alta transmitância óptica na faixa do visível, os tornam altamente aplicáveis na fabricação de celulas solares, sensores [23], display de cristal líquido, OLEDs [76]. De maneira a se obter filmes transparentes de baixa resistência, o $\mathrm{SnO}_{2}$ pode ser dopado com diferentes elementos como antimónio (Sb), arsénio (As), fósforo (P), Indio (In), Molibidênio (Mo), Flúor (F) e Cloro $(\mathrm{Cl})$ 23. Os filmes finos de dióxido de estanho dopado com flúor, por serem termicamente mais estáveis, muitas vezes são utilizado como uma alternativa ao ITO (Óxido de Estanho dopado com Índio), além disso possuem elevada capacidade de aderir fortemente ao vidro, baixo custo e simplicidade [74], resistente à abrasão física e são facilmente volatilizados, permitindo elevada mobilidade e filmes menos resistivos. Trata-se de um semicondutor degenerado tipo-n, resultante da dopagem do óxido de estanho pela substituição do $\mathrm{O}_{2}$ por flúor que age como doador de elétron [75].

No que diz respeito a deposição, FTO pode ser aplicado por diversos métodos incluindo deposição por vapor químico, pirólise por spray, evaporação térmica, evaporação por laser pulsado e sputtering 23,76$]$.

\subsection{Semicondutores naturais: Carotenóides}

A natureza é repleta de moléculas com ligações $\pi$ conjugadas sugerindo a possibilidade de aproveitamento como material semicondutor em dispositivos eletrônicos. Dentre essas moléculas destaca-se os carotenóides - como o $\beta$-caroteno - que possui ligações $\pi$ conjugadas lineares atuando como transportadores de lacunas [26]. 
Os carotenóides são pigmentos orgânicos encontrados nos cloroplastos e cromoplastos de plantas e alguns outros organismos fotossintéticos como algas, bactérias e fungos [77]. Atualmente são identificados mais 600 tipos na natureza, cuja molécula possui 9 ligações duplas na cadeia de polieno que podem formar configurações cis e trans, totalizando um número possível de compostos de 200 mil [78. Dividem-se em duas classes, xantofilas (que contêm oxigênio) e carotenos (que são puramente hidrocarbonetos, e não contêm oxigênio) [79].

Em sua grande maioria são tetraterpenóides com 40 carbonos, produzidos a partir de 8 unidades de isopreno (2-metil-1,3-butadieno) ligados linearmente e simétricos. A estrutura básica pode ser alterada por processos de hidrogenação, desidrogenação, ciclização ou oxidação [7, 80] .

Olson 78 atenta para as propriedades optoeletrônicas dos carotenóides. Os mesmos possuem capacidade de absorção na luz visível, uma vez que, seus elétrons delocalizados podem sofrer transformação induzida por fótons, gerando um estado singleto excitado. Oliveira [81] acrescenta que a absorção de luz dá-se porque a cadeia de duplas ligações conjugadas atua como cromóforo, onde podem absorver luz na região do ultravioleta (UV) e visível do espectro, o restante é transmitido ou refletido.

Carotenóides são os pigmentos naturais mais usados no mundo, com destaque para os carotenóides bixin, norbixin e $\beta$-caroteno 82$]$.

\subsection{1 Óleo de Buriti (Mauritia flexuosa $L$.)}

O óleo de Buriti é extraído da planta tropical Mauritia flexuosa L., apresenta a cor vermelhoamarelada, com as seguintes propriedades físico-químicas: índice de acidez 4,00 - 4,80mg NaOH/g, índice de peróxido 20,35 - 24,45meq $/ \mathrm{kg}$, viscosidade 33,90 - 41,90 cSt e cerca de 0.60 de dienos conjugados. Possui muitos ácidos graxos, principalmente o ácido oléico [33], cuja função protetora da pele permite o seu uso em cremes, loções para o corpo, óleos de banho e sabonetes 83 .

Quanto aos carotenóides, especificamente, o $\beta$-caroteno (figura 2.13 (b)), a polpa do fruto maduro (figura 2.13 (a)) possui a maior concentração dentre todas as outras polpas de frutas. O $\beta$-caroteno, por sua vez, é constituído por cadeias de hidrocarbonetos lineares que podem ser ciclizados em uma ou ambas as extremidades da molécula [80].

Durães [33 informa que as principais propriedades do óleo de buriti são: boa difusividade térmica, capacidade de absorver radiação com comprimento de onda entre 300 e $550 \mathrm{~nm}$ e a fotoluminescência na região correspondente ao verde no espectro eletromagnético, atribuídas à presença do ácido oléico e do $\beta$ - caroteno.

Albuquerque [28], extraiu o óleo a partir da polpa do Buriti em frações com elevada concentração de $\beta$-caroteno. Algumas importantes propriedades físicas e químicas já haviam sido reportadas para o referido óleo, tais como, difusividade térmica e por meio de medidas da constante dielétrica observou-se as transições de fase. Através de espectroscopia Raman, o autor identificou as bandas de infravermelho baseadas nas correlações com ácidos graxos, ésteres e triglicérideos, constatando que o espectro de óleo Buriti é muito semelhante ao de trioleína, um triglicérido de ácido oleico. 


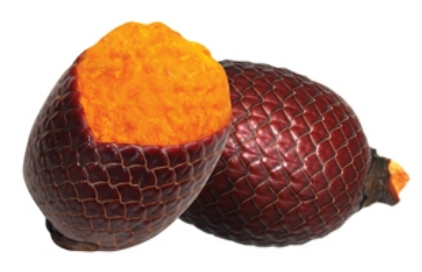

(a)

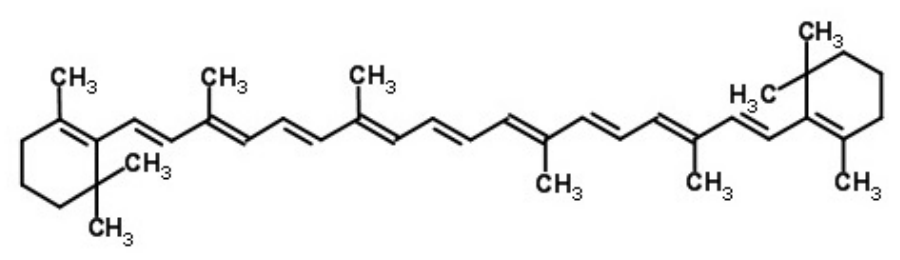

(b)

Figura 2.13: (a) Fruto do Buriti (b) Estrutura molecular do $\beta$-caroteno

\subsection{2 Óleo de Urucum (Bixa orellana L.)}

O urucum é um extrato vermelho-alaranjado encontrado na camada resinosa externa das sementes de Bixa orellana L. (Bixaceae) [84,85, uma planta tropical conhecida popularmente como urucum ou urucu (figura 2.14 (a)). Essa resina de suas sementes contem $80 \%$ do pigmento carotenóide, chamado cis-bixina [83. Trata-se de um composto lipossolúvel, com ocorrência na formas cis e trans 86, 87. A bixina (nome IUPAC: (2E, 4E, 6E, 8E, 10E, 12E, 14E, 16Z, 18E) -20metoxi-4,8,13,17-tetrametil-20-oxoicosa 2,4,6,8,10,12,14,16,18-ácido nonaenoico) é composta por uma cadeia isoprênica de 24 carbonos, contendo um ácido carboxílico e um éster metílico nas extremidades, como ilustrado na figura 2.14 (b) 88.

Tem sua origem na América do Sul com difusão para a América Central, África e Índia 31,84. A principal função econômica do Urucum é no setor de corantes para têxteis, vernizes, cosméticos e tatuagens [31, no qual é o segundo corante natural mais utilizado no mundo, tendo o Brasil como maior produtor e exportador [86], cujo plantio ocorre principalmente nas regiões Norte e Nordeste [77. Garcia [89 enfatiza por meio de dados do IBGE que, a produção anual é de aproximadamente 17 mil toneladas, das quais 12 mil são originárias do Brasil.

Trata-se de um corante norcarotenóide poli-insaturado, solúvel em gorduras, mas insolúvel em água, porém, se exposto aos álcalis, o éster metílico é hidrolisado e produz o ácido dicarboxílico norbixina 2.14 (c), que é solúvel em água 77,83 . Os isômeros cis, tanto da bixina quanto da norbixina, estão presentes naturalmente na planta, sendo convertidos na forma trans, mais estável, quando submetidos a temperatura adequada [89. Quando isolado torna-se quimicamente instável, de maneira que sua conversão em trans-bixina ( $\beta$-bixina) é realizada por isomerização.

No tocante a sensibilidade, a bixina mostra-se sensível a temperaturas elevadas e exposição a luz por tempo prolongado [89]. Caso não sejam dados os cuidados apropriados, pode ocorrer 


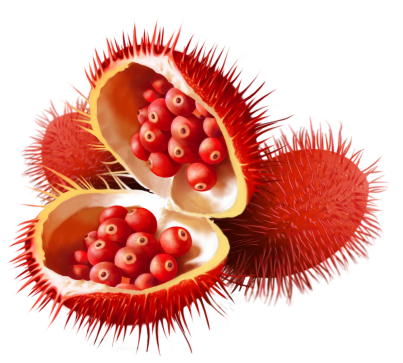

(a)

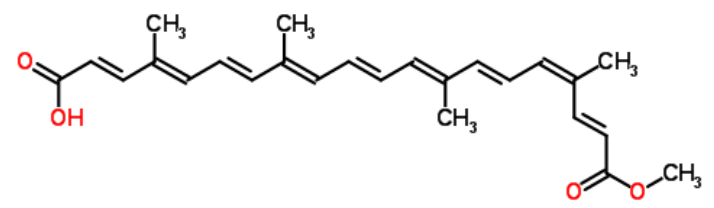

(b)

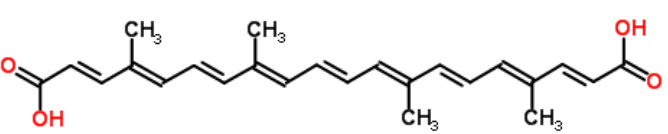

(c)

Figura 2.14: (a) Semente de Urucum (b) Bixina (c) Norbixina

decomposição foto-mecânica e oxidação da mesma. Seu ponto de fusão é $198^{\circ} \mathrm{C}$ e se decompõe a $217^{\circ} \mathrm{C}$. Possuem cromóforos que absorvem comprimento de onda $>290 \mathrm{~nm}$. Com relação a extração, as sementes são tratadas com solvente adequado para dissolver o pigmento. Esse extrato então é filtrado para remoção de materiais insolúveis e em seguida ocorre a eliminação gorduras e ácidos graxos

\subsection{Mecanismos de degradação de um dispositivo orgânico}

Quando se desenvolve dispositivos orgânicos em atmosfera/pressão ambiente, a sensibilidade dos materiais com o meio torna-se um desafio. A figura 2.15 exibe os principais mecanismos degradativos que podem afetar as amostras. Politiofenos são instáveis à atmosfera ambiente, pois a cadeia hexil, que o torna solúvel, também acarreta mudança no seu potencial de oxidação devido ao efeito indutivo no anel aromático, tornando-o sensível à oxidação [39].

\section{Interface Metal/semicondutor}

Em se tratando do contato eletrodo de topo e semicondutor, Park [54 menciona o fato da migração do metal para o polímero. O desempenho de transistores de P3HT são influenciados pela interface metal-semicondutor, cuja penetração é mais crítica em filmes não tratados termicamente e depende de mudanças na orientação molecular e ordenação do P3HT. Em contrapartida, Pei [90] demonstrou que a eletro-migração do alumínio, após sofrer estresse por campo elétrico, aumenta a interface metal-polímero melhorando o contato elétrico e injeção de carga do eletrodo, resultando em uma maior performance da célula solar. Além disso, a oxidação do contato metálico pode ocorrer, visto que é o eletrodo mais exposto ao ambiente. Tal oxidação reduz a área ativa de injeção e limita a eficácia do contato. 


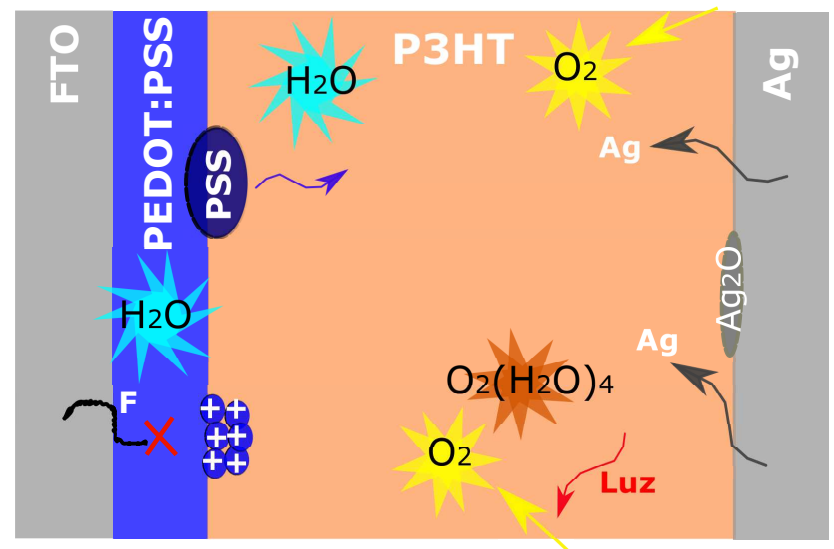

(a)

Figura 2.15: Processos degradativos em um dispositivo à base de P3HT 10 .

\section{Interação do semicondutor com o meio}

Materiais orgânicos e eletrodo são reconhecidamente susceptíveis à atmosfera ambiente, a degradação química é devido principalmente ao oxigênio, água e reação do eletrodo com a camada ativa. Durante a fabricação, água e oxigênio podem ser absorvidos em diferentes camadas e difundir para dentro do dispositivo [10,91].

O oxigênio atmosférico forma um complexo reversível de transferência de carga (CTC) com semicondutores orgânicos, como P3HT, e atua como receptor de elétrons que conduzem a dopagem não intencional. A reação entre eles é acelerada pela iluminação e a dopagem podem ser revertida pelo aquecimento, o qual desarmadilha os elétrons capturados pelo oxigênio. Ademais, o referido gás pode reagir mais fortemente com o polímero degradando-o de maneira irreversível, pois os grupos carbonila gerados atuam como armadilhas para elétrons e desfazem duplas ligações ao longo da cadeia polimérica acarretando em uma diminuição do comprimento conjugados, que por sua vez, reduz a mobilidade efetiva. Apesar do efeito aparentemente deletério, por meio dele é possível realizar um monitoramento de oxigênio no meio e tem sido explorado como aplicação de sensor 92 . A água também tem papel importante na degradação desses materiais expostos a atmosfera ambiente pela geração de compostos hidróxidos [93].

\section{Influência da camada de PEDOT:PSS}

O uso do PEDOT:PSS como camada transportadora de lacunas entre o óxido de estanho e o semicondutor acarreta vantagens e desvantagens e em alguns casos chega a ser controverso. Abdulrazzaq [70] explica que em virtude da natureza ácida do referido polímero, pode haver degradação do eletrodo ITO por decapagem do Índio com transporte para a camada ativa. Esse mecanismo ocorre durante o processamento, recozimento e envelhecimento das amostras. Além disso, o autor alerta para a higroscopicidade do PEDOT:PSS, já que este absorve água do ambiente e a conduz para a camada ativa, comprometendo o dispositivo pelo aumento da resistência em série (Rs). Por outro lado, autores relatam a boa influência dessa camada [42,71,73, a qual contribui para um maior tempo de vida do dispositivo impedindo a reação entre o substrato óxido e a camada ativa. 
Outra vantagem relatada, refere-se a diminuição do efeito de carga imagem por parte da camada HTL. Esse efeito surge quando o eletrodo injeta uma carga no semicondutor deixando para trás uma carga de sentido oposto. Por forças coulombianas, a carga injetada é forçada a retornar para o eletrodo de origem, prejudicando a injeção de cargas na camada ativa [22].

Ainda no tocante ao filme de PEDOT:PSS, outro efeito acreditado por diversos pesquisadores da área [66 68,70], diz respeito ao surgimento de uma 'pele' de PSS na superfície do referido filme, quando depositado em atmosfera ambiente. Sabendo que a função trabalho do PSS é maior que a do PEDOT, o filme formado possui maior função trabalho que o PEDOT puro. Hwang [11 realizou um experimento no qual a superfície e a composição de filmes de PEDOT:PSS (tipo P AI 4083) antes e após a retirada da camada de PSS por sputtering, foi investigada. Com a remoção do PSS, fica exposta a grande densidade de estados próximo do nível de Fermi que corresponde ao PEDOT dopado-p, tornando mais fácil a remoção de um elétron ao nível do vácuo, em outras palavras reduzindo a função trabalho do filme (figura2.16). Mais ainda, observou-se um maior dipolo na interface e maior barreira de injeção, corroborando com a presença de maior densidade de estados de interface induzidas no gap, aumentando a interação com a camada semicondutora. Mesmo resultado foi constatado mais recentemente por Ying-Jie [67].

Parnell [16] mostrou que o filme de PEDOT:PSS incha quando exposto a umidade, pois as gotas de água se condensam na superfície do polímero e quando evaporam deixam deformações em microescala naquele.

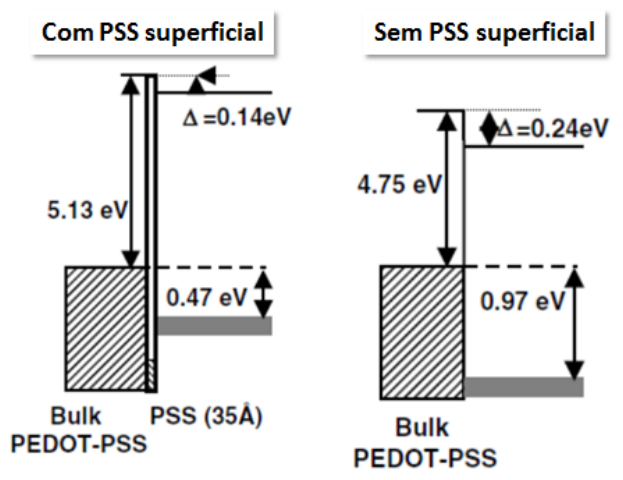

Figura 2.16: Energia de banda do filme PEDOT:PSS antes e após ser removida um película de $35 \AA$ de PSS da superfície 11$]$.

\section{Soluções possíveis}

Materiais antioxidantes, como os carotenóides, podem surgir como uma saída para a problemática citada. A ação antioxidativa dessas moléculas ocorre de duas maneiras: reação com oxigênio singleto e interação com radicais livres. O oxigênio singleto constitui-se numa forma altamente reativa, o qual apresenta dois elétrons de spins opostos ocupando orbitais diferentes ou não. Pode ser formado pela transferência de energia eletrônica de um composto em um estado excitado para o oxigênio triplete: ${ }^{1} \mathrm{O}_{2}+$ CAR $\rightarrow \mathrm{O}_{2}+{ }^{*}$ CAR. Após a reação, o carotenóide no estado excitado $\left({ }^{*} \mathrm{CAR}\right)$ pode facilmente retornar ao estado fundamental, dissipando energia na forma de calor. A capacidade em estabilizar o oxigênio reativo vai depender da quantidade de duplas ligações e 
aos grupos laterais da cadeia [79]. Fontana 94 salienta que, a ação antioxidante é encontrada em carotenóides acíclicos, com nove ou mais duplas ligações conjugadas; Esses carotenóides são capazes de capturar espécies reativas de oxigênio, como o radical peroxil (ROO•) e o oxigênio singleto $\left(\mathrm{O}_{2}\right)$ estabilizando o elétron desemparelhado do radical por ressonância. A ordem crescente de capacidade de seqüestrar o oxigênio singleto por parte dos carotenos e xantofilas é: licopeno, astaxantina ou cantaxantina, $\beta$ - caroteno ou bixina, luteína e crocina. Dessa forma, os carotenóides são capazes de retirar do meio espécies altamente reativas, aumentando o tempo de vida dos dispositivos que os contem.

Um dos principais desafios a serem vencidos para a produção comercial de dispositivos orgânicos tem sido o aumento no tempo de vida dos materiais, que em termos de uso comercial deve atingir no mínimo 10.000 horas. Uma maneira de contornar essa problemática é o desenvolvimento de tecnologias de encapsulamento dos dispositivos, garantindo bloqueio satisfatório de efeitos ambientais como oxigênio, umidade, os quais, na presença de luz, induzem à degradação (perda da conjugação) do polímero e, dessa forma, afetando o desempenho dos dispositivos [22]. 


\section{Capítulo 3}

\section{Desenvolvimento}

A abordagem do tema proposto depende, significativamente, de fatores relacionados a fabricação dos dispositivos, condições ambientais e higienização da preparação, para citar alguns. O desempenho ótimo dos dispositivos eletrônicos orgânicos, depende criticamente da natureza da injeção de carga dos eletrodos em contato com os semicondutores orgânicos, seguido pelo transporte eficaz dos portadores através do volume do material [13]. Quando se pretende desenvolver, analisar e monitorar dispositivos orgânicos sob condições normais de atmosfera e pressão, a dificuldade é ainda maior, uma vez que são materiais altamente reativos ao ambiente.

Nesta seção, serão descritos os métodos de fabricação pelo qual foi possível obter dispositivos orgânicos e investigar, com sucesso, alguns fenômenos físico-químicos envolvidos no seu funcionamento.

\subsection{Confecção de dispositivos orgânicos: Aspectos relevantes}

\subsubsection{Arquitetura molecular}

A escolha dos materiais que irão compor o dispositivo deve levar em consideração a interação entre solventes de camadas adjacentes e as reações químicas ou difusão física entre as moléculas dos materiais, devem permitir a interação com os eletrodos e com elas próprias, no intuito de diminuir as barreiras resistivas e morfologia adequada para mobilidade de carga [41].

A estrutura estabelecida para a realização do presente trabalho foi a de camadas sobrepostas sobre um substrato rígido condutivo, no formato 'sandwich', por assim dizer. Tendo em vista que, a mobilidade eletrônica em materiais poliméricos é mais lenta, torna-se necessário uma estrutura que favoreça o fluxo de corrente, como a utilizada.

Uma boa confecção de amostras leva em consideração a limpeza, quando da manipulação dos materiais e vidrarias empregadas na preparação de soluções, sob pena de contaminação e alteração química destes. Para Boudouris [56], a otimização da performance para aplicações em dispositivos orgânicos, requerem um rigoroso domínio da estrutura e design molecular para o 
controle da morfologia. Santos 22 ressalta ainda que, a estabilidade dos dispositivos é dependente dos processos de limpeza química dos substratos (ITO ou FTO, por exemplo), ao passo que o desempenho dos dispositivos também pode ser otimizado por modificações na superfície do ânodo por meio de tratamentos por plasma de oxigênio, água régia, e UV-Ozônio que alteram a função trabalho e assim aumentam a injeção de portadores de carga na camada semicondutiva do dispositivo.

\subsubsection{Técnicas de processamento}

A técnica de deposição dos filmes tem papel crucial no desempenho do dispositivo. Essa influência pode atingir dimensões das camadas, morfologia, interação entre camadas e consequentemente respostas elétricas, ópticas, dentre outros processos físico-químicos. Estudos realizados indicam que a técnica de impressão por jato de tinta, por exemplo, promove uma orientação vertical das moléculas poliméricas com maior condutividade se comparado a técnica de spin coating, que deixa as moléculas 'congeladas' horizontalmente 13,69 . Do ponto de vista da interação física entre eletrodo de topo e camada semicondutora, Silva et. al. [41] informa que, a interface metálica promove imobilização dos modos vibracionais da camada orgânica com uma profundidade de até $75 \mathrm{~nm}$ do filme.

O processo de fabricação laboratorial envolve equipamentos simples como spin-coating ou drop casting, oferecendo baixo custo na obtenção de dispositivos de ótimo desempenho. Para produção em largas escala, as técnicas de produção envolvem impressão por jato de tinta, serigrafia, doctor blading, dentre outros. Azarova 95 empregou em seu trabalho a deposição de camada de semicondutor orgânico por meio de spray, para fabricação de OFETs de alto desempenho demonstrando a viabilidade desta abordagem se comparado a técnica de spin-coating.

O eletrodo de topo em nossas amostras, foi depositado com auxílio de espátula, por se tratar de um método mais aproximado da técnica de impressão, cujo equipamento é aquisição do nosso laboratório, necessitando de alguns ajustes para sua utilização. Além disso, trata-se de um método menos agressivo para os materiais verdes, que seguirão este protocolo.

Alguns métodos de deposição da camada ativa - tanto com P3HT quanto com compósitos dos óleos - foi averiguado, a saber: spin coating, dip coating e drop casting. Amostras obtidas por spin coating resultam em curto-circuito para ambos materiais, em função da fina espessura alcançada, a qual colapsa com a deposição da prata. Além disso, esta técnica não confere elevada cristalinidade ao filmes, pois a brusca evaporação do solvente durante a formação do filme cria condições cineticamente desfavoráveis ao crescimento do cristal [54]. O dip coater acarretou mesmo problema de espessura para filmes de P3HT, mas mostrou-se ideal para os materiais verdes.

A técnica de deposição do PEDOT:PSS foi investigada por meio de spin coating, dip coating e imersão (dip coating manual), analisando-se o reflexo destas nas curvas $I(V)$ medidas.

A compreensão dos mecanismos dominantes em cada interface de um dispositivo orgânico é de suma importância para se estabelecer uma melhoria no seu desempenho global. Sabendo-se que 
a interação metal-polímero ocorre pela sobreposição de estados contínuos daquele com orbitais moleculares discretos destes, gerando um novo nível energético ainda pouco compreendido, o processamento químico e físico da camada ativa tem papel fundamental na promoção de uma melhor interação.

O processamento de dispositivos baseados em polímeros semicondutores requerem técnicas de deposição bem estudadas sob a óptica da boa qualidade dos filmes, atuando diretamente nos parâmetros elétricos do dispositivo e por consequência na sua eficiência [17.

\subsection{Materiais utilizados}

Neste trabalho utilizou-se como substrato e também como eletrodo de base, o vidro com uma camada condutiva de FTO (óxido de estanho dopado com flúor) oriundo da Flexitec com resistência por quadrado em torno de $5 \Omega$.

Para a camada ativa do dispositivo empregou-se o polímero semicondutor comercial P3HT (Poly(3-hexylthiophene-2,5-diyl) adquirido da Ossila, cuja regioregularidade é 94,4. Possui uma faixa de mobilidade entre $10^{-4}$ e $10^{-1} \mathrm{~cm}^{2} / \mathrm{V} \cdot \mathrm{s}$.

Em um dos tipos de dispositivos desenvolvidos, fez-se uso do PEDOT:PSS - Al4083 fornecido pela Ossila, com função trabalho de $5.2 \mathrm{eV}$ e condutividade de até $0.2 \times 10^{-3} \mathrm{~S} / \mathrm{cm}$.

Uma pasta de micropartículas de prata, adquirida da Sigma Aldrich, foi empregada para o eletrodo de topo.

Para preparação de amostras verdes, oriundas de óleos vegetais, adquiriu-se no comércio local os seguintes óleos: Óleo de Buriti (OB) (Mauritia flexuosa L.) e Óleo de Urucum (OU)(Bixa orellana). O óleo de Buriti, tem se mostrado adequado para fabricação de compósitos poliméricos em estudos de dispositivos orgânicos, pois exibem maior estabilidade térmica e flexibilidade que o polímero puro. A presença do óleo na matriz polimérica reduziu a temperatura de transição vítrea $(\mathrm{Tg})$, além disso, análises de ressonância magnética nuclear (RMN), Microscopia eletrônica de varredura (MEV) e calorimetria exploratória diferencial (DSC) tem indicado uma boa dispersão do óleo no polímero [91]. Ao passo que, a utilização do óleo de Urucum faz-se interessante pela rica presença do composto bixin, cujas propriedades semicondutoras são reconhecidas.

A plastificação dos óleos foi conseguida pelo uso do polímero isolante Poliestireno (PS) procedente da Sigma Aldrich.

Foram realizados experimentos com substratos flexíveis de PET+Alumínio, PET+ouro e vidro+ITO, em uma análise preliminar do trabalho. 


\subsection{Metodologia de fabricação}

\subsubsection{Preparação da solução de P3HT}

Inicialmente é realizada a dissolução do P3HT tendo o Clorofórmio como solvente. A concentração definida foi $10 \mathrm{mg}$ de soluto/1ml de solvente. Para uma melhor dissolução a mistura é levada ao agitador magnético por 30 minutos, como recomenda o fabricante. Uma vez preparada a solução do semicondutor orgânico, dá-se inicio a fabricação dos diodos.

\subsubsection{Preparação das soluções de óleo de Buriti e óleo de Urcum}

A fim de se empregar como camada ativa nos dispositivos propostos, foram preparadas soluções de óleos de Buriti (OB) e Urucum (OU), utilizando o polímero Poliestireno como plastificante. Inicialmente o PS é dissolvido em clorofórmio sob agitação magnética, por cerca de 1 hora, até total dissolução. Em seguida adiciona-se o óleo, deixando-o por mais 3 horas sob agitação. Os óleos foram dissolvidos nas seguintes concentrações: $47 \%$ para o OB e 28, 34 e $47 \%$ para OU. A tabela 3.1 resume as soluções nas concentrações preparadas, bem como suas denominações.

\begin{tabular}{|c|c|c|}
\hline Materias & $\begin{array}{c}\text { Concentrações } \\
\text { (Óleo vegetal\%PS) }\end{array}$ & Representação \\
\hline OB/PS & $47 \% 53$ & OB47/PS \\
\hline & $47 \% 53$ & OU47/PS \\
OU/PS & $34 \% 64$ & OU34/PS \\
& $28 \% 76$ & OU28/PS \\
\hline
\end{tabular}

Tabela 3.1: Concentrações dos compósitos Óleo vegetal/Polímero

\subsubsection{Procedimento para confecção dos dispositivos}

A princípio idealizou-se dois tipos de dispositivos para análise da injeção de cargas: Dispositivo tipo 1 (DO-1) (FTO/P3HT/Prata) e Dispositivo tipo 2 (DO-2) (FTO/PEDOT:PSS/P3HT/Prata). No intuito de se investigar a eficácia de diferentes eletrodos na injeção de carga, foram fabricadas amostras contendo FTO, ITO, Alumínio e Ouro como substrato condutivo. No entanto, para realização de outras análises, fez-se uso apenas do substrato de FTO. Também construiu-se dispositivos do tipo 1 e 2, substituindo-se o P3HT pelas soluções dos óleos.

Os dispositivos foram construídos de acordo com uma arquitetura em camadas sobrepostas sobre um substrato. De maneira a se obter um maior aproveitamento da área, inseriu-se mais de um contato sobre a camada ativa, perfazendo assim, uma maior quantidade de diodos por amostra, como visto na figura 3.1 (b) e (c).

A sequência esquemática da figura 3.1 (a) descreve os passos de montagem do dispositivo. $\mathrm{O}$ processo inicia-se com a limpeza dos substratos num banho ultrassônico de acetona, álcool metílico 

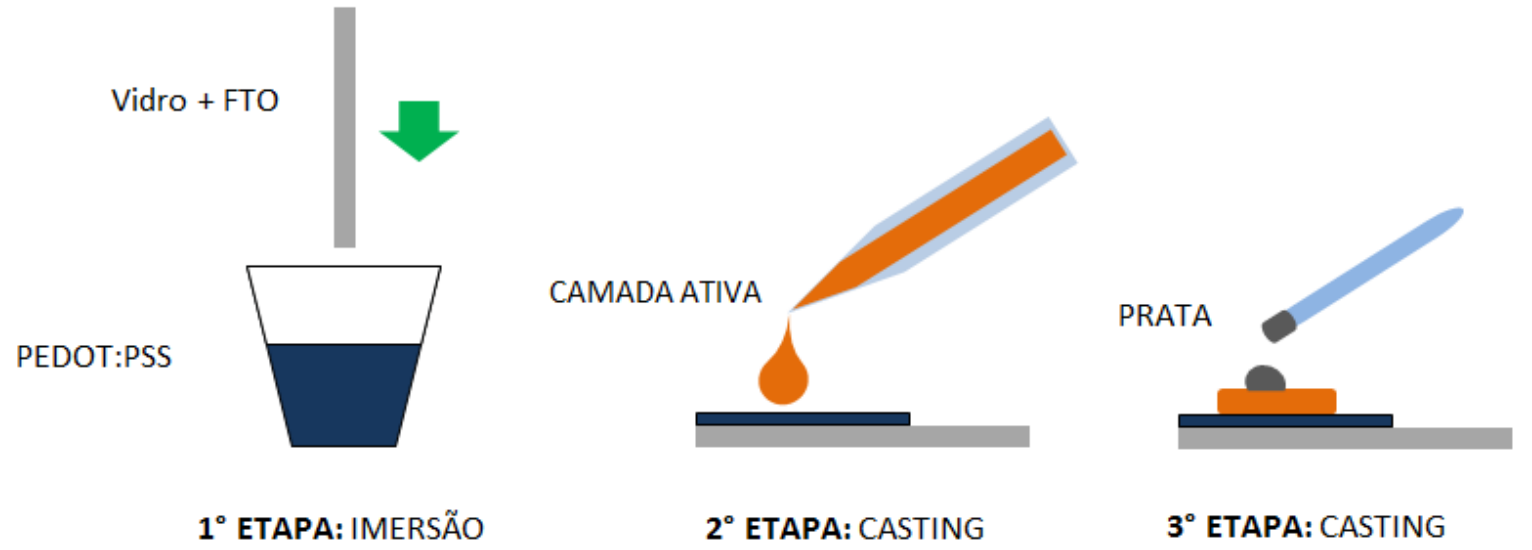

(a)

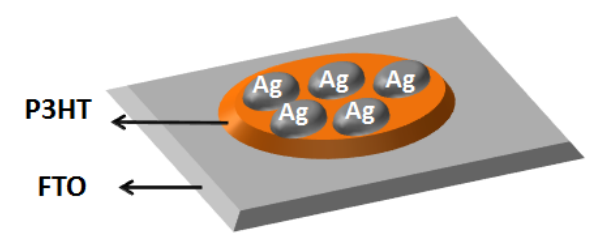

(b)

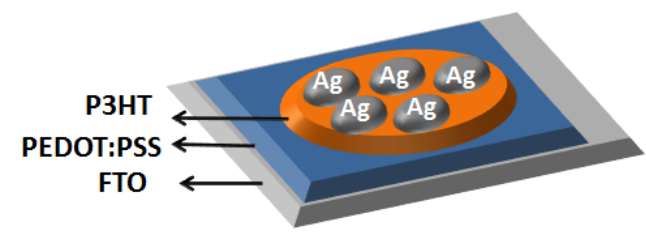

(c)

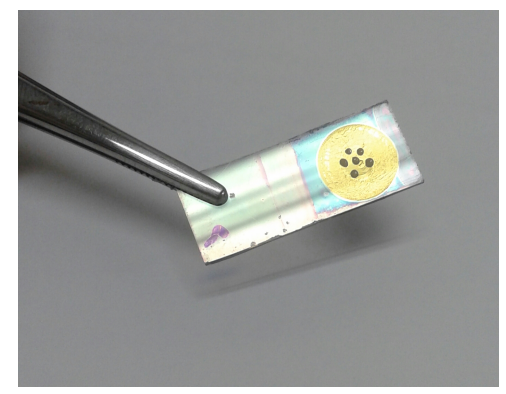

(d)

Figura 3.1: (a) Técnicas de processamento utilizadas (b) Arquiteturas desenvolvidas para os dispositivos Ag/P3HT/FTO (DO-1) e (b) Ag/P3HT/PEDOT:PSS/FTO (DO-2) (c) fotografia de uma amostra real fabricada 
e água deionizada por 10 minutos cada. Após a secagem do substrato, o polímero PEDOT:PSS pode então recobrí-lo por meio de imersão ( $1^{a}$ Etapa)(no caso do diodo tipo 1 essa etapa não é realizada). Quando este encontra-se seco, após 5 minutos a $100^{\circ} \mathrm{C}$ na estufa, faz-se a deposição por casting do P3HT com auxílio de uma pipeta e bomba tipo pêra ( $2^{a}$ Etapa). Aquece-o novamente por 20 minutos a $60{ }^{\circ} \mathrm{C}$. Por fim, é depositado o contato de prata usando uma espátula, esperando secar para medir eletricamente ( $3^{a}$ Etapa).

As amostras foram divididas por categoria de secagem. O Grupo 1 refere-se àquelas caracterizadas após a $3^{a}$ Etapa de fabricação e nelas foram realizados alguns experimentos como estudos de substratos, detalhamento de dispositivos, verificação de área ativa, medida de resistência de contato, estudo de histerese e capacitância. As medidas elétricas nesse grupo de amostras, podem ser comparadas nas mesmas condições na qual os dispositivos verdes são processados, visto que tanto o óleo vegetal quanto o PS não podem ser expostas a temperaturas elevadas, sob pena de degradação daqueles e amolecimento deste. Entretanto, é sabido que o P3HT absorve impurezas (umidade, oxigênio, etc) do ambiente durante a fabricação, sendo necessária uma temperatura mais elevada para eliminá-las. Por essa razão, aplicou-se uma $4^{a}$ Etapa ao Grupo 2 de amostras, aquecendo-as por 10 minutos à $120^{\circ} \mathrm{C}$.

\subsubsection{Realização de tratamento térmico (annealing)}

Realizou-se tratamento térmico no filme de P3HT isoladamente (DO-1) e no dispositivo completo (DO-2). Para tanto, fez-se uso de uma placa aquecida e as amostras foram expostas à temperaturas por tempos pré-definidos em diferentes configurações de annealing, ao final coletouse as medidas elétricas das mesmas.

Seguiu-se duas sequências de tratamentos diferentes, a saber: Sequência A - 60, 80, 100, 120, 140 e $150^{\circ} \mathrm{C}$, em uma única amostra do DO-1 e outra do DO-2, com 5 minutos de aquecimento em cada temperatura; Sequência B $-80+150^{\circ} \mathrm{C}, 100+150^{\circ} \mathrm{C}, 120+150^{\circ} \mathrm{C}$ e $140+150{ }^{\circ} \mathrm{C}$, uma amostra do DO-2 para cada temperatura. Na primeira etapa, as temperaturas tiveram 10 minutos de exposição, em seguida feita as medidas, e na segunda etapa, 2 horas com segunda realização de medidas. Em ambas as sequências, aguardou-se o resfriamento para medição elétrica.

O contato de prata foi depositado antes do tratamento térmico, para promover melhor interação com a camada ativa, pela formação de ligações químicas entre eles e, consequentemente, diminuição da barreira de injeção, além de redução na resistência serial, como sugerido por Kim [58 e Narisi [18. Lee [96], relata que ao depositar o contato de topo antes da aplicação do annealing em um diodo orgânico, em altas temperaturas forma-se uma camada próxima ao eletrodo por interação química deste com o polímero, resultando em um aumento da área efetiva para injeção eletrônica, elevando a eficiência do dispositivo.

\subsubsection{Microscopia de força atômica (AFM) e medidas da geometria}

A microscopia de força atômica (AFM, do inglês, Atomic Force Microscopy) é uma técnica muito empregada para caracterizar topologias de superfícies. A análise pode ser feita no modo 
contato, onde a sonda toca a superfície da amostra com força constante [97]. A medida é feita por meio de uma sonda presa a uma haste (Cantiléver) que varre a superfície da amostra através da movimentação de um sistema piezoelétrico, podendo se deslocar nos eixos X, Y e Z. O deslocamento da sonda é registrado por um sistema óptico composto de um laser incidindo sobre a haste e de um fotodetector, o mesmo envia as informações para um software que processa as imagens. Trata-se de uma técnica amplamente utilizada na caracterização de filmes finos de polímeros condutores devido à sua boa resolução vertical, à obtenção de um perfil topográfico, à quantificação do tamanho dos grãos e à possibilidade de avaliar a rugosidade dos filmes depositados 22

A figura 3.2 (a) mostra o esquemático de funcionamento do AFM, onde a sonda condutiva é coalinhada com um laser (ou LED pulsado) fornecendo ao mesmo tempo tensão e iluminação para a superfície da amostra. As amostras foram caracterizadas do modo contato, verificando-se apenas a rugosidade de superfície. No intuito de se investigar as características morfológicas dos materiais utilizados nos dispositivos, submeteu-se o substrato de vidro com FTO, filme de PEDOT:PSS (depositado por imersão em um substrato com FTO) e filme de P3HT (depositado por casting também sobre FTO) à microscopia de força atômica (AFM) em equipamento Innova ${ }^{\mathrm{TM}}$ (Veeco Instruments) (3.2 (b). Cada filme foi escaneado em três diferentes regiões e os valores médios de rugosidade Rms (root-mean-square) representam as propriedades morfológicas da superfície dos mesmos. Na tentativa de medir a espessura da camada ativa, realizou-se microscopia óptica da seção transversal de amostra contendo PET como substrato e P3HT por casting, em microscópio Olympus Lext OLS4100. Mais tarde, com o funcionamento do perfilômetro Dektak150 (Veeco Instruments)(figura 3.2 (c) em nosso laboratório, pôde-se confirmar o valor inferido anteriormente. Realizou-se 5 medidas de espessura em cada filme, obtendo-se uma média para o valor final. As áreas dos contatos de topo foram medidas com auxílio do software ImageJ (figura 3.2)(d).

\subsection{Medida de Resistência por quadrado: Sonda de quatro pontas}

No intuito de se medir a resistência por quadrado dos substratos de FTO, ITO e filme de PEDOT:PSS obtido por imersão no vidro, fez-se uso do equipamento Jandel RM3000 (figura 3.3), cujas medidas são realizadas por sondas de quatro pontas.

\subsection{Caracterização Elétrica dos dispositivos desenvolvidos}

Existem alguns métodos experimentais para a investigação dos processos de transporte em polímeros semicondutores, dentre estas destaca-se a medida I(V), uma vez que, suas curvas podem ser modeladas mediantes modelos de transporte de corrente estacionária [2].

As caracterizações elétricas realizadas no presente trabalho foram obtidas por meio do sistema de medição Keysight B2901A, fazendo-se uso de duas sondas metálicas para contactar os eletrodos das amostras (figura 3.4). Esta estação de medidas foi aprimorada com aquisição de micromanipuladores que permitem maior precisão no posicionamento das sondas. Além disso, foram inseridos acopladores tri-axiais ao equipamento de maneira a reduzir os ruídos e interferências da rede. 


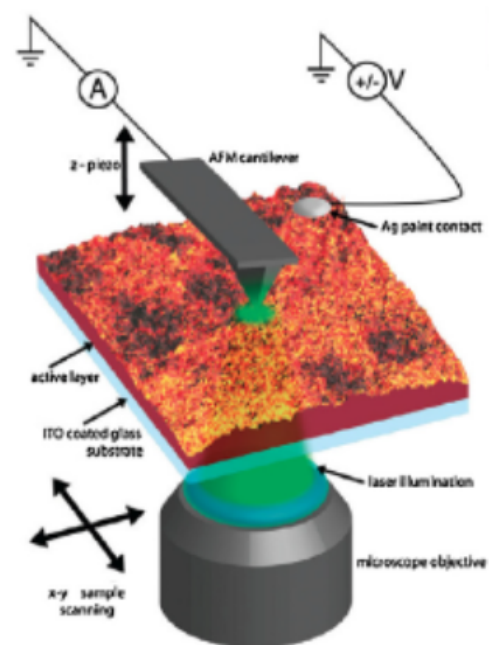

(a)

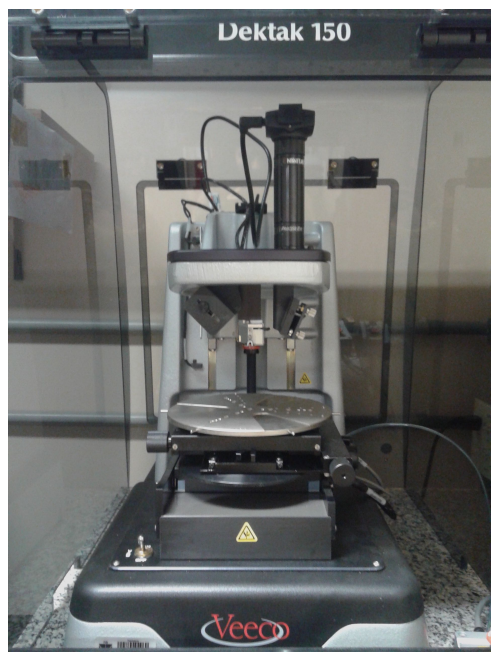

(c)

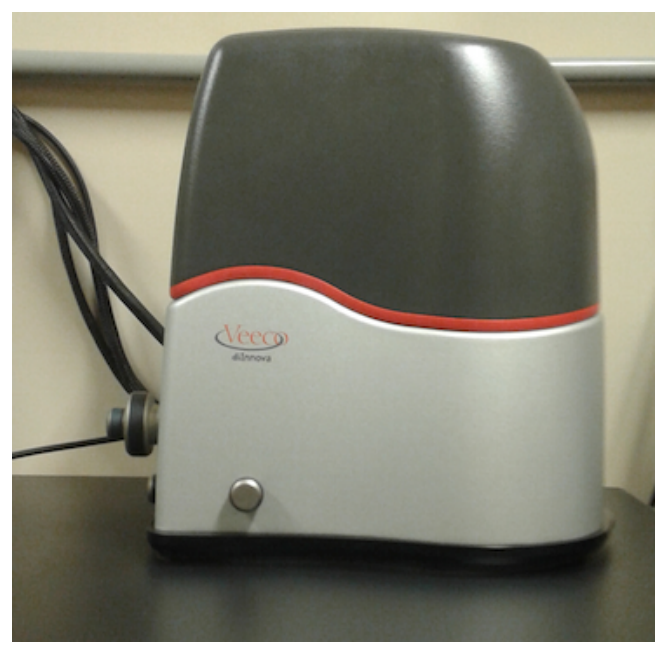

(b)

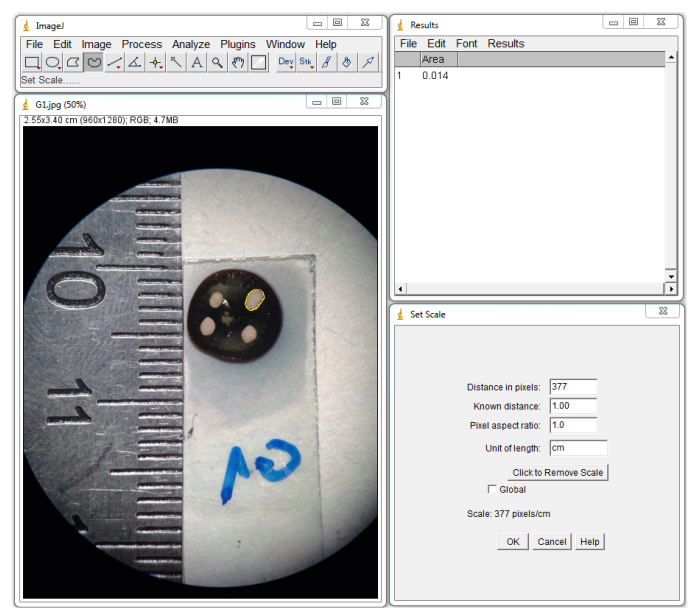

(d)

Figura 3.2: Ilustração representativa de funcionamento de AFMs (a) Microscópio de Força atômica Innova $^{\mathrm{TM}}$ (Veeco Instruments) (b) Perfilômetro Dektak150 (Veeco Instruments)(c) Realização de uma medida no Image J (d)

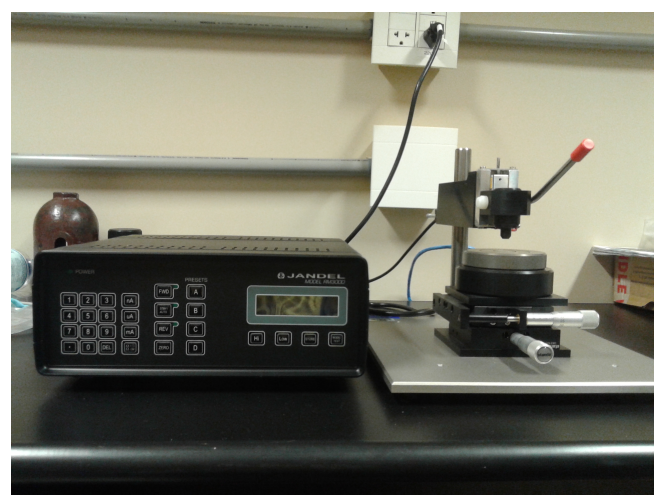

(a)

Figura 3.3: Equipamento Jandel RM3000 para medidas de sondas de quatro pontos. 
Criou-se um protocolo de utilização do SMU, descrito na próxima seção, de maneira a se obter o melhor resultado sem comprometimento da amostra.

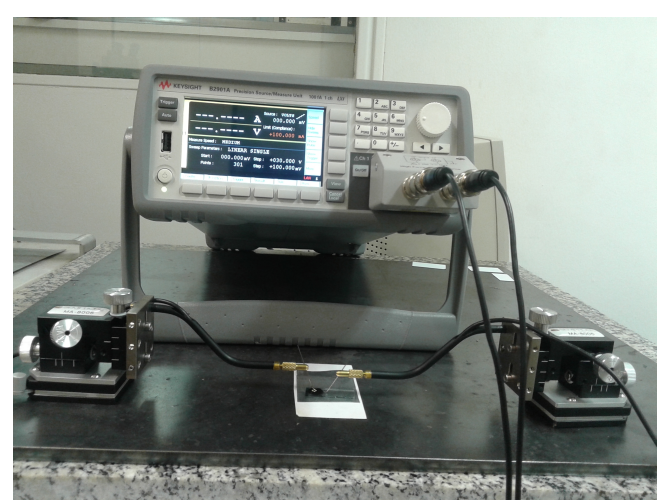

(a)

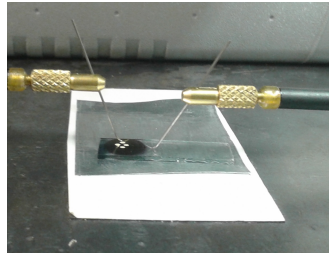

(b)

Figura 3.4: Sistema de medição Keysight B2901A (a) Micromanipuladores e sondas metálicas contactadas à uma amostra (b).

Para as medidas elétricas aplicou-se uma diferença de potencial entre dois eletrodos $(30 \mathrm{~V}$ para amostras poliméricas e $10 \mathrm{~V}$ para amostras verdes) verificando-se a corrente resultante. Covencionou-se os seguintes sentidos para aplicação das tensões: polarização 1 - conector fonte na prata e o conector terra no substrato condutivo (Prata $(+) / \mathrm{FTO}(0)$ ); polarização 2 - conector fonte no substrato e o conector terra no contato de prata (Prata $(-) / \mathrm{FTO}(0))$.

\subsection{Descrição do Modelo TCAD}

Possui grande aceitação na comunidade acadêmica a seguinte abordagem para modelagem de dispositivos: assumir uma contato ôhmico e visualizar a baixa mobilidade do material como o fator de limitação de corrente. Modelos analíticos foram usados com sucesso para descrever a condução por SCLC, usando para tanto, uma distribuição espacial de armadilhas no material ou o conceito da mobilidade hopping dependente da temperatura e do campo elétrico livre de armadilhas ou a combinação dos dois. Os resultados encontrados são coerentes com experimentos [98].

Com auxílio do software comercial Sentaurus TCAD [99], realizou-se simulações com base na resolução das equações de Poisson e de continuidade para elétrons e lacunas. O modelo criado para a realização das simulações consiste em uma estrutura 2D (Pseudo) metal-semicondutormetal (MSM), cuja área de contato é de $A=0.014 \mathrm{~cm}^{2}$

As densidades de corrente em uma posição $x$ são dadas como correntes de difusão-deriva e expressas como gradientes de potencial quasi-Fermi para elétrons e lacunas, $\Phi_{n}(x)$ e $\Phi_{p}(x)$, respectivamente. Uma vez que, a densidade de portadores de cargas e os campos elétricos são baixos, assume-se um valor constante para a mobilidade. Densidades de elétrons livres e lacunas seguem a partir das estatísticas de Fermi determinados por $E_{\mathrm{F}, n}=-q \Phi_{n}$ e $E_{\mathrm{F}, p}=-q \Phi_{p}$. Sabendo que, $p \approx N_{\mathrm{v}} \exp \left[\left(E_{\mathrm{HOMO}}-E_{\mathrm{F}, p}\right) / k T\right]$, interpreta-se $N_{\mathrm{v}}$ como densidade de unidades conjugadas do semicondutor e $E_{\mathrm{HOMO}}$ como o único nível energético quando as unidades são ocupadas por lacu- 


\begin{tabular}{|c|c|}
\hline Parâmetros & OSC \\
\hline Permitividade $\epsilon_{r}$ & 3 \\
Afinidade eletrônica (LUMO) $\chi_{0}$ & $2.9 \mathrm{eV}$ \\
Band gap $E_{\mathrm{g}}$ & $2.1 \mathrm{eV}$ \\
DOS banda de condução $N_{\mathrm{c}}$ & $2 \times 10^{20} \mathrm{~cm}^{-3}$ \\
DOS banda de valência $N_{\mathrm{v}}$ & $2 \times 10^{20} \mathrm{~cm}^{-3}$ \\
\hline Variáveis & \\
\hline Mobilidade $\mu$ & {$\left[\mathrm{cm}^{2} / \mathrm{Vs}\right]$} \\
Dopagem de aceitadores $N_{\mathrm{a}}$ & {$\left[\mathrm{cm}^{-3}\right]$} \\
Função trabalho dos eletrodos $\Phi$ & $\mathrm{eV}$ \\
\hline
\end{tabular}

Tabela 3.2: Parâmetros dos materiais usados nas simulações TCAD. Os valores em [colchetes] podem ser modificados para ilustrar fenômenos principais ou para adaptar as medições. Multiplicadores Gaussianos podem ser aplicados para armadilhas e distribuição de dopagem a fim de se modelar os fenômenos de interface.

\begin{tabular}{|c|c|c|}
\hline Parâmetros & M1 & M2 \\
\hline Função trabalho $\Phi$ & {$[4.9 \mathrm{eV}]$} & {$[4 \mathrm{eV}]$} \\
\hline
\end{tabular}

Tabela 3.3: Condições de contorno aplicadas a portadores de corrente em contatos Schottky.

nas, ignorando a extensão da desordem. Para os parâmetros do material orgânico semicondutor (OSC) e os metais (M1=Ânodo e M2=Cátodo), assumiu-se os valores típicos dados na tabelas 3.2 e 3.3 .

Três diferentes distribuições de cargas entram como cargas espaciais na equação de Poisson: (i) cargas livres, ou seja, principalmente lacunas $p(x)$ devido às condições de contorno do contato de injeção, (ii) aceitadores e (iii) lacunas armadilhadas. Para estimar $N_{\mathrm{v}}$ pode-se iniciar com uma solução OSC típica de $10 \mathrm{mg} \mathrm{cm}^{-3}$. Assumindo-se polímeros com um peso molecular médio de 30000, um número de 10 unidades de conjugação (conjugation units (CU)) por polímero e um volume de encolhimento de $99 \%$ durante a evaporação do solvente, densidade de CUs de $N_{\mathrm{v}}=2 \times 10^{20} \mathrm{~cm}^{-3}$. Aceitadores são sempre completamente ionizados. Portanto, receptores são tratados como cargas positivas fixas e a densidade de carga decorrente de receptores não depende dos potenciais quasi-Fermi contrários as cargas móveis e presas. A exposição ao ar pode resultar em uma camada de óxido natural do metal na interface MOP que tem sido interpretado como dopagem interfacial do tipo $\mathrm{p}$ [100].

Sabendo que, Sentaurus TCAD usa representação de níveis discretos, um número grande o suficiente de níveis foi escolhido (TrapDLN $=200$ ). A distribuição de armadilhas no espaço pode ser modificado por uma função multiplicativa. Para modelar o volume de armadilhas, considerouse um valor uniforme $H_{0}(x)=$ const. Para o transporte de corrente no contato Schottky esquerdo (M1) e direito (M2), usou-se as seguintes condições de contorno, implementadas no Sentaurus. 


$$
\begin{aligned}
\psi(\mathrm{M} 1, \mathrm{M} 2) & =V_{\mathrm{M} 1, \mathrm{M} 2}-\Phi_{\mathrm{B}}+\frac{k T}{q} \ln \left(\frac{N_{\mathrm{c}}}{n_{i}}\right), \\
\vec{J}_{n} \cdot \hat{n} & =+q v_{n}\left(n-n_{0}\right)(M 1, M 2), \\
\overrightarrow{J_{p}} \cdot \hat{n} & =-q v_{p}\left(p-p_{0}\right)(M 1, M 2),
\end{aligned}
$$

Com o vetor normal $\hat{n}$ apontando para dentro, ou seja, do metal para o semicondutor, e $n_{i}$ sendo a densidade intrínseca de portadores de carga. O equilíbrio das densidades de portadores de carga nos contatos são dados por $n_{0}=N_{\mathrm{c}} \times \exp \left[-q \Phi_{\mathrm{B}} / k T\right]$ e $p_{0}=N_{\mathrm{v}} \times \exp \left[\left(q \Phi_{\mathrm{B}}-E_{\mathrm{g}}\right) / k T\right]$ para elétrons e lacunas, respectivamente. 


\section{Capítulo 4}

\section{Resultados e Discussões}

A fim de se aliar estabilidade e performance, faz-se necessário um bom entendimento dos fenômenos físicos que descrevem o comportamento de dispositivos orgânicos como por exemplo, transporte de carga, densidade de armadilhas, mobilidade dentre outros fatores [15. Nesta seção encontram-se os principais resultados alcançados no decorrer do presente trabalho. Como ferramenta de auxílio para compreensão de alguns deles, utilizou-se simulações computacionais. Os elementos que influenciam transporte de cargas em um dispositivos orgânico foram investigados por meio da caracterização elétrica $I(V)$.

\subsection{Microscopia de força atômica (AFM) e medidas da geometria}

As imagens da microscopia obtidas para os filmes de FTO, PEDOT:PSS e P3HT estão expostas nas figuras 4.1 (a)-(c) e em (d) imagem de microscopia óptica da seção transversal de uma amostra. Os valores de rugosidade Rms e de espessura encontram-se na tabela 4.1 .

\begin{tabular}{|c|c|c|}
\hline Amostra & Rugosidade $(\mathrm{nm})$ & Espessura $(\mu \mathrm{m})$ \\
\hline FTO & 13.77 & - \\
PEDOT:PSS & 1.14 & 2.0 \\
P3HT & 4.41 & 4.8 \\
\hline
\end{tabular}

Tabela 4.1: Valores de rugosidade e espessura dos materiais utilizados.

A miscroscopia nos permitiu verificar que a rugosidade do FTO é drasticamente reduzida pelo filme do PEDOT:PSS, passando de $13.77 \mathrm{~nm}$ para $1.14 \mathrm{~nm}$. Valor este muito aproximado daquele medido por Abdulrazzaq [70] de $0.9 \mathrm{~nm}$ para o mesmo tipo de PEDOT:PSS. A espessura indicada pela microscopia óptica foi de $6 \mu \mathrm{m}$, enquanto que pelo perfilômetro $4.8 \mu \mathrm{m}$, valor este mais confiável e considerado em análises posteriores. Apesar de ter apresentado maior espessura que o PEDOT:PSS, como era esperado em virtude da técnica de deposição, o filme de P3HT promoveu menor diminuição na rugosidade do FTO, indicando que por si só, possui uma rugosidade razoável. A área de contato inferida pelo software ImageJ é em média $0.014 \mathrm{~cm}^{2}$. 


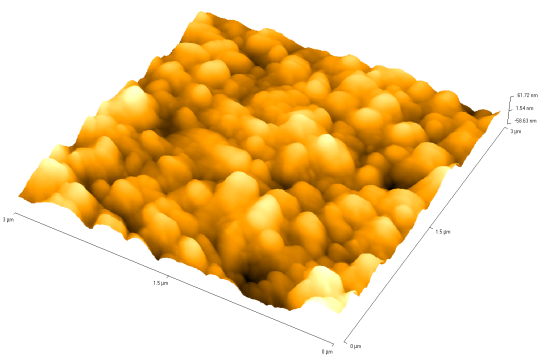

(a)

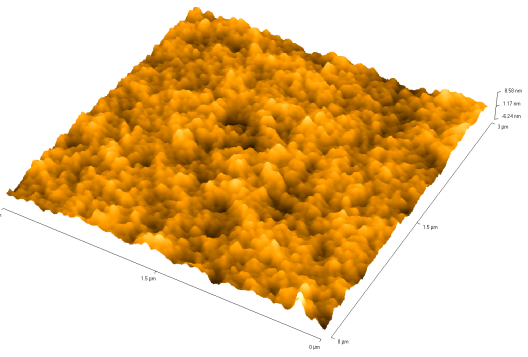

(b)

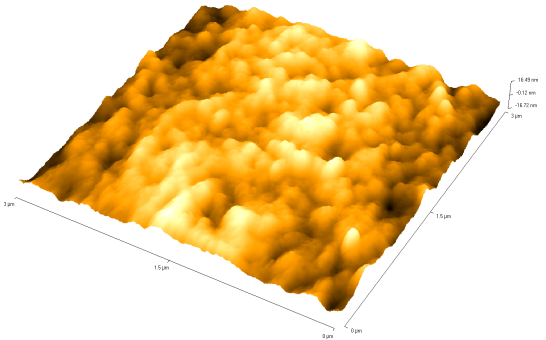

(c)

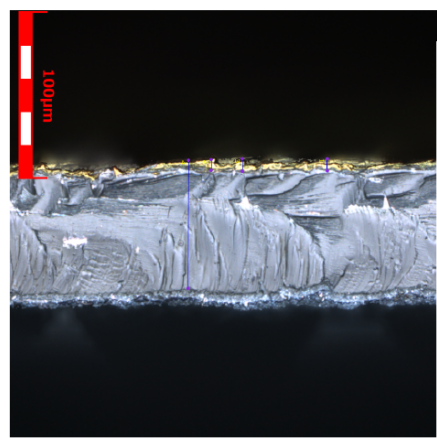

(d)

Figura 4.1: Microscopia de força atômica (a) FTO (b) PEDOT:PSS (c) P3HT (d) Seção transversal de amostra PET/P3HT evidenciando a espessura do filme .

\begin{tabular}{|c|c|}
\hline Materiais & Resistência $(\Omega / \square)$ \\
\hline FTO & 48 \\
ITO & 12 \\
PEDOT:PSS & acima do limite \\
\hline
\end{tabular}

Tabela 4.2: Valores de resistência por quadrado medidos através de sondas de quatro pontos.

\subsection{Medida de Resistência por quadrado: Sonda de quatro pontas}

A tabela 4.2 resume os valores medidos de resistência por quadrado para os materiais analisados.

As resistências por quadrado dos filmes de FTO e ITO foram medidas com sucesso, no entanto, não foi possível obter essa característica para o filme de PEDOT:PSS, provavelmente as sondas o perfuraram atingindo o vidro e o valor medido mostrou-se maior que o limite máximo de resistência do equipamento, a saber: $500 \mathrm{M} \Omega / \square$. 


\subsection{Caracterização elétrica do Grupo 1 de amostras}

\subsubsection{Investigação de substratos condutivos: DO-1 (FTO/P3HT/Ag)}

As amostras contendo P3HT obtidas por imersão e spin coating, geraram uma grande quantidade de curtos circuitos (corrente máxima permitida pelo equipamento em tensões menores que $1 \mathrm{~V}$ ), pelo colapso da fina espessura gerada. Por esse motivo, foram considerados apenas os resultados de amostras fabricadas por casting, como observado nas figuras 4.2 (a)-(d).

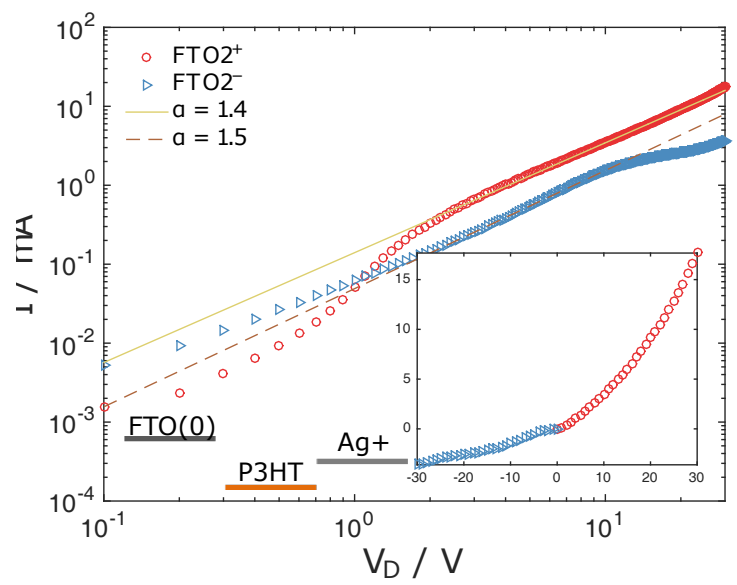

(a)

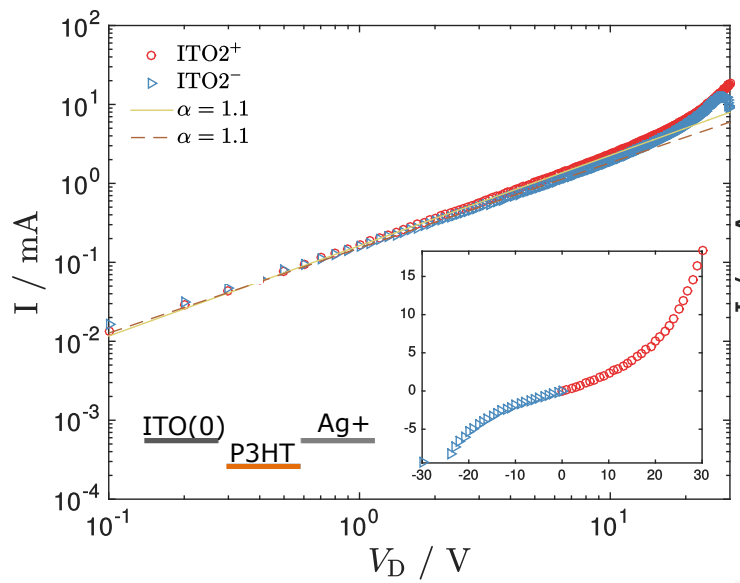

(c)

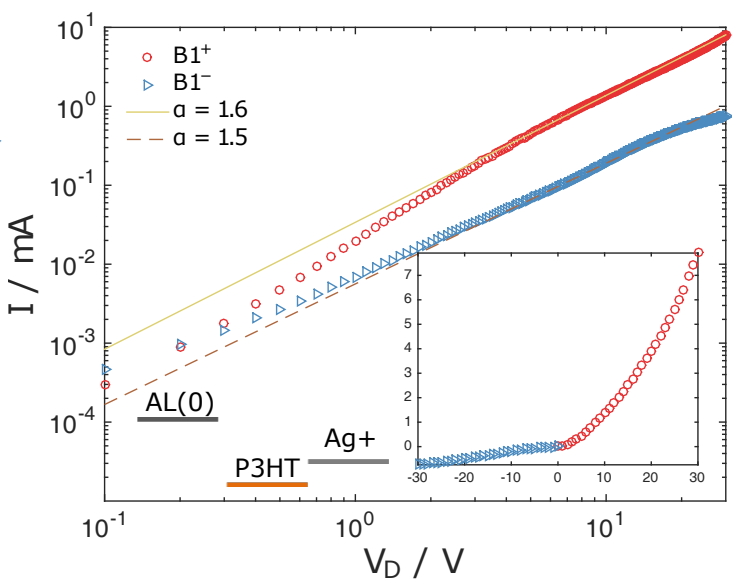

(b)

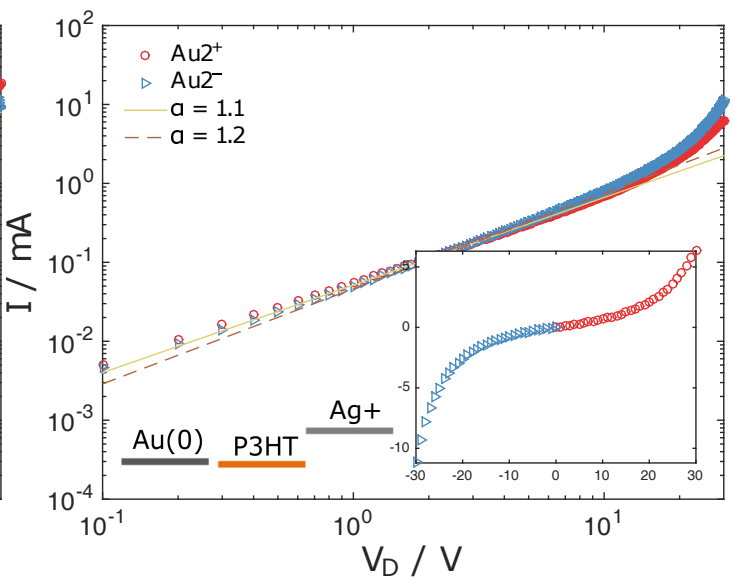

(d)

Figura 4.2: Características elétricas de DO-1 obtidos por casting para ambas polarizações e com diferentes eletrodos de base (a) FTO (b) Alumínio (c) ITO e (d) Ouro. O gráfico interno refere-se a escala linear e à esquerda uma analogia as bandas de energia dos materiais. O indice $\alpha$ indica as inclinações das curvas em baixas e altas tensões.

Dois fatos consistentes podem ser identificados a partir das figuras 4.2 (a)-(d). O primeiro é a simetria visualizada nos dispositivos com ITO e Ouro e comportamento inverso naqueles com FTO e alumínio. Uma vez que, o nível energético HOMO do P3HT encontra-se em torno de $5 \mathrm{eV}$ e a função trabalho da prata $4.7 \mathrm{eV}$, contatos de base com valores de função trabalho próximos da prata devem apresentar curva simétrica, pois possuem barreira de injeção semelhante 
em ambas polarizações. Caso observado em amostras de ITO e Ouro, porém este apresentou uma contribuição ligeiramente maior na polarização 2, indicando função trabalho maior que ITO. Situação oposta é esperada quando contatos de base possuem função trabalho menor que a prata. Neste caso, a polarização 2 encontra maior barreira de injeção que a polarização 1 e a curva IV é assimétrica, como observado em FTO e alumínio, com alumínio mais assimétrico que o FTO. Desta forma, foi possível ordenar as funções trabalho dos substratos condutivos investigados da seguinte forma: $\phi_{\mathrm{Al}}<\phi_{\mathrm{FTO}}<\phi_{\mathrm{ITO}}<\phi_{\mathrm{Au}}$. Resultado coerente com aqueles fornecidos pela literatura, cuja ordem dos valores aproximados é de $\phi_{\mathrm{Al}}=4.0 \mathrm{eV}<\phi_{\mathrm{FTO}}=4.4 \mathrm{eV}<\phi_{\mathrm{ITO}}=4.7 \mathrm{eV}<\phi_{\mathrm{Au}}=5.0 \mathrm{eV}$. As respostas elétricas dependem do substrato condutivo, o que sugere uma dependência da altura da barreira de injeção pela função trabalho do condutor. De acordo com a teoria da barreira, nas condições de fabricação dessas amostras o fator $\mathrm{S}$ tende a 1 .

A segunda observação, são as inclinações em torno de 1 para todas as amostras, independentemente do substrato condutivo empregado, evidenciando comportamento ôhmico em ambas polarizações, portanto, não foi possível a verificação da injeção de cargas de acordo com modelos teóricos. No entanto, aquelas com substrato de ITO e Ouro exibem o referido expoente até altas tensões quando então nota-se um aumento na inclinação. Provavelmente, esses substratos conferem canais de resistências (Resistência shunt) ao filme polimérico, o qual são vencidos apenas com maiores tensões aplicadas. Já para FTO e Ouro, acredita-se que o mecanismo é descrito pela concorrência entre corrente difusiva e de deriva, com influencia menos notória de resistências em altas tensões shunt.

Algumas hipóteses podem vir a explicar o comportamento, no que se diz respeito à tendência ôhmica averiguada: i) A possibilidade de difusão de partículas do óxido condutivo que recobrem o substrato para a camada ativa, comprometendo o desempenho do dispositivo; ii) Outro fator crítico reside na irregularidade da superfície do FTO/ITO [101. Correntes de fuga podem surgir quando existem vias de baixa resistência através do filme, e estas podem ser causadas por rugosidade ou picos localizados na topografia do substrato condutivo [71] [73]; iii) O fenômeno de eletromigração entre o contato de prata e a camada semicondutora, onde moléculas de prata se desprendem com a tensão aplicada e difundem pelo filme até o contato oposto, gerando correntes de fuga.

Faz-se importante ressaltar ainda os elevados níveis de corrente observados em todos os dispositivos, indicando uma provável contaminação decorrente de dopagem não intencional ou impurezas absorvidas durante a preparação das amostras, tais como resíduo de solvente.

\subsubsection{Investigação de substratos condutivos: DO-2 (FTO/P3HT/PEDOT:PSS/Ag)}

O segundo tipo de dispositivo contendo PEDOT:PSS como camada polimérica transportadora de lacunas (HTL) entre o eletrodo de base e a camada ativa, apresentaram curvas IV descritas nas figuras 4.3 (a)-(d). A confecção de amostras contendo ouro como substrato condutivo não foi possível de se obter, pois o ouro é hidrofóbico e não permite a adesão do PEDOT:PSS que contem água como solvente.

Ao contrário do DO-1, a inserção da camada de PEDOT:PSS permitiu a injeção de cargas na 


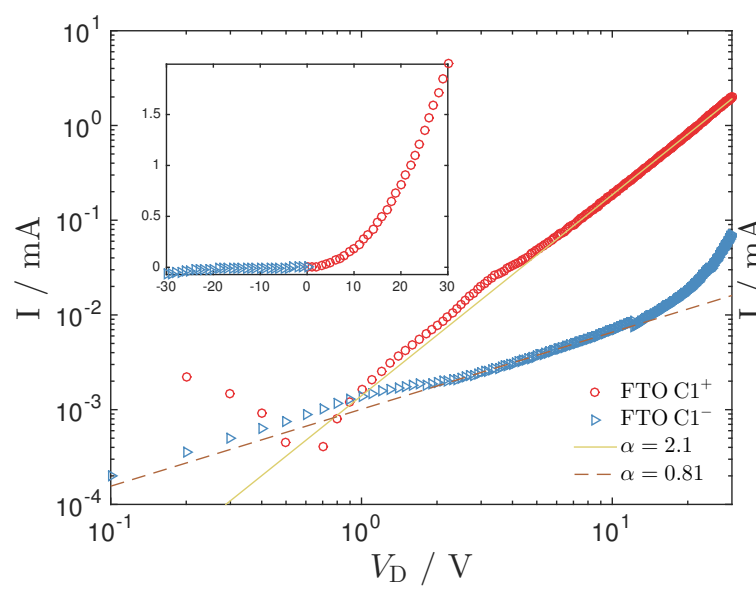

(a)

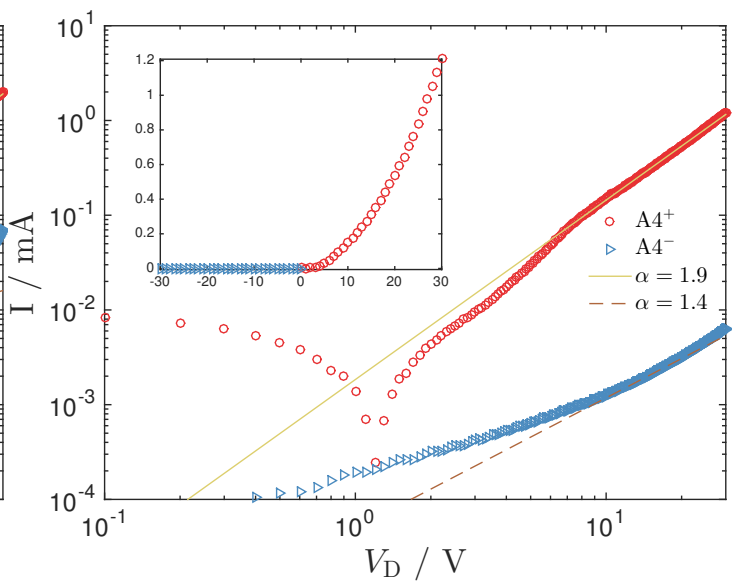

(b)

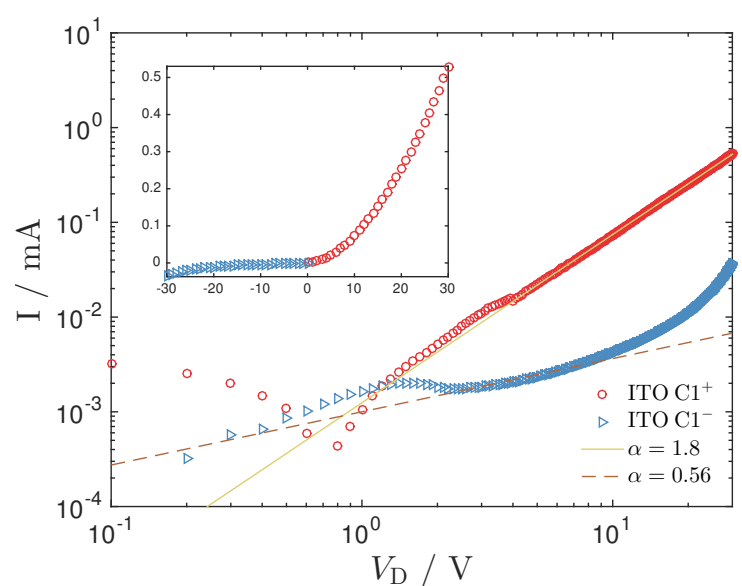

(c)

Figura 4.3: Características elétricas de DO-2 obtidos por casting para ambas polarizações e com diferentes eletrodos de base (a) FTO (b) Alumínio e (c) ITO. 
polarização 1, caracterizada pelo expoente dois, ou seja, as resistências parasíticas não mascararam a região SCLC. Os níveis de corrente diminuíram pelo aumento da espessura o que contribui para formação de contatos ôhmicos. Alguns fatores devem ser considerados aqui: o PEDOT:PSS suaviza a superfície áspera do ITO/FTO e assim evita curtos-circuitos, bem como protege a camada ativa de reações com Índio/Flúor ou oxigênio, aumentando o tempo de vida [71]. A capacidade do PEDOT:PSS em suavizar a superfície do FTO, reduz as correntes de fuga e ruídos elétricos influenciando na performance do dispositivo [73]. De fato, os valores de rugosidade obtidos por AFM comprovam a forte suavização da superfície de FTO por parte do PEDOT:PSS, como mencionado na seção 4.1. Em contrapartida, a injeção no sentido oposto mostrou-se dificultado. Ao contrário do que se esperava, evidenciando algum efeito inesperado entre FTO-PEDOT:PSS, cuja discussão é inserida na próxima seção. Deste ponto em diante, seguiu-se os experimentos com foco no DO-2 contendo o FTO como substrato condutivo.

\subsubsection{Detalhamento do dispositivo Ag/P3HT/PEDOT:PSS/FTO}
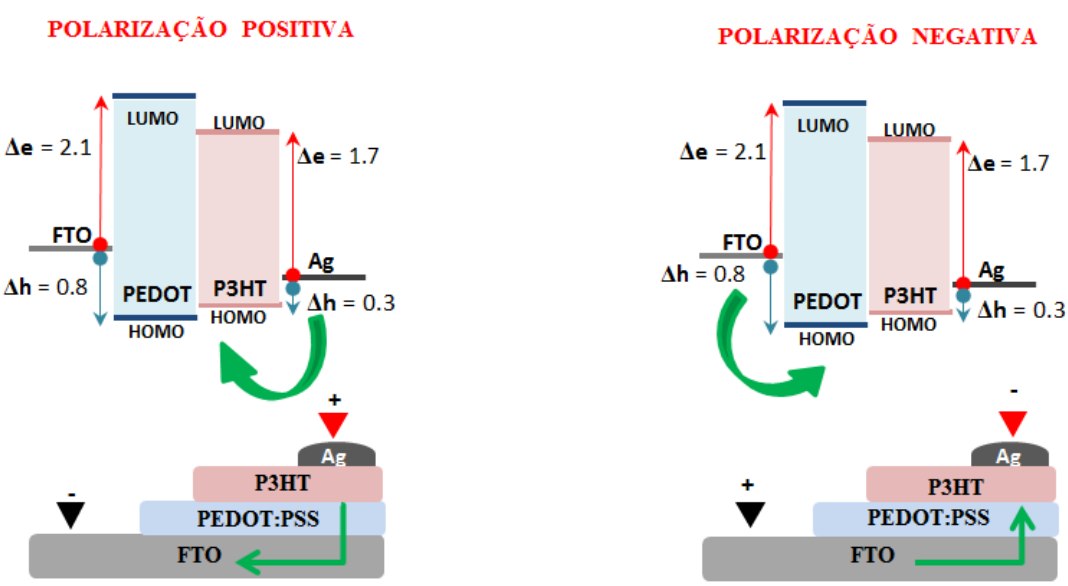

Figura 4.4: Bandas de energias dos materiais antes do contato, apenas para indicar o fluxo majoritário de lacunas em ambas polarização, devido a elevada altura de barreira para injeção pelo LUMO.

A compreensão dos tipos de interfaces do dispositivo, faz-se essencial para a análise dos fenômenos que atuam sobre o mesmo.

Tendo em vista que a injeção de cargas por parte do substrato foi dificultada, acredita-se haver duas possíveis origens para tal: uma má interação por parte do contato entre o FTO e o polímero condutor PEDOT:PSS, que se dá por meio de uma forte depleção se o PEDOT:PSS estiver devidamente dopado, o que pode não ser o caso. A injeção de elétrons a partir do FTO para o polímero ocorre por tunelamento, quando a espessura de depleção formada é extremamente fina, se for espessa torna-se bloqueante. No entanto, acredita-se que a origem do efeito se deve muito mais provavelmente ao contato entre os dois polímeros, pois o experimento descrito na seção 4.3.2 mostrou que o resultado não depende do substrato condutivo. Com relação ao contato entre metal-polímero conjugado, este pode ou não ser ôhmico. Existe uma dependência em termos 
de proximidade entre níveis energéticos da amostra e os níveis de Fermi dos eletrodos [101. Utilizando os métodos e condições de processamento do presente trabalho essa interação mostrouse de acumulação.

No que diz respeito aos portadores do dispositivo, a injeção de elétrons em ambas as interfaces catodo/anodo-semicondutor é dificultada pela elevada altura das barreiras. Quando a função trabalho do eletrodo encontra-se muito distante do nível de quase-Fermi do semicondutor, a diferença de potencial é negativa e existe barreira para a extração/injeção de elétrons a partir do semicondutores para o eletrodo. Esta barreira pode ser reduzida por mudanças nos materiais, tais como dopagem ou reações químicas ao longo da interface, flexão de banda, ou mudança de nível do vácuo [68. Os elétrons, então, encontram grande dificuldade para vencer a barreira de potencial entre o nível de Fermi da prata e o nível energético LUMO do P3HT, cerca de 1.7 eV. O mesmo ocorre na polarização 2 com barreira de potencial de 2.1 eV entre FTO/PEDOT:PSS-P3HT. Valendo salientar ainda que, a mobilidade desses portadores em materiais poliméricos, é muito menor que a de lacunas [101]. Os portadores de deriva em materiais orgânicos e, especialmente, naturais podem ser severamente prejudicados pela presença de armadilhas de carga e é a principal razão para uma inferior corrente de deriva por elétrons em relação a corrente de deriva por buracos 47. Desta forma, trata-se de um diodo de portadores únicos de lacunas.

As interfaces híbridas geradas agem de maneira distintas sob o ponto de vista do transporte de cargas, portanto, é necessário estudá-las de maneira isoladas. No presente trabalho as interfaces metal-semicondutor e semicondutor-óxido de estanho comportaram-se de maneira singular. Em outras palavras, a preferência pela condutividade em determinada junção híbrida tem o potencial de indicar quais os mecanismos de transferência de cargas são beneficiados e, consequentemente, contribuem para desenvolvimento de dispositivos mais eficazes à luz da engenharia de interfaces.

\subsection{Efeitos de histerese e capacitância parasítica}

A investigação de histereses constatou três tipos distintos do fenômeno. Assim como observado nas figuras 4.5 .

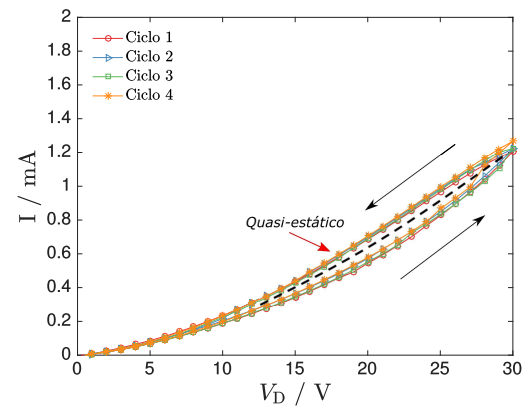

(a)

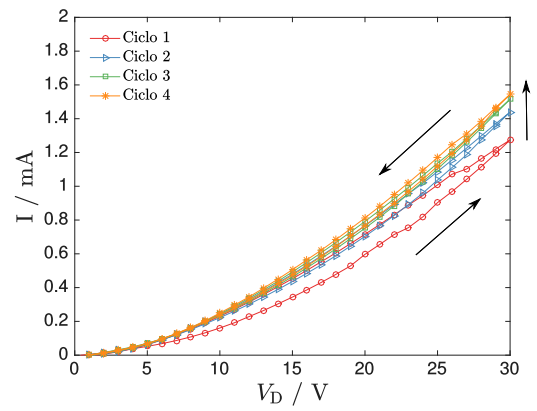

(b)

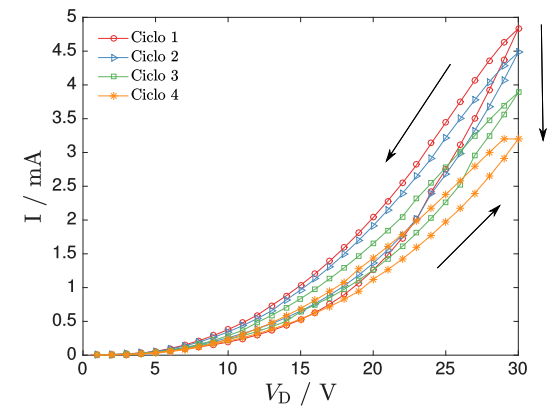

(c)

Figura 4.5: Três perfis de histereses visualizados para amostras DO1(FTO/P3HT/PEDOT:PSS/Ag) secas à $60^{\circ} \mathrm{C}$ (a) Fixa (b) Crescente (c) Decrescente. 
A análise dessas curvas devem levar em consideração duas informações: (i) armadilhas e cargas móveis possuem níveis de Fermi iguais no estado estacionário; (ii) o filme possui íons armadilhados em decorrencia de impurezas.

Em uma situação quase-estática as armadilhas e as cargas móveis teriam o mesmo nível de Fermi, representada pela linha pontilhada na figura 4.5 (a), no entanto, sabe-se que para uma mesma tensão aplicada o nível de fermi de armadilhas difere daquele de cargas móveis, pois aquelas precisam de mais tempo para estabilizar a energia do que estas, o que gera um desequilíbrio. Este efeito por sua vez, pode ser visualizado na figura 4.5 (a): para baixas tensões positivas o nível do fermi de armadilhas é maior que o de cargas livres e o tempo de aplicação da rampa não é suficiente para o preenchimento de boa parte delas, logo, as cargas vão sendo aprisionadas e a corrente vai aumentando, já que, há menos armadilhas e as cargas móveis conseguem atravessar o filme. Quando a rampa é imposta no sentido contrário, as armadilhas que estavam outrora ocupadas começam a liberar cargas para retornar o nível de Fermi, e a corrente é maior, pois recebe a contribuição dessas cargas liberadas. O mesmo se repete nos ciclos subsequentes.

Por outro lado, no caso exposto na figura 4.5 (b), para alcançar a curva quasi-estática, mais acima do ciclo inicial, é necessário a aplicação de mais rampas acarretando num deslocamento ascendente. E no caso decrescente (figura 4.5 (b)), a amostra contem uma quantidade elevada de íons de impurezas que ao serem submetidos a um campo elétrico externo, são forçados contra a interface oposta, gerando um campo elétrico interno oposto, que atua na diminuição da corrente até um ciclo onde não se vê mais a influência de tais cargas.

A presença de histerese em dispositivos orgânicos ainda é pouco esclarecida, no entanto, estudos sugerem que o solvente empregado na obtenção dos filmes semicondutores tem papel importante nesse efeito. Cheng [55] testou três diferentes solventes: Clorofórmio, tolueno e triclorobenzeno para dissolver P3HT e ao caracterizar as amostras por clorofórmio exibiram maior histerese em consequência do seu menor ponto de ebulição que ao evaporar deixa maior quantidade de vacâncias, além disso, contribuem para a formação de aglomerados poliméricos. Desta forma, a histerese seria explicada pelo mecanismo de armadilhas de cargas causado pelos defeitos presentes na estrutura, como agregados, e excesso de vacâncias deixadas pela evaporação do solvente.

Capacitâncias foram catalogadas em algumas medidas elétricas, evidenciadas por picos de correntes negativas em baixas tensões positivas. Como exposto na figura 4.6, aplicou-se rampas de tensões positivas a uma amostra, com tensões crescentes e em seguida decrescentes $(0 \rightarrow 30 \rightarrow$ $0)$.

O fenômeno observado provavelmente se origina pela presença de impurezas na amostra acarretando em íons distribuídos no material, como mencionada para a histerese decrescente. Durante o ciclo 1, a rampa para frente impulsiona essas cargas para o eletrodo oposto, onde ficam acumuladas com um pequeno campo elétrico interno. Com a rampa no sentido contrário, essas cargas acumuladas interferem no fluxo de corrente. Nos ciclos subsequentes, esses íons atuam sempre contra o campo elétrico externo.

Tendo em vista que esse perfil capacitivo mascara a caracterização elétrica intrínseca das amostras, idealizou-se uma espécie de protocolo de maneira a descarregar esse efeito, com a seguinte 


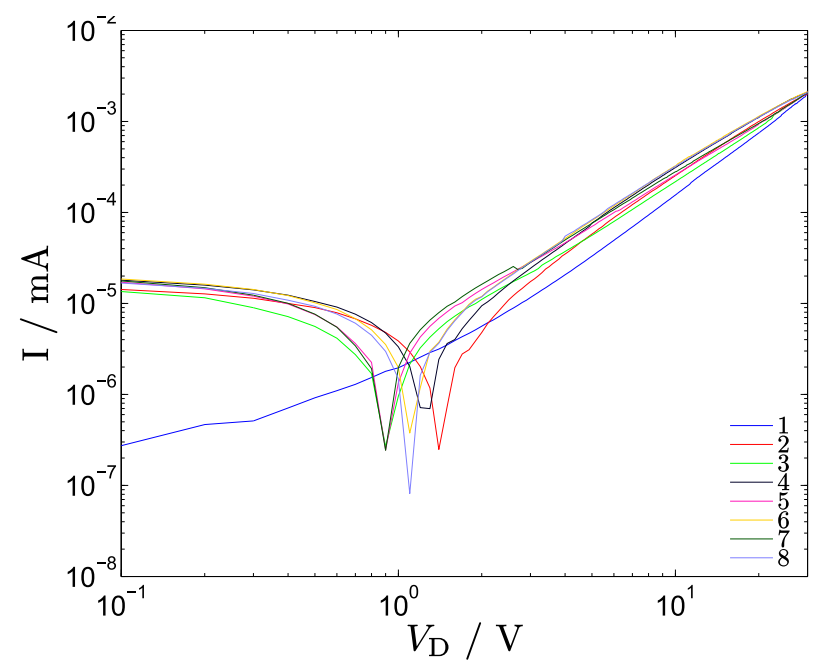

Figura 4.6: Correntes negativas em baixas tensões para 8 rampas de tensões aplicadas, evidenciadas pelo pico nas curvas que na escala logarítmica representa valor zero.

sequência:

1. Aplicar 0V de tensão à amostra por 5 minutos;

2. Aplicar uma rampa de $0 \mathrm{~V}$ a $30 \mathrm{~V}$;

3. Esperar 5 minutos sem aplicar tensão alguma;

4. Repetir os passos de 1 a 3 pelo menos duas vezes;

O protocolo foi aplicado a uma amostra, com 10 aplicações (figura 4.7 (a)). O valor médio com suas margens de erro é mostrado na figura 4.7 (b).

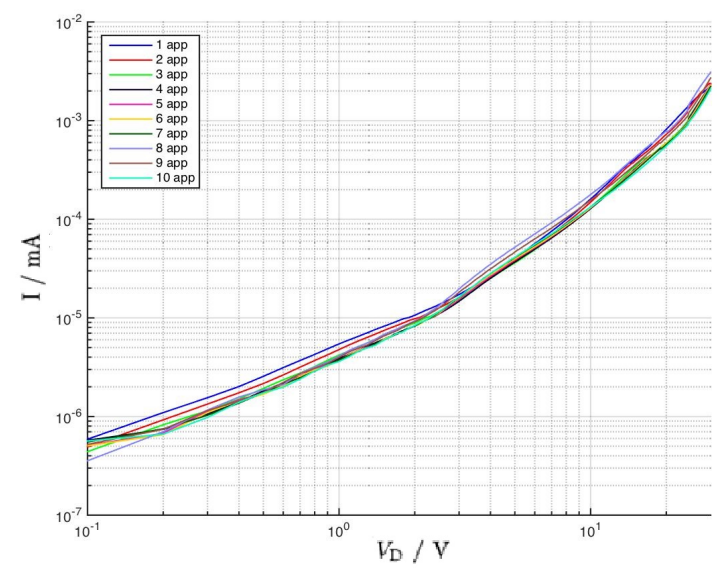

(a)

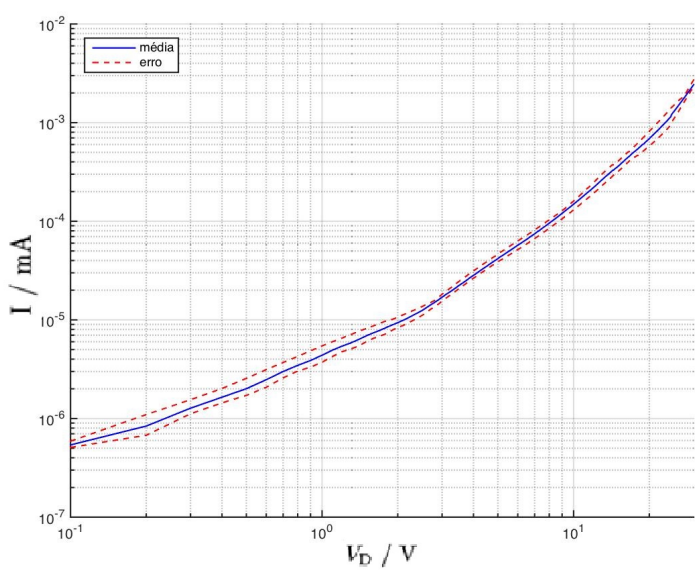

(b)

Figura 4.7: Aplicação do protocolo para descarregamento da capacitância (a) Dez aplicações a uma amostra (b) Valor médio para 3 medidas com o erro associado. 
A aplicação do protocolo mostrou-se satisfatória na eliminação das cargas aprisionadas. A tensão de 0V aplicada por 5 minutos permite o alinhamento das cargas no filme, assim quando aplica-se uma rampa de tensão não ocorre o acumulo destas na interface oposta, portanto não se tem o campo elétrico interno contrário ao fluxo. Mesmo após 10 repetições as curvas não parecem sugerir acréscimo ou decréscimo sistemáticos de corrente. Desta forma, utilizar como resultado o valor médio, é uma boa estratégia. Porém, cada aplicação leva cerca de 10 minutos, tornando-se inviável realizar sempre as 10 medidas, assim, para a definição do protocolo, utilizou-se somente 3 rampas e adicionou-se o erro associado à média (figura $4.7(\mathrm{~b})$ ) .

\subsection{Verificação da área dos dispositivos}

Tendo em vista que os métodos de deposição empregados na realização desse trabalho resultam em espessuras maiores tanto da camada ativa quanto da camada HTL, achou-se conveniente realizar um experimento com a intenção de confirmar se o fluxo de cargas atravessa os filmes poliméricos até o eletrodo oposto ou ocorre um espalhamento da corrente na interface entre os polímeros, visto que a condutividade anisotrópica dos filmes de PEDOT Clevios P AI 4083, é

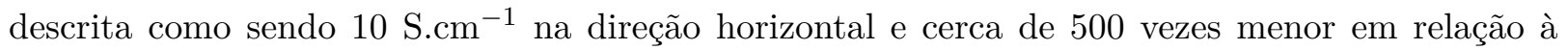
vertical (perpendicular) [73].

Para tanto, montou-se um dispositivo com dois caminhos possíveis para o fluxo de cargas: um com um comprimento maior que o outro além de um terceiro contato sobre o filme de PEDOT:PSS, como mostrado na figura 4.8 (a). Para o percurso entre contato de topo (Ag1 ou Ag2) e o contato oposto de FTO designou-se fluxo 1. Ao passo que, para a trajetória entre contato de topo (Ag1 ou Ag2) e o terceiro contato de prata sobre o filme de PEDOT:PSS chamou-se de fluxo 2. O circuito equivalente (figura 4.8 (b)) considera o filme de FTO como um curto, pois a resistência superficial medida foi baixa $(48 \Omega / \square)$, além disso as resistências transversais para os filmes de P3HT e PEDOT:PSS estão designadas por $\mathrm{R}_{A g 1}$ e $\mathrm{R}_{A g 2}$. As características elétricas observadas encontram-se na figura 4.9 (a)-(d).

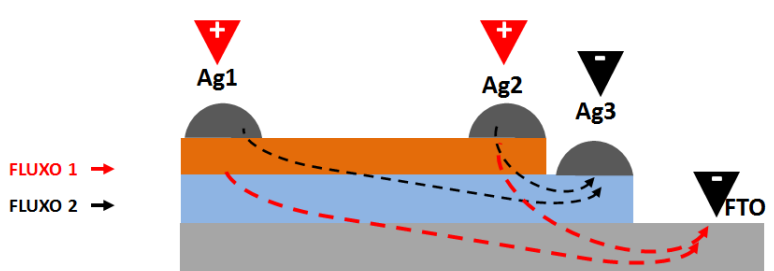

(a)

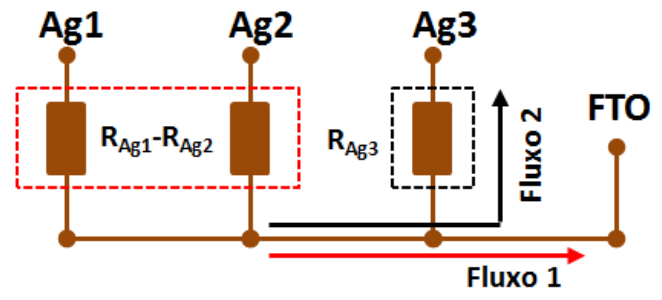

(b)

Figura 4.8: Estrutura de dispositivo montado para a verificação do experimento (a) Fluxo 1 de corrente: Ag1 ou Ag2-P3HT-PEDOT:PSS-FTO e Fluxo 2 de corrente: Ag1 ou Ag2-P3HTPEDOT:PSS-Ag3. Obs.: as setas indicam apenas o caminho representativo da corrente (b) Circuito equivalente associado. 


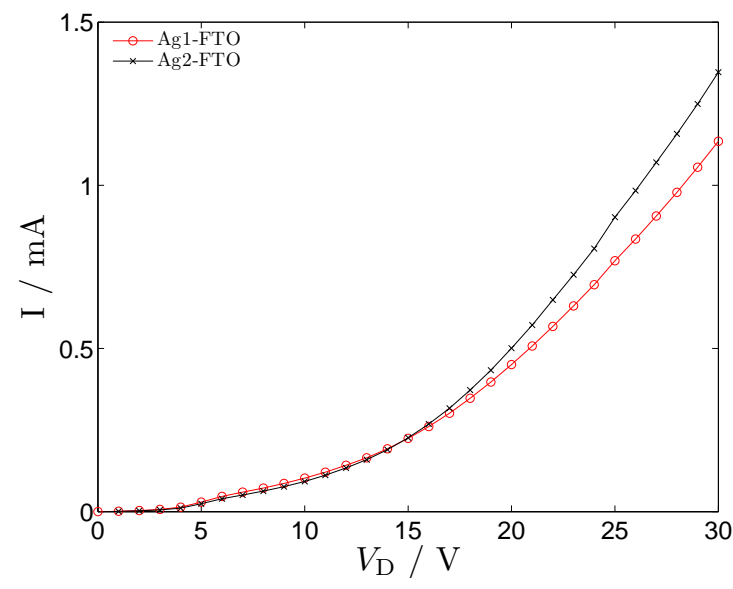

(a)

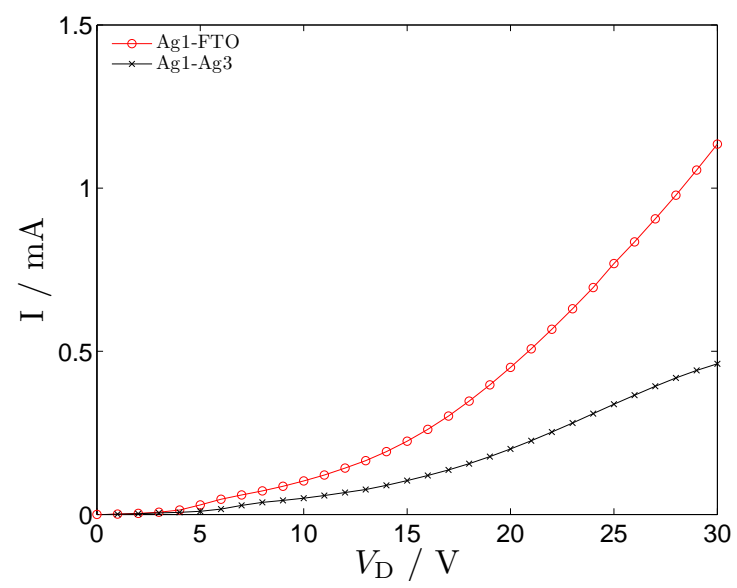

(c)

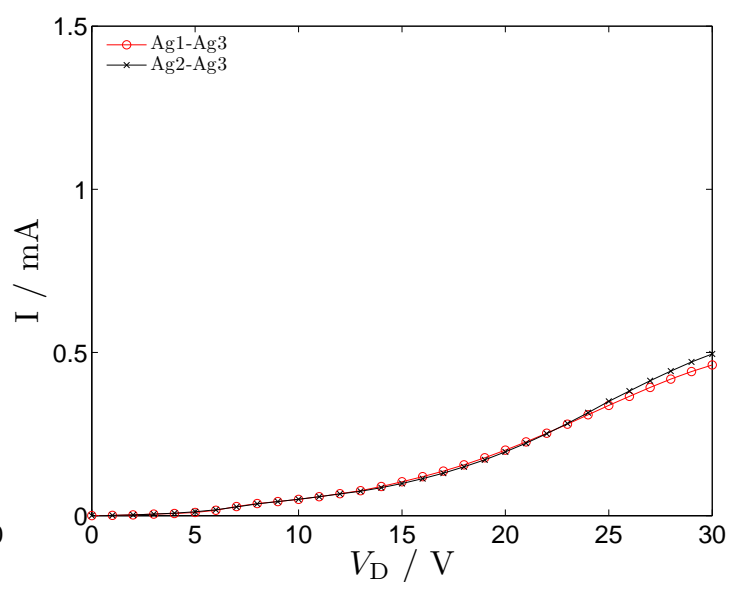

(b)

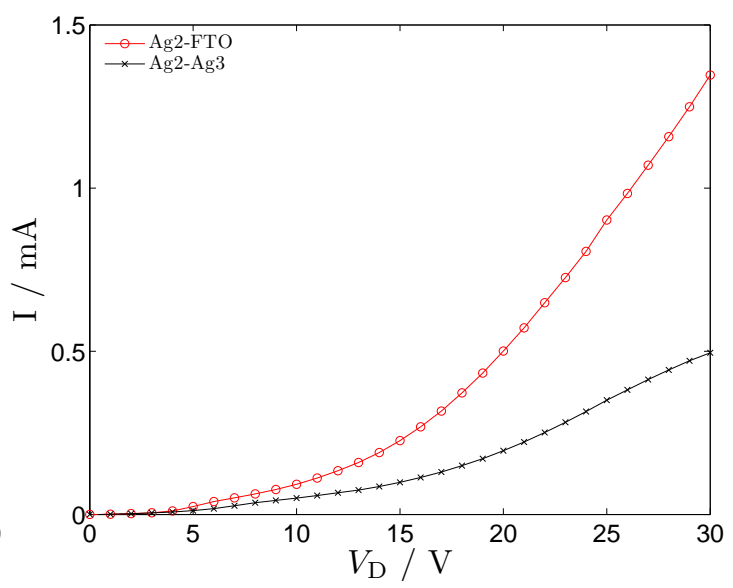

(d)

Figura 4.9: Comparativos entre os contatos Ag1 e Ag2 (a) Fluxo 1 (b) Fluxo 2 e comparativos entre os fluxos 1 e 2 (c) Ag1 (d) Ag2

De acordo com o circuito equivalente, se não há espalhamento da corrente na interface P3HTPEDOT:PSS nos fluxos propostos, a resistência calculada entre o fluxo 1 para Ag1 e fluxo 1 para Ag2 resultará na diferença entre $\mathrm{R}_{A g 1}-\mathrm{R}_{A g 2}$, ou seja as resistências associadas aos filmes de P3HT e PEDOT:PSS, que na melhor das hipóteses deve ser o menor valor possível, visto que ambos fluxos percorrem as mesmas camadas poliméricas. O valor obtido, foi de $1.98 \times 10^{3} \Omega$. E pelas curvas da figura 4.9 (a), vê-se que os percursos das correntes são muito aproximados. Para corroborar tal observação, analisemos os fluxos 2 para ambos contatos Ag1 e Ag2. O valor da resistência foi $2.92 \times 10^{3} \Omega$, estando de acordo com o valor para o fluxo 1 . Ademais, as intensidades de correntes para o fluxo 2 (figura 4.9 (b)) são visivelmente reduzidas se comparado ao fluxo 1, pois a corrente precisa atravessar a camada P3HT-PEDOT:PSS para descer até o substrato e depois a camada do PEDOT:PSS mais uma vez para alcançar o contato Ag3.

Com relação a resistência $\mathrm{R}_{A g 3}$, esta foi calculada por meio do comparativo entre os fluxos 1 e 2 para um mesmo contato. As curvas para Ag1 podem ser vistas na figura 4.9 (c) e para Ag2 figura 4.9 (d). A diferença entre os fluxos para o contato Ag1 foi $21 \times 10^{3} \Omega$ e para Ag2 $20 \times 10^{3} \Omega$ 


\begin{tabular}{|c|c|c|c|c|}
\hline Contatos & Área $\left(\mathrm{cm}^{2}\right)$ & Distância fluxo 1 & Distância fluxo 2 & $\mathrm{R}_{A g 3}$ \\
\hline $\mathrm{Ag} 1$ & 0.015 & $0.8 \mathrm{~cm}$ & $0.6 \mathrm{~cm}$ & $20 \times 10^{3} \Omega$ \\
$\mathrm{Ag} 2$ & 0.014 & $0.4 \mathrm{~cm}$ & $0.2 \mathrm{~cm}$ & $21 \times 10^{3} \Omega$ \\
\hline
\end{tabular}

Tabela 4.3: Distâncias a serem percorridas pelos fluxos 1 e 2, além das resistências calculadas para um contato com relação aos dois caminhos estabelecidos, resultando em $\mathrm{R}_{A g 3}$.

como descrito na tabela 4.3. Essa é a resistência perpendicular do filme de PEDOT:PSS, porém deve-se levar em conta a resistência de contato prata-PEDOT:PSS.

De posse dos valores calculados e das características elétricas observadas, pode-se afirmar que não ocorre espalhamento, significativo, no filme de P3HT quando a prata injeta cargas. Assim, o fluxo de portadores de carga atravessa os filmes poliméricos, perfazendo trajetória vertical, em outras palavras temos que a área ativa dos diodos estudados é aquela delimitada abaixo do contato de topo.

\subsection{Protocolo de medidas elétricas}

O presente trabalho tem na caracterização elétrica sua principal fonte de análise de dados, por esse motivo é importante parametrizar o equipamento empregado de maneira a se obter o melhor compromisso entre análise dos resultados e integridade da amostra.

Através dessa óptica, verificou-se as configurações do equipamento SMU Keysight, em termos de velocidade de tensão aplicada a uma amostra, com rampa de 0 a 30V. O SMU possui alguns modos distintos de velocidade. Foram averiguados: short, medium, normal e long. A unidade de medida utilizada no equipamento é PLC (Power Line Cycle) que correnponde a $\mathrm{T}=\frac{1}{f}$, onde $f$ é a frequência de rede $(60 \mathrm{~Hz})$. Além disso, o tempo de medida (Measurement time $-M T$ ) entre um ponto e outro na rampa é feito pela seguinte relação: Tempo de abertura (Aperture time -AT), que corresponde ao tempo necessário para a coleta dos dados somado ao Tempo de atraso (Overhead time - OT) relacionado aos tempos para armazenamento de dados, mudança entre pontos na rampa, condição de medição, etc. Na tabela 4.4 estão os valores calculados para AT, a partir dos valores de PLC informados pelo fabricante, e OT calculados por meio dos arquivos recolhidos do equipamento referente a cada modo de varredura.

\begin{tabular}{|c|c|c|c|}
\hline Modos & Tempo AT(ms) & Tempo OT(ms) & Tempo MT(ms) \\
\hline Short & 0.167 & 3.9 & 4.1 \\
Medium & 1.67 & 2.4 & 4.1 \\
Normal & 16.7 & 5.3 & 22 \\
Long & 167 & 33 & 200 \\
\hline
\end{tabular}

Tabela 4.4: Tempos necessários para aplicação das rampas nos modos short, medium, normal e long. 


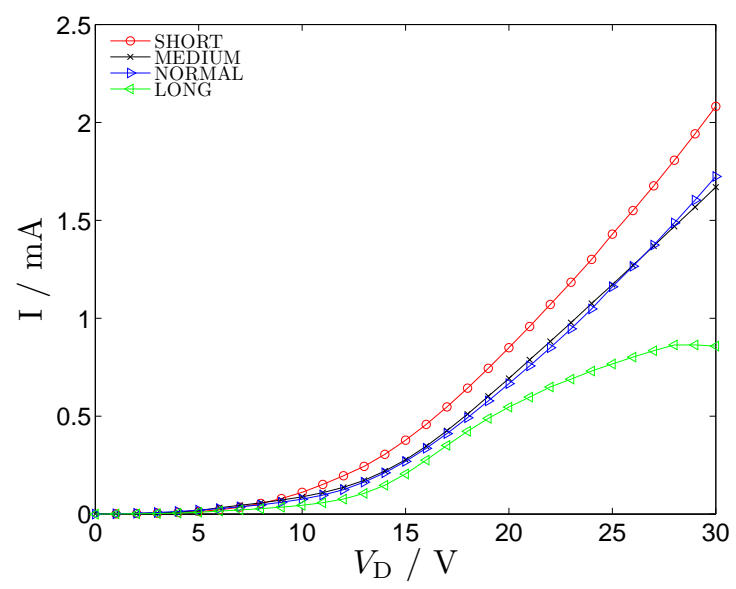

Figura 4.10: Resposta elétrica das velocidades: short, medium, normal e long aplicadas a uma amostra DO-1 do grupo 1

Entre os modos short e medium o tempo MT é o mesmo, no entanto a janela de abertura AT para medir os dados é 10 vezes menor. Por apresentarem regiões amorfas, os polímeros exigem maior tempo para o fluxo eletrônico alcançar o estado estacionário (quasi), portanto, velocidades de varredura elevadas fornecem medidas transientes da amostra. Se compararmos os modos medium e normal, este possui tempos AT e OT mais elevados que aquele, porém como exibido na figura 4.10 com característica elétrica muito aproximada. Já o modo long, com maior tempo de medição exibiu menor resposta elétrica, pois promove maior dissipação de energia o que acaba degradando a amostra. Por essa razão, optou-se por utilizar o modo medium como padrão para realização das medidas elétricas, uma vez que este alia tempo de abertura nem tão curto quanto short nem tão longo quanto os OTs e ATs dos demais modos, permitindo medição de dados representativos e evitando degradação da amostra durante a aplicação da tensão.

É interessante mencionar um fato curioso visualizado. A primeira aplicação da rampa apresentou perfil de curva IV distinta das subsequentes, como pode ser apreciado na figura 4.11 .

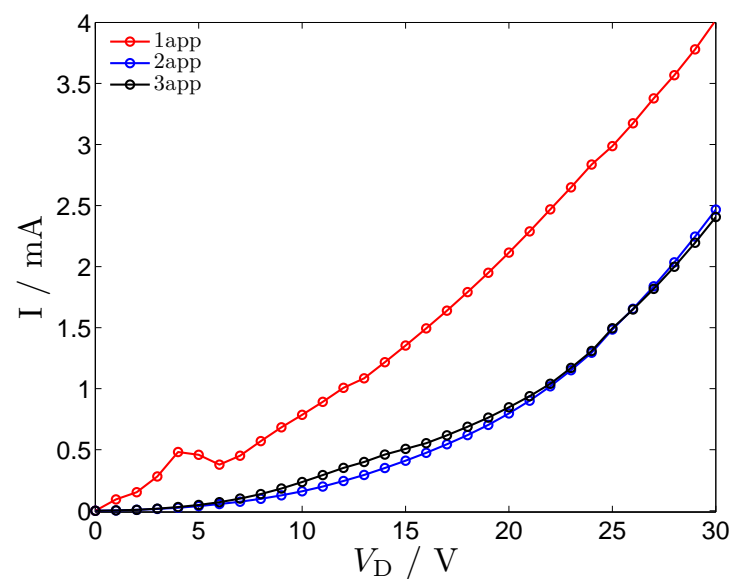

Figura 4.11: Comportamento distinto entre aplicação de primeira rampa (1app) e as subsequentes.

Observou-se que na primeira medida o perfil da curva diferiu da segunda, mas não houve variação entre a segunda e a terceira. Para a análise dos resultados usou-se a segunda. Tal 


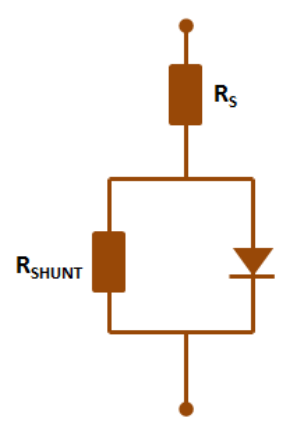

Figura 4.12

comportamento foi fielmente observado por Lupton [98. A investigação desse fato deverá ser considerado em trabalhos futuros.

\subsection{Resistência de contato}

A interação entre o contato de topo e a camada semicondutora tem papel importante no desempenho de um dispositivo. Pouco se sabe sobre a estabilidade nesta interface e de que maneira a penetração do metal no polímero pode ser otimizada a fim de se melhorar a mobilidade. Como esquematizado na figura 4.12, o circuito equivalente contem a resistência serial, que inclui resistência de contato, resistência por quadrado. Vias de resistência de fuga (resistência shunt) podem surgir em paralelo com o funcionamento do diodo, mascarando seu efeito em alguns casos. Durante a operação de OFETs, por exemplo, o transporte de portadores de carga depende fortemente das propriedades de interface. Os principais parâmetros extraídos do dispositivo, tais como a mobilidade, tensão limiar, e corrente on / off são afetados pela resistência de contato. Em pequenos dispositivos, a resistência de contato se torna importante, pois limita a injeção de cargas no dispositivo [54]. Shen 102 relata que, a resistência em série é um fator preponderante para células solares, pois se esse parâmetro é alto o fator de preenchimento é reduzido, diminuindo a eficiência da célula.

No intuito de se extrair o valor de resistência do contato e da camada de P3HT, empregouse o modelo TLM (do inglês, transmission line model), o qual é um método bem aceito para caracterizar resistência de contato em semicondutores orgânico 102 .

Para melhor compreensão do modelo proposto, a figura 4.13 traz a seção transversal de um resistor de comprimento L com dois contatos metálicos em cada lado. A resistência total é resultado da soma dos seguintes componentes:

$$
R_{\text {Total }}=2 R_{\text {metal }}+2 R_{\text {contato }}+R_{\text {semicondutor }}
$$

Uma vez que, a resistividade do metal não contribui no contato, esta pode ser ignorada. 
Sabendo que a resistência no semicondutor é dada por: $R_{\text {semicondutor }}=R_{\text {sheet }}\left(\frac{L}{W}\right)$, vêm:

$$
R_{\text {Total }}=R_{\text {sheet }}\left(\frac{L}{W}\right)+2 R_{\text {contato }}
$$

Tais resultados sugerem um método para medição da resistência de contato. Construindo-se alguns resistores de comprimentos diferentes e áreas de contatos semelhantes (figura 4.14 (a)), a resistência total de cada um pode ser obtida e plotada (figura 4.14 (b)). No limite de um resistor de comprimento zero, a resistência residual é apenas duas vezes a resistência do contato, extrapolando-se a reta de interpolação para $\mathrm{L}=0$. Uma segunda medida que pode ser aferida é a resistência sheet do semicondutor, pela inclinação da curva. Pode-se ainda calcular a resistividade do contato, considerando-se a pequena região exposta na figura 4.13 (b), têm-se: $R_{\text {contato }}=\rho \frac{\Delta_{\mathrm{x}}}{A c}$, onde Ac é a área do contato, então:

$$
\rho_{\mathrm{c}}=\lim _{\Delta_{\mathrm{x}} \rightarrow(0)}\left(\rho \Delta_{\mathrm{x}}\right)=R_{\text {contato }} A c
$$

Como pode ser observado na figura 4.13 (c), a área do contato não é completamente utilizada para aplicação da corrente, desta forma, o fluxo através do semicondutor é uniforme, mas não nos contatos. Sabendo disto, não se pode utilizar o comprimento físico e largura para determinar a área de contato. No ângulo do contato, o fluxo de corrente é mais acentuado. Afastando-se da borda, a corrente diminui até que não há mais corrente. Isto é conhecido como corrente de aglomeração 103. Uma análise da mesma, mostra que a diminuição na corrente a partir da borda do contato segue a expressão:

$$
I(x)=\propto \exp \left(\frac{x}{L_{\mathrm{T}}}\right)
$$

$L_{\mathrm{T}}$ é o comprimento de transferência, o qual representa a distância média que um elétron (ou lacuna) flui no semicondutor abaixo do contato antes de atingí-li. Sabendo que: $L_{\mathrm{T}}=\sqrt{\frac{\rho_{\mathrm{c}}}{R_{\mathrm{sheet}}}}$, temos:

$$
R_{\text {Total }}=\frac{R_{\text {sheet }}}{W}\left(L+2 L_{\mathrm{T}}\right)
$$

A partir das equações do modelo TLM mencionadas acima, extraiu-se os valores de Resistência de contato $R_{\text {contato }}$, Resitência de folha $R_{\text {sheet }}$, Comprimento de transferência $L_{\mathrm{T}}$ e Resistividade do contato $\rho_{\mathrm{c}}$, expostos na tabela 4.5 .

Uma equação muito utilizada na literatura relaciona resistência de contato com resistência por quadrado: $\mathrm{R}_{c i}=\sqrt{\rho_{c} R_{\text {sheet }}}$, cujo valor foi de $3.25 \mathrm{~K} \Omega \mathrm{cm}$. Se compararmos com o silício, que apresenta $0.1 \Omega \mathrm{cm}$, trata-se de uma resistência de contato baixa. Sabendo disso, calculou-se a tensão em que o contato metálico passaria a ser limitado. Se consideramos $\frac{1}{R_{\text {channel }}}=\frac{d I}{d V}=\frac{9}{8} \mu$ $\epsilon \frac{V}{L^{3}} \mathrm{~A}_{c}$, temos que: $\mathrm{R}_{\text {channel }}=\frac{4 L^{3}}{9 \mu \epsilon V A c}$. Tomando $\mathrm{R}_{\text {channel }}=\mathrm{R}_{\text {contato }}=\frac{\rho_{c}}{A_{c}}$ resulta em:

$$
V=\frac{4 L^{3}}{9 \mu \epsilon \rho_{c}}
$$




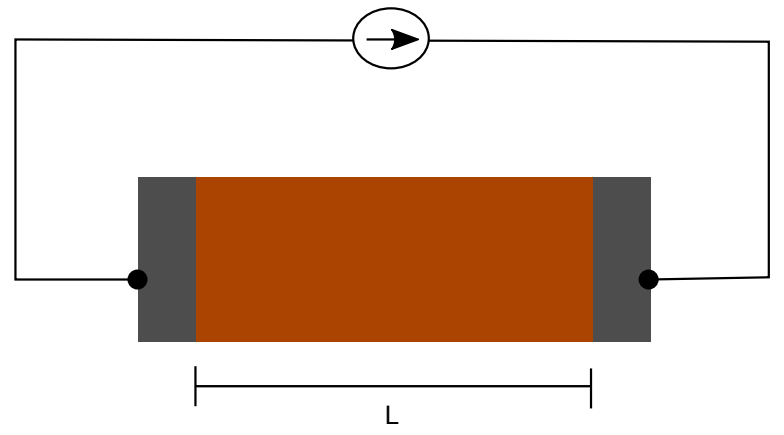

(a)

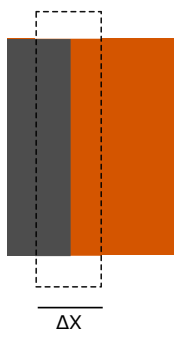

(b)

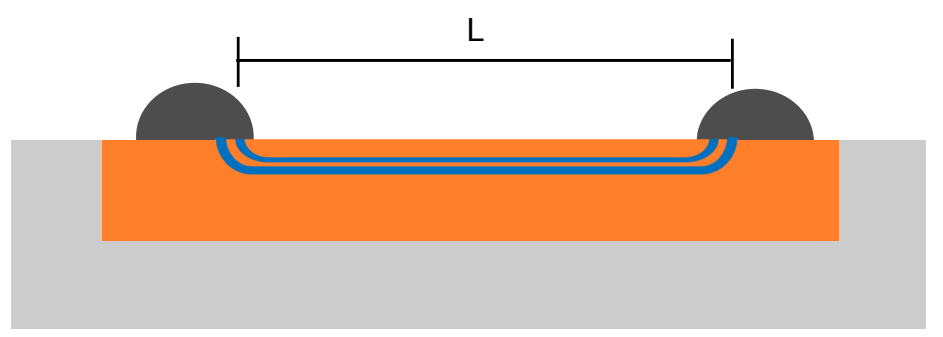

(c)

Figura 4.13: Esquemáticos (a) resistor de comprimento L, conectado a dois contatos metálicos (b) região de distância $\Delta_{\mathrm{x}}$ abaixo do contato (c) Fluxo de corrente em uma porção do contato viajando ao contato oposto

\begin{tabular}{|c|c|}
\hline Parâmetros & Valores \\
\hline$R_{\text {contato }}$ & $132 \times 10^{3} \Omega$ \\
$R_{\text {sheet }}$ & $176 \times 10^{3} \Omega / \square$ \\
$L_{\mathrm{T}}$ & $0.0187 \mathrm{~cm}$ \\
$\rho_{\mathrm{c}}$ & $60 \Omega \mathrm{cm}^{2}$ \\
\hline
\end{tabular}

Tabela 4.5: Parâmetros extraídos da curva Resistência vs Comprimento, obtida no experimento TLM 


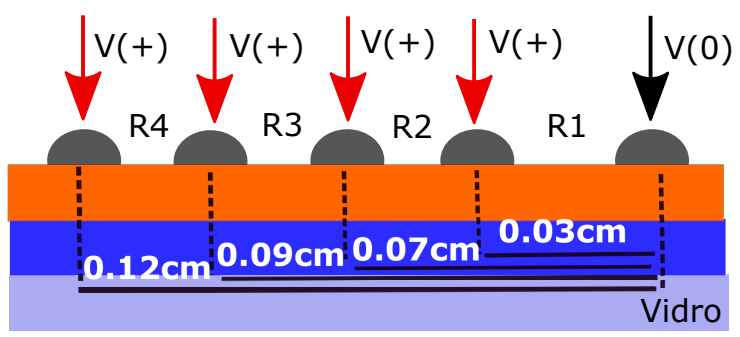

(a)

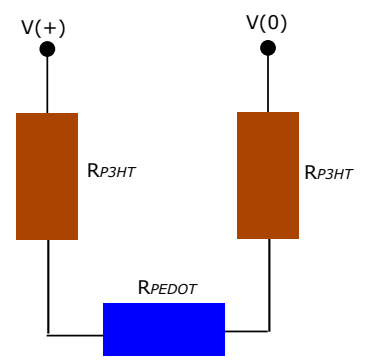

(b)

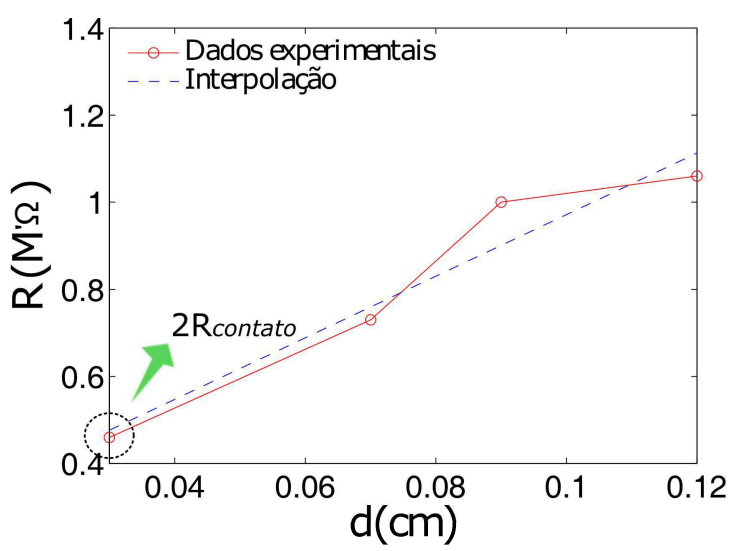

(c)

Figura 4.14: Experimento realizado para extração da resistência do contato dos filmes poliméricos (a) esboço do experimento (b) Circuito equivalente (c) Curva resistência em função da distância dos contatos. 
A tensão no qual o contato passa a ser limitado para injeção é de $77 \mathrm{~V}$, portanto, para nossas amostras mostra-se eficiente.

\subsection{Estudo da injeção de carga: Grupo 2 de amostras}

O segundo grupo de dispositivos, secos à $120^{\circ} \mathrm{C}$, apresentou curva $I(V)$ como mostrado na figura 4.15. A partir desses resultados, foi possível identificar alguns parâmetros elétricos que descrevem o funcionamento dos mesmos.

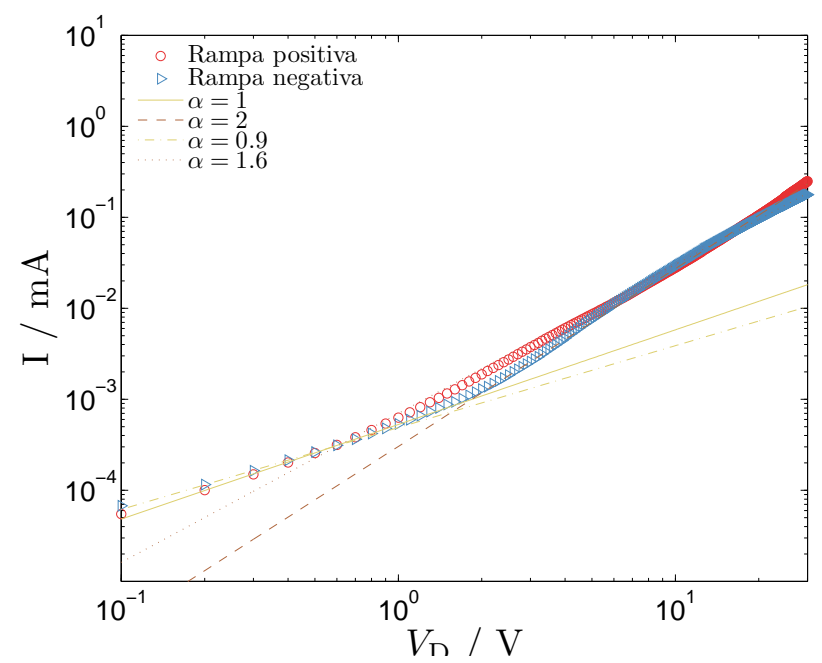

(a)

Figura 4.15: Curvas $I(V)$ de um dos dispositivos obtidos com secagem de $120^{\circ} \mathrm{C}$, mostrando as inclinações $\alpha$ em baixas e altas tensões, para tensões positivas e negativas.

Como pode ser observado, a corrente elétrica não apresenta a mesma dependência com a tensão para os dois sentidos de polarização. Indicando que os mecanismos que governam a injeção de carga dependem da polarização aplicada. Desta forma, as análises de ambos sentidos foram averiguados separadamente a seguir. A simetria das curvas é observada após a eliminação de impurezas de processamento.

\subsubsection{Regime de polarização 1: $\operatorname{Prata}(+) / \mathrm{FTO}(0)$}

Dois regimes distintos podem ser identificados na figura 4.15. Consideremos a região até aproximadamente $1 \mathrm{~V}$, como sendo a região de baixas tensões. $\mathrm{O}$ comportamento mostra-se linear, com $J \propto V$, em função de resistências de fuga (shunt) presentes.

A transição entre regime ôhmico e regime de carga espacial ocorre de maneira, relativamente, abrupta. Neste ponto, a corrente de deriva domina o fluxo de cargas - $J \propto V^{2}$ - obedecendo a equação de Mott-Gurney 2.2. Quando o contato metálico injeta cargas no polímero, chegará um eventual momento de acumulo de cargas espalhadas em torno da interface com extensão no volume do semicondutor, uma vez que este possui baixa mobilidade. Em outras palavras, o eletrodo fornece 
mais corrente do que o semicondutor pode transportar e a corrente é, consequentemente, limitada por carga espacial [38, 15$]$.

\subsubsection{Simulação aplicada}

Algumas dados obtidos experimentalmente a partir das amostras nomeadas: TT3A-Ag2, TT3A-Ag3 e TT5A-Ag1, foram utilizados para ajuste seguindo o modelo de simulação proposto, como pode ser visto nas figuras 4.16 .

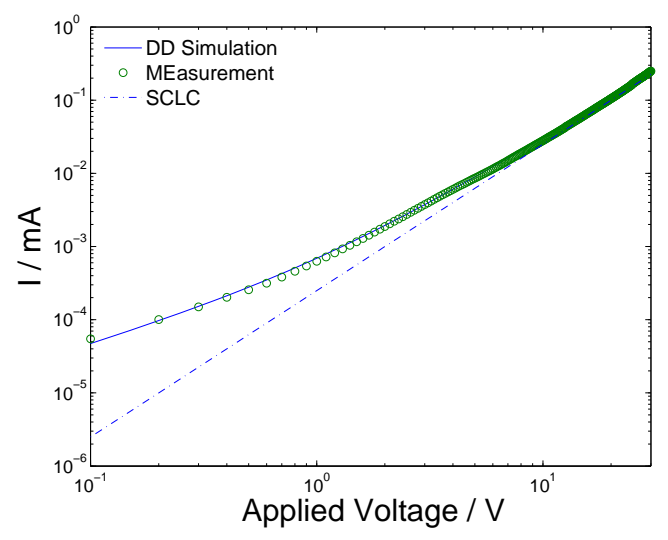

(a)

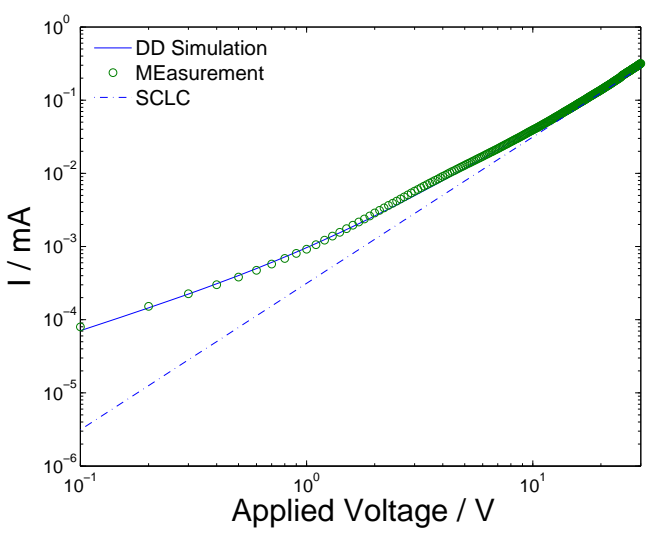

(b)

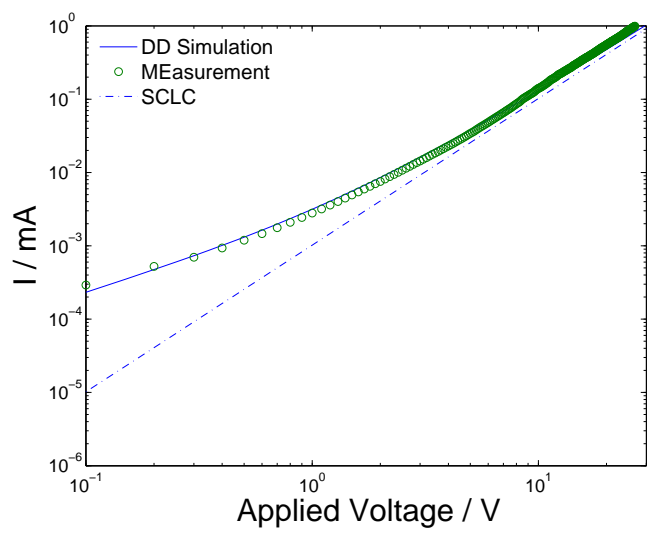

(c)

Figura 4.16: Curvas $I(V)$ de amostras de segundo grupo (a) TT3A-Ag2 (b) TT3A-Ag3 (c) TT5AAg1. A linha preenchida representa a curva simulada difusão-deriva (DD) e a tracejada o regime SCLC.

Claramente, o comportamento observado não pode ser descrito puramente como deriva SCLC/TLC. Foram considerados os seguintes parâmetros: i) O DOS da banda de condução/valência é ajustado para $N_{\mathrm{v}}=N_{\mathrm{c}}=2 \times 10^{20} \mathrm{~cm}^{-3}$; ii) Os contatos MOP (termo do inglês, Metal on Polymer) e POM (termo do inglês, Polymer on Metal) tem as mesmas funções trabalho $(\phi M O P=P O M=$ $|4.7| e V)$, uma vez que, as curvas $\mathrm{I}(\mathrm{V})$ medidas não mostram significantes barreiras de potencial próximo aos contatos, nem para baixas nem para altas tensões. 


\begin{tabular}{|c|c|c|}
\hline Amostras & $\mu\left(\mathrm{cm}^{2} / V s\right)$ & $N_{\mathrm{a}}\left(\mathrm{cm}^{-3}\right)$ \\
\hline TT3A-Ag2 & $6.6 \times 10^{-3}$ & $0.77 \times 10^{13}$ \\
TT3A-Ag3 & $8.3 \times 10^{-3}$ & $0.99 \times 10^{13}$ \\
TT5A-Ag1 & $23 \times 10^{-3}$ & $1.0 \times 10^{13}$ \\
\hline
\end{tabular}

Tabela 4.6: Valores de mobilidade $\mu$ e densidade de dopagem não intencional $N_{\mathrm{a}}$ extraídos das amostras experimentais a partir da simulação realizada

Para explicar os parâmetros do modelo, aplicou-se as seguintes estratégias de ajustes: Primeiro, a mobilidade de deriva SCLC é determinada usando correntes para as mais altas tensões disponíveis. Segundo, a mobilidade é ajustada empregando simulações difusão-deriva (DD) mais uma vez, apenas com correntes de tensões mais elevadas. O ajuste é necessário porque mesmo em $\mathrm{V}=30 \mathrm{~V}$ a contribuição de difusão para a corrente total não é negligenciável. Em paralelo, dopagem não intencional é adicionada ao modelo TCAD na tentativa de obter os níveis de correntes experimentais em baixas tensões. Os valores dos parâmetros extraídos são dados na tabela 4.6 . Extrapolando-se a corrente de difusão em baixas tensões a densidade de dopagem não intencional pode ser determinada e é da ordem de $10^{13} \mathrm{~cm}^{-3}$. E as mobilidades extraídas são na faixa de $10^{-3} \mathrm{~cm}^{2} / V s$ e $10^{-2} \mathrm{~cm}^{2} / V s$, como esperado para P3HT.

\subsubsection{Regime de polarização $2 \operatorname{Prata(-)/FTO(0)}$}

Neste sentido do fluxo de cargas, a região de baixas tensões exibe comportamento similar a polarização 1, com comportamento ôhmico, porém, a região de corrente limitada por cargas espaciais não é completamente observada, pois a dependência da corrente em função da tensão não é quadrática.

Como discutido na seção 4.3.3, na situação em que o FTO/PEDOT:PSS injeta carga o acumulo de lacunas nessa interface é maior, logo, esperava-se que a resposta elétrica indicasse maiores correntes nesse sentido, porém, não foi observado. Algumas possibilidades podem justificar tal comportamento. Primeiramente, o contato polímero sobre metal (POM) não ocorre de maneira tão precisa quanto o contato MOP. Liu 104 afirma que, existe um aumento na barreira de energia para injeção de cargas, quando se faz o contato POM. Outra hipótese, diz respeito a higroscopicidade do PEDOT:PSS quando exposto a condições ambiente, tornando o mais resistivo. Elschner [73] e Jorgensen [10] explicam que, assim como outros polímeros contendo grupos de ácido sulfônico, PEDOT: PSS é altamente higroscópico, absorvendo humidade quando manuseado em condições ambientais acarretando no ataque ao substrato de óxido de estanho. A interface entre PEDOT: PSS e semicondutores orgânicos é ainda mal compreendida, mostrou-se recentemente que para alguns compostos orgânicos semicondutores, a injeção de lacunas é limitada por uma barreira de injeção que não dependente da função trabalho do ânodo devido a estabilidade do nível de Fermi 105 . 


\subsubsection{Comportamento sublinear em baixas tensões}

Um fenômeno intrigante de inclinações menores do que um em baixas tensões, foi observado em algumas medidas na polarização 1 e em todas na polarização 2 , como pode ser verificado nos gráficos de tendências de todas as amostras de grupo 2 (figura 4.17 (a) e (b)).

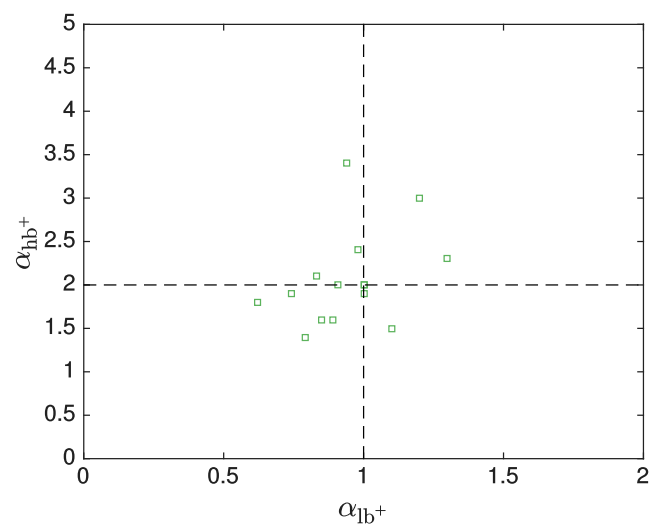

(a)

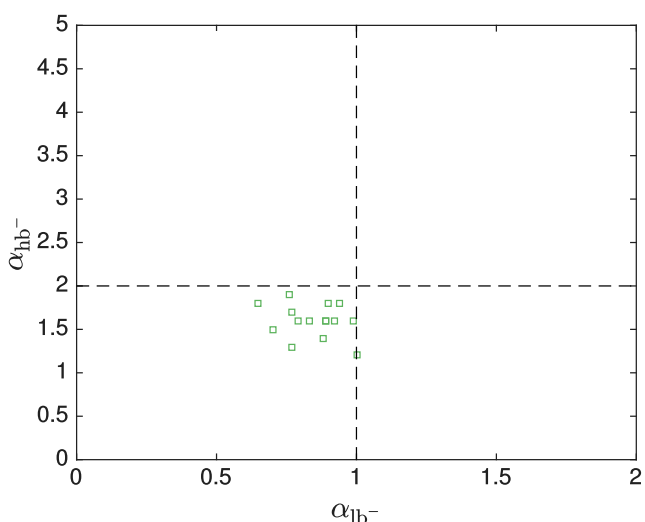

(b)

Figura 4.17: Relação entre expoentes para baixas e elevadas tensões (a) polarização 1 e (b) polarização 2, indicando a tendência de ocorrer inclinações sublineares para algumas amostras na polarização 1 e em todas na polarização 2 .

O curioso fenômeno observado deve ocorrer em virtude de alguns fatores que imprimem irregularidade aos filmes de PEDOT:PSS. As figuras 4.18 (a) e (b) trazem uma ilustração da ideia proposta.

Vários artigos têm reportado modelos para descrever a topografia do filme PEDOT:PSS, um deles, proposto por Nardes et. al. [106], sugere que a morfologia do filme assemelha-se a discos achatados empilhados. Quando em solução o PEDOT:PSS geram esferas de géis, ao secar essas formas prevalecem, porém achatam-se verticalmente formando discos com PSS localizado na área de contato do filme. Os portadores preferem seguir o diâmetro maior desses discos do que atravessálos verticalmente. O mesmo resultado foi encontrado por Moulé [68 através de Elipsometria e medidas de condutividade.

Lang et al. [107 realizou experimento para analisar a morfologia desses grãos remanescentes, verificando que o tamanho destes permanece o mesmo de quando estavam em dispersão após a secagem. Os mesmos foram detectados na superfície dos filmes por meio de Raio-x de energia dispersiva (EDX). A análise dos filmes revelou que, a superfície desses grãos continha acumulo de íons alcalinos e alcalinos terrosos formando complexos iônicos com a zona enriquecida de PSS, presente entre ele.

Sabe-se ainda que, a deposição de filmes do referido polímero em atmosfera ambiente, resulta no surgimento de uma 'pele' de PSS na superfície do filme [68. No entanto, não existe registro literário sobre inclinações sublineares até então. Acredita-se que isso se deve ao fato de que o PEDOT:PSS empregado nas amostras do presente trabalho - AL 4083 - contem proporção entre 


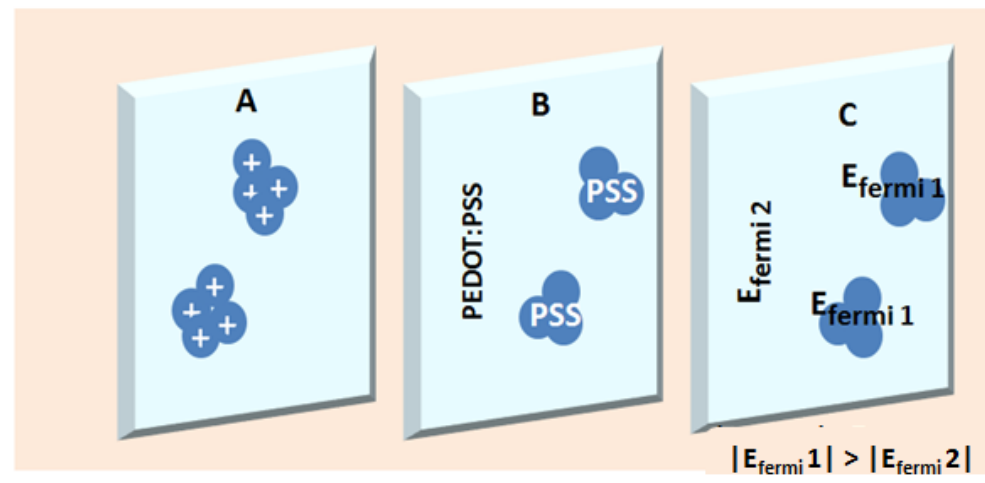

(a)

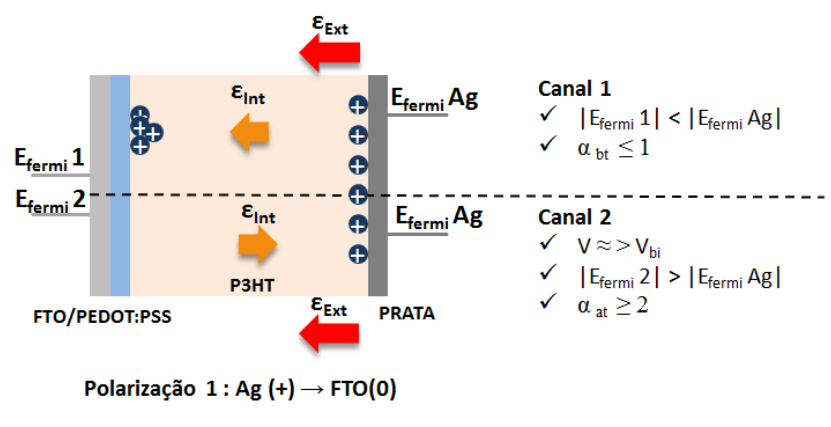

(b)

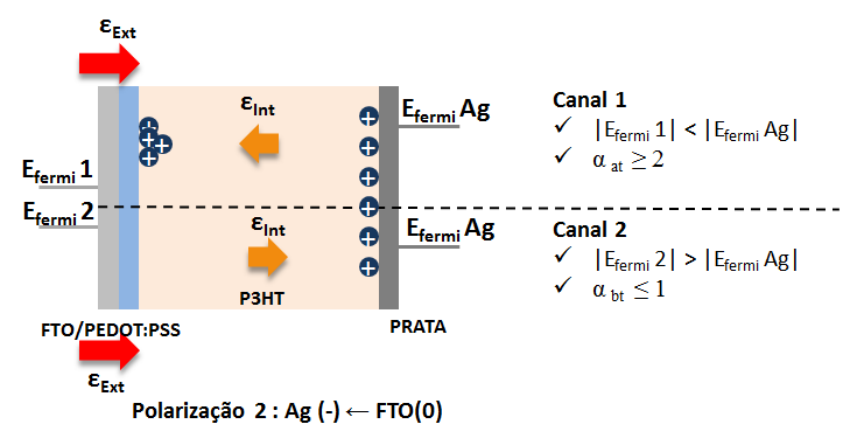

(c)

Figura 4.18: Ilustrações para elucidação do fenômeno (a) 3 diferentes explicações do filme de PEDOT:PSS (b) Sentido das cargas com base nos campos elétricos internos e externos na polarização 1 e (c) polarização 2 
PEDOT e PSS de 1:6, ou seja, 6 PSS para cada molécula de PEDOT, podendo levar a maior migração de PSS para superfície se comparado com outros tipos desse polímero, como sugerido por Abdulrazzaq [70. Ying-Jie [67] esclarece que, o raio de PSS/PEDOT na superficie do filme é um fator determinante na função trabalho. Uma fina camada de PSS sempre aparece na superfície dos filmes devido a segregação vertical durante a formação do filme, uma vez que a função trabalho do PSS é maior que a do PEDOT, o filme formado possui maior função trabalho que o PEDOT puro. Mais ainda, o aumento dessa propriedade foi alcançada através de soluções de PEDOT:PSS enriquecida com PSS, pois uma redução na função trabalho da superfície do filme foi constatada quando feita a remoção da camada rica em PSS. Aliado a isso, o processamento dos nossos filmes de PEDOT:PSS conferem uma espessura relativamente elevada, $2 \mu \mathrm{m}$, como visto na seção 4.1 . permitindo que o PSS viaje pelo filme até formar pequenos aglomerados ((A) e (B)). O PSS por se tratar de um isolante, eleva o nível de fermi destas ilhas, havendo um contato de forte acumulação ali (C).

Durante o funcionamento dos dispositivos, como representado na figura 4.18 (a), existe um campo elétrico interno $\epsilon_{\text {Int }}$ que surge porque os níveis de Fermi dos contatos não são iguais, tensão $\mathrm{V}_{b i}$. Assumindo a existência de dois canais de injeção, no canal 1 esse campo tem o sentido da direita para esquerda pois o FTO/PEDOT:PSS, com maior nível de Fermi, tende a transferir lacunas para a prata no intuído de promover o equilíbrio. A medida que se aplica um campo elétrico externo $\epsilon_{\text {Ext }}$ com o mesmo sentido que o interno, injeta-se lacunas de encontro àquelas já acumuladas nas ilhas de PSS, gerando um gradiente de cargas oposto ao fluxo, o que reflete nas inclinações sublineares observadas. Este comportamento se dá até aproximadamente $1 \mathrm{~V}$, acima disso o segundo canal, começa a ser percebido pois o somatório dos campos externos e internos seguem o mesmo sentido, se fazendo perceber no aumento significativo da corrente.

Em contrapartida, quando o FTO/PEDOT:PSS passa a injetar cargas - polarização 24.18 (c)) - a região do contato com menor nível de fermi é responsável pela injeção, pois representa a maior área, visto que o PSS acumulado contem apenas pequenas ilhas. Desta forma, apenas o canal 2 é evidenciado com os campos elétricos externo e interno direcionando cargas no sentido das cargas acumuladas uniformemente do contato da prata, resultando em inclinação sublinear para todas as amostras, e o canal 1 nunca é alcançado, logo não é percebida a corrente limitada por cargas espaciais. Podemos concluir que as correntes resultantes em ambas polarizações estão associadas às áreas dos contatos de injeção pela relação: $\mathrm{I}_{\text {Total }}=\mathrm{A}_{\text {Canal1 }} \mathrm{J}_{1}+\mathrm{A}_{\text {Canal2 }} \mathrm{J}_{2}$

A simulação implementada aqui, não pôde ser desenvolvida por meio dos mesmos mecanismos que na figura 4.16. Considerando-se os caminhos de correntes dominantes em baixas tensões de dopagem e altas tensões de canais de injeção, foi realizada simulação TCAD de maneira a elucidar a teoria proposta. As figuras 4.19 trazem em (a) resultado experimental de uma amostra de perfil sublienar e em (b) o resultado da simulação para a mesma amostra. Para a implementação da simulação considerou-se para o canal 1: $\Phi_{\text {prata }}=|4.54|$ e $\Phi_{\text {FTO/PEDOT:PSS }}=|5.2|$ e para canal 2: $\Phi_{\text {prata }}=|4.7|$ e $\Phi_{\text {FTO } / \text { PEDOT:PSS }}=|3.42|$. Empregando a mesma mobilidade nos dois canais e dopagem não intencional apenas no canal 1 .

De maneira interessante, a característica elétrica do dispositivo pôde ser explicado como a soma 


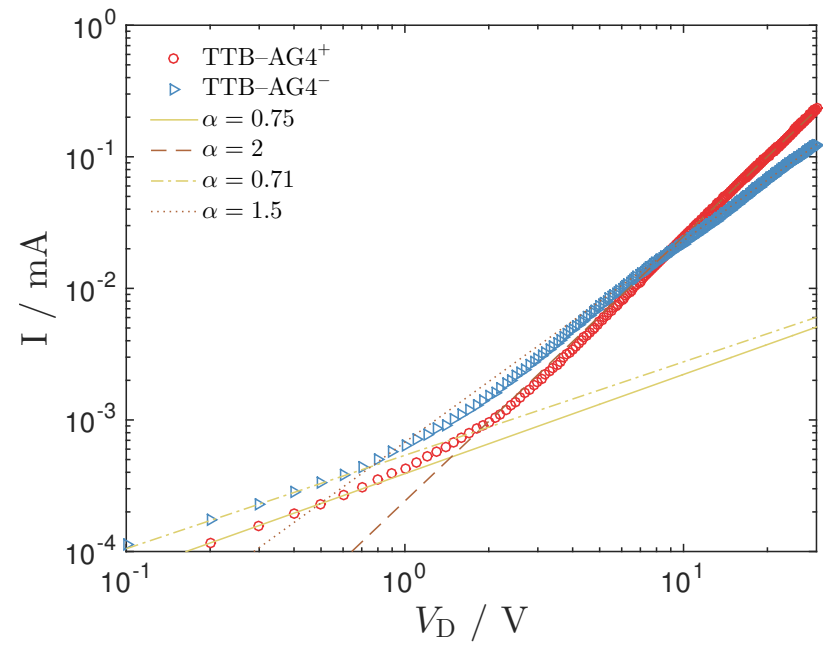

(a)

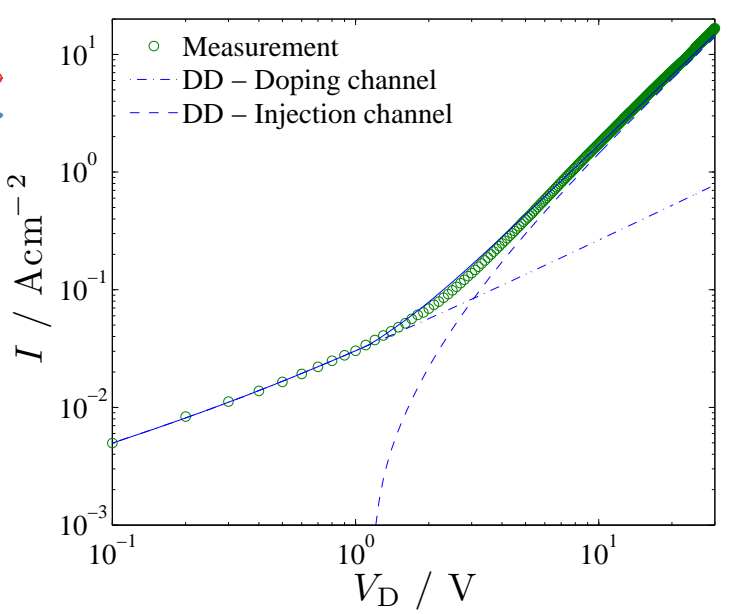

(b)

Figura 4.19: Curvas $I(V)$ da amostra nomeada TTB-Ag4 (a) Resultado experimental (b) Simulação incluindo a existência de dois canais. A linha preenchida representa a curva simulada difusão-deriva (DD) e a tracejada o regime SCLC.

de duas correntes possivelmente resultantes de dois canais de condução paralelos. Os dois caminhos de correntes seriam caracterizados por diferentes densidades e/ou mobilidades de dopagem e seriam limitados por um campo elétrico ou um gradiente de lacuna oposto, respectivamente. Além dos efeitos de interface puros, podem surgir limitações de contato, quando a difusão e a deriva de portadores de carga se opõem uma à outra em baixas tensões, uma vez que, a corrente é acionada pelo gradiente de quasi-Fermi e não pelo potencial eletrostático.

As curvas sublineares corrente-tensão surgem a partir de uma corrente de injeção limitada por um gradiente de portadores oposto, a qual domina em baixas tensões mas contribuem fracamente em altas tensões. No exemplo dado, a estrutura MSM comporta-se mais como um dispositivo metal-isolante-metal com posição independente do campo elétrico através do dispositivo. A mobilidade e a densidade de dopagem não intencional extraídos da amostra TTB foi $\mu=6.4 \times 10^{-3} \mathrm{~cm}^{2} / V s$ e $N_{\mathrm{a}}=2.0 \times 10^{13} \mathrm{~cm}^{-3}$, respectivamente.

\subsection{Tratamento térmico: análise qualitativa}

Foram realizados tratamentos térmicos em diferentes temperaturas a fim de se verificar a influência dessa variável sobre a performance do dispositivo. O efeito do tratamento térmico sobre características como cristalinidade e a morfologia tem sido alvo de muitos estudos, bem como a correlação entre estrutura morfológica e características elétricas [54]. Para [108], a caracterização térmica de filmes poliméricos é muitas vezes uma tarefa difícil, porque as propriedades térmicas do polímero são muito sensíveis ao arranjo das moléculas no seu interior. Portanto, adquirir uma compreensão mais profunda destes efeitos permitirá a otimização mais eficiente das condições de processamento necessárias para atingir o máximo desempenho de dispositivos orgânicos [109]. Além disso, o tratamento térmico é um método eficaz que melhora a morfologia, a compacidade, 
e cristalinidade dos filmes finos orgânicos [51.

Estudos realizados sobre fatores que influenciam a eficiência de dispositivos orgânicos apontam uso de tratamento térmico, solvente e aditivos como responsáveis pela melhoria no desempenho [66. O efeito de tratamento térmico é aumentar a transferência de carga no tempo [61]. Desta forma, faz-se importante a investigação do efeito térmico causado à heterojunção PEDOT:PSSP3HT, ao P3HT separadamente e ao dispositivo como um todo sendo relevante para estudos futuros.

A temperatura e a duração do tratamento térmico são características importantes, uma vez que, permitem eliminar fatores que impedem o real funcionamento do dispositivo, bem como torna possível a observação dos fenômenos físicos responsáveis pelo aumento de sua eficiência. Parker 110 relata que o aumento da temperatura eleva a eficiência quântica dos filmes poliméricos por causa da mudança na morfologia entre polímero-eletrodo.

Partindo-se desses pressupostos, foram realizados experimentos para analisar o efeito do tratamento térmico sobre o comportamento elétrico das amostras desenvolvidas. Como descrito na subseção 3.3.4, optou-se por promover 2 sequências distintas de annealing, de maneira a observar o efeito de diferentes variações térmicas.

\subsubsection{Sequência de annealing térmico 'A'}

A sequência A foi aplicada a uma única amostra dos dois tipo de dispositivo, com 5 minutos de exposição para cada temperatura. Cada amostra continha 8 contatos de prata, $\operatorname{logo} 8$ diodos por amostra. A figura 4.20 mostra as curvas I-V do experimento para 1 diodo de cada.

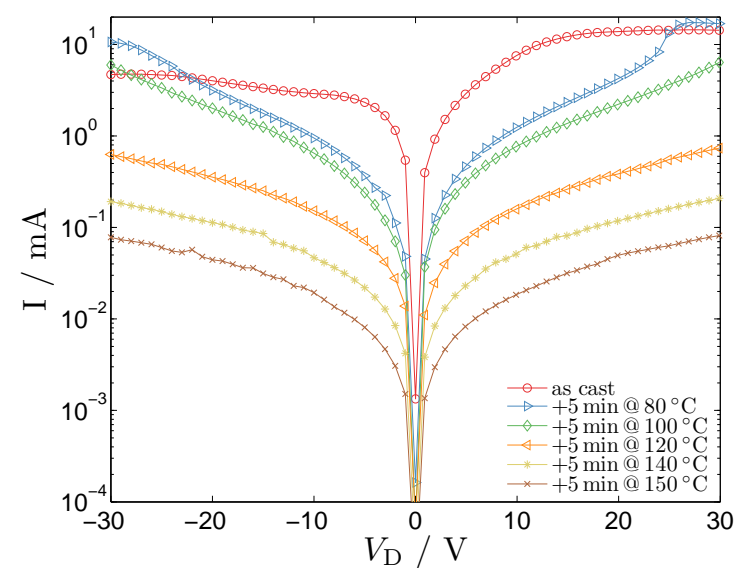

(a)

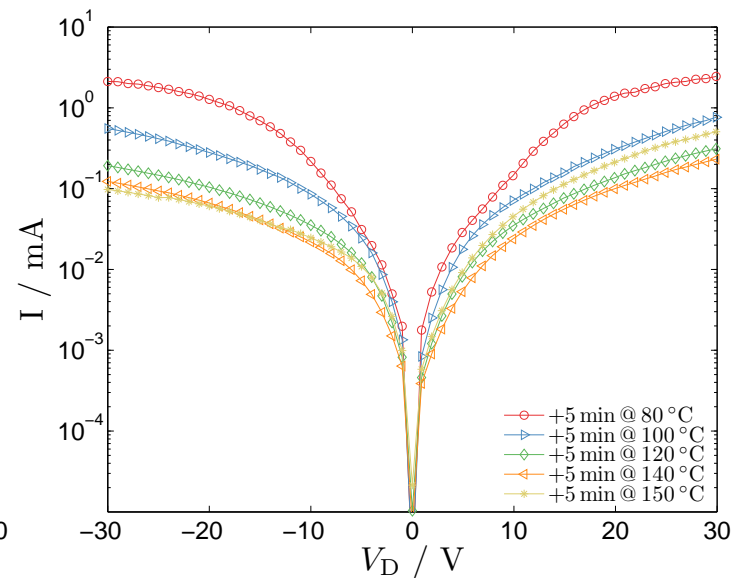

(b)

Figura 4.20: Caracterização elétrica dos dispositivos submetidos à sequência $\mathrm{A}$ de annealing (a) DO-1(FTO/P3HT/Ag) (b) DO-2 (FTO/P3HT/PEDOT:PSS/Ag).

O perfil decrescente da intensidade de corrente é um comportamento comum aos dois dispositivos em todas as temperaturas. Esperava-se que a condutividade elétrica do P3HT aumentasse em temperaturas mais elevadas, em virtude do aumento da cristalinidade e coplanaridade das cadeias 
principais, elevando a mobilidade entre as cadeias [111. No entanto, não foi observado esse efeito no referido experimento. Resultado encontrado também por Chiguvare [52]. Tal comportamento é atribuído a dopagem por impurezas decorrentes da preparação da amostra, tais como umidade, solvente remanescente, assim, quando eliminadas ocorre diminuição na condutividade. Ao mesmo tempo, o movimento térmicamente induzido das cadeias poliméricas formam um empacotamento mais aproximado, e portanto com maior interação entre elas aumentando a condutividade [52,110]. Os referidos fenômenos se desenvolvem paralelamente, porém a dopagem por impurezas prevalece.

Um fenômeno intrigante percebido no presente experimento, ocorreu entre as temperaturas de 140 e $150{ }^{\circ} \mathrm{C}$. No DO-2 a corrente aumentou, mas apenas na polarização 1. Chiguvare [52], Friedel 71, Bange [105] e Marsh [61], observaram comportamento semelhante, em seus estudos de um diodo orgânico contendo P3HT e PEDOT:PSS medido sob atmosfera de nitrogênio. Suas conclusões baseiam-se na cristalização do P3HT a essa temperatura, aumentando assim a condutividade do dispositivo.

O perfil decrescente da corrente e em seguida um aumento, em temperatura mais elevada, foi verificado também por Friedel [71, cuja melhora observada no desempenho do dispositivo se deu em uma região em que não há grandes mudanças químicas no PEDOT: PSS, apenas uma perda de água e mudanças provavelmente estruturais, como a segregação.

De fato, tem-se retratado na literatura que com a deposição no ar, PEDOT e PSS formam uma camada vertical segregada, contendo o PSS na superfície [66]. Geram-se microdomínios de PEDOT:PSS ricos em PEDOT no centro e pobre na superfície. Com o aquecimento, essa região mais rica forma domínios no plano muito mais condutivos do que perpendicularmente a superfície [14. Moulé et al 68 realizou uma análise a cerca da interface P3HT-PEDOT:PSS e concluiu que com tratamento térmico acima de $150{ }^{\circ} \mathrm{C}$ o P3HT se mistura com o PSS do PEDOT que segrega para a interface, formando uma camada que influencia positivamente no desempenho do dispositivo.

Para elucidar esse fenômeno encontrado em nossos dispositivos, duas possíveis explicações são sugeridas: (i) A interação entre essas camadas promove uma dopagem por parte do PSS segregado no P3HT que passa a conter cargas positivas, favorecendo apenas um sentido de injeção de lacunas. Tal hipótese foi mencionada por Huang et al [66], que ao realizar uma série de ensaios como espectroscopia e medidas por sonda de Kelvin, verificou que o P3HT reage com o PSS sob temperatura acima de $150{ }^{\circ} \mathrm{C}$ formando P3HT dopado tipo-p. Bange 105 também analisou a interação PEDOT:PSS - camada ativa e observou um aumento na barreira de injeção de lacunas como consequência de elétrons acumulados na camada de PSS segregado; (ii) O contato do polímero sobre metal não ocorre de maneira satisfatória. Esse comportamento foi investigado por Liu et. al. [104, cuja conclusão foi de que a presença de grupos laterais alquil em um contato polímero/metal resulta em um componente extra para a altura da barreira. Este componente adicional altera, negativamente, a eficiência da injeção de carga e subsequentemente, o desempenho global do dispositivo.

Desta forma, acredita-se ocorrer o melhoramento na morfologia do filme semicondutor, justificando o aumento na mobilidade na polarização 1. Ao mesmo tempo, a reação PSS-P3HT acontece 
e altera os níveis energéticos naquela interface, dificultado a injeção na polarização 2 .

\subsubsection{Sequência de annealing térmico 'B'}

Para a sequência de annealing $\mathrm{B}$, fez-se uso de uma amostra para cada temperatura, apenas do DO-2 (FTO/P3HT/PEDOT:PSS/Ag). Os tempos de exposição foram de 10 minutos para a primeira temperatura e 2 horas para a segunda, aguardando-se sempre o resfriamento para medição. A caracterização elétrica desta sequência encontra-se nas figuras 4.21 (a)-(d).

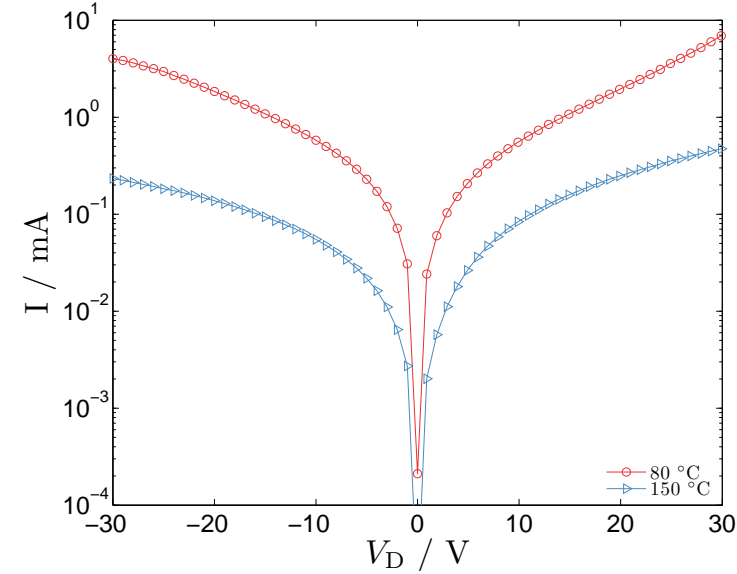

(a)

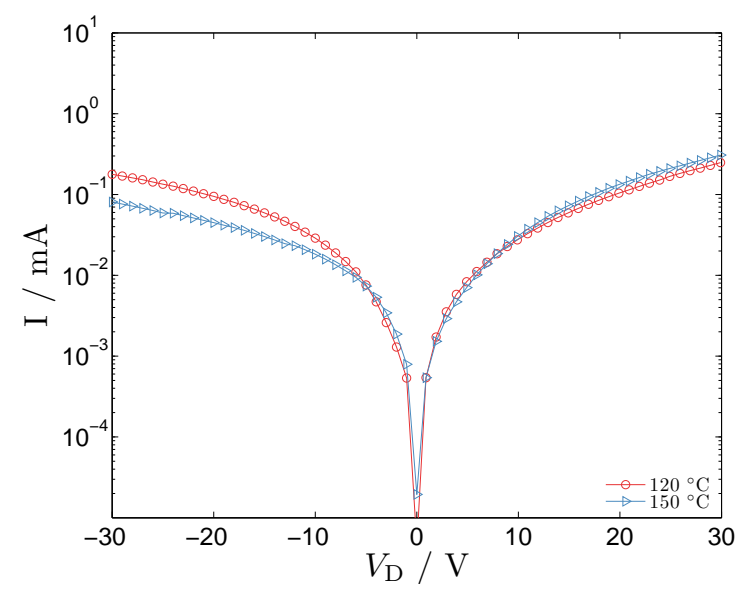

(c)

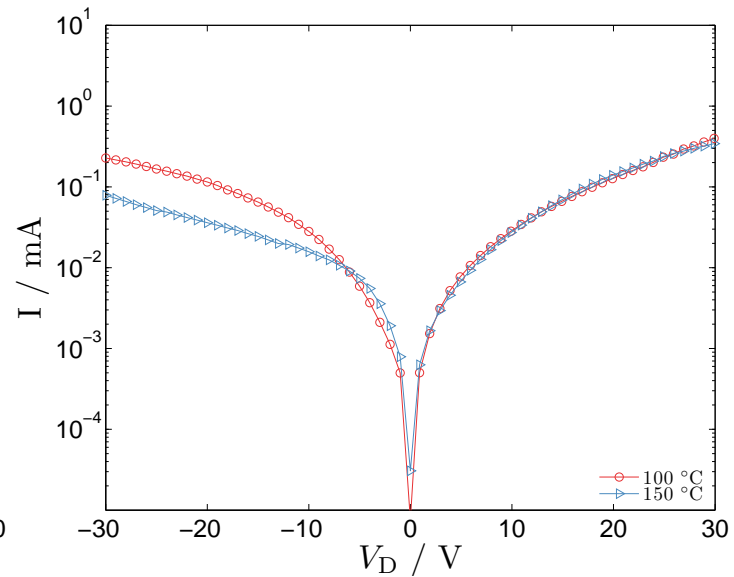

(b)

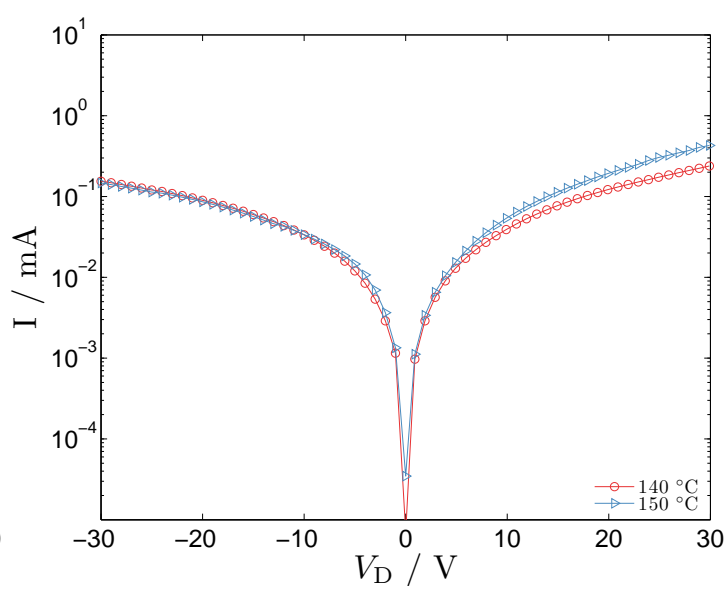

(d)

Figura 4.21: Caracterização elétrica de DO-2 (FTO/P3HT/PEDOT:PSS/Ag) para sequência de annealing $\mathrm{B}$ (a) 80 (10 minutos) $+150^{\circ} \mathrm{C}$ (2 horas) (b)100 (10 minutos) $+150^{\circ} \mathrm{C}$ (2 horas) (c) 120 (10 minutos $)+150^{\circ} \mathrm{C}(2$ horas $)$ (d) 140 (10 minutos $)+150{ }^{\circ} \mathrm{C}$ (2 horas).

Entre as temperaturas de 80 e $150^{\circ} \mathrm{C} 4.21$ (a), houve diminuição da condutividade pela eliminação de impurezas. A amostra tratada a $100{ }^{\circ} \mathrm{C} 4.21$ (b) ainda deve possuir água adsorvida, apresentando ligações mais fortes com o material, sendo eliminada a temperaturas mais altas. No experimento, apenas a polarização 2 diminui, evidenciando a reação na interface PSS-P3HT com elevação da corrente na polarização positiva que se sobrepõe a perda de água. De fato, ao 
analisarmos a 4.21 (c), quando a amostra é tratada a mais de $100{ }^{\circ} \mathrm{C}$ já não há água presente, logo não se observa diminuição de condutividade. A polarização negativa permanece quase estável e apenas em tensões positivas se vê aumento de corrente. Por fim, com anneling de 140 e 2 horas à $150{ }^{\circ} \mathrm{C}$ percebeu-se a elevação em ambas tensões positivas e negativas, em função da cristalização do P3HT. O tratamento térmico permite a migração termicamente induzida das cadeias de P3HT, surgimento de maiores agregados ou até mesmo maiores porções condensadas de múltiplas espécies de intercadeias [58]. Park [54] investigou os efeitos de tratamento térmico sobre a interface ouro-P3HT por meio de AFM, difração de raio-X e medidas elétricas, verificando que o tratamento aumenta a cristalinidade, pois induz a re-orientação e reduz a tensão residual envolvida durante o processamento. A resistência de contato reduz abruptamente, já que a probabilidade de que um átomo do eletrodo metálico penetre na superfície do filme semicondutor termicamente tratada, com uma maior densidade de empacotamento é menor do que para filmes não tratados.

\subsection{Tratamento térmico: análise quantitativa}

A análise quantitativa do tratamento térmico faz-se fundamental para a observação de outros fenômenos físicos presentes nos dispositivos, tais como mobilidade de portadores e dopagem não intencional. A figura 4.22 exibe as curvas $\mathrm{I}(\mathrm{V})$ de uma amostra tratada termicamente pela sequencia A de annealing, em escala semilogarítmica.

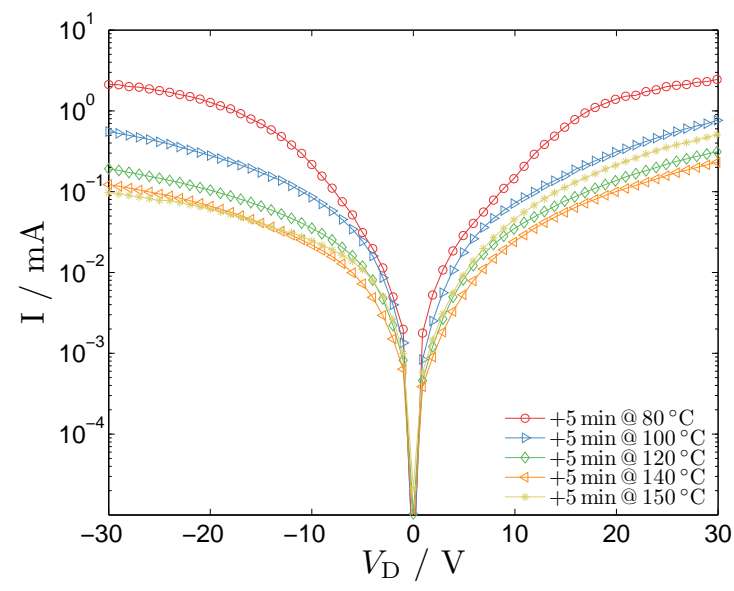

(a)

Figura 4.22: Caracterização elétrica de amostra DO-2 (FTO/P3HT/PEDOT:PSS/Ag), submetida à sequência $\mathrm{A}$ de annealing

O declínio nos níveis de corrente é notório até a penúltima etapa de annealing, entretanto, aumentam com temperatura de $150^{\circ} \mathrm{C}$. Este comportamento foi documentado pela primeira vez em 52 e interpretado como desdopagem da amostra, seguido de uma melhoria da cristalinidade do filme amorfo. Contudo, em nossas amostras a corrente só melhora quando injetado a partir da prata, mas não quando injetados a partir do FTO, o que não pode ser explicado apenas pela cristalinidade do P3HT. 


\begin{tabular}{|c|c|c|c|c|c|}
\hline$T_{\mathrm{An}}$ & $\alpha_{\mathrm{lb}}$ & $\alpha_{\mathrm{hb}}$ & $I_{\min } / \mu \mathrm{A}$ & $I_{\max } / \mathrm{mA}$ & $\mu / 10^{-3} \mathrm{~cm}^{2} \mathrm{~V}^{-1} \mathrm{~s}^{-1}$ \\
\hline $100^{\circ} \mathrm{C}$ & 0.941 & 2.19 & 0.101 & 0.772 & 22 \\
$120^{\circ} \mathrm{C}$ & 0.845 & 2.02 & 0.069 & 0.314 & 9.2 \\
$140^{\circ} \mathrm{C}$ & 0.768 & 2.04 & 0.070 & 0.234 & 6.4 \\
$150^{\circ} \mathrm{C}$ & 0.826 & 2.19 & 0.088 & 0.509 & 15 \\
\hline
\end{tabular}

Tabela 4.7: Variações das curvas $I(V)$ durante sequência A de annealing.

Por conseguinte, extraiu-se os parâmetros de TCAD para as últimas quatro etapas do tratamento térmico (tabela 4.7). Para todas as curvas $\mathrm{I}(\mathrm{V})$ analisadas, a abordagem de dois canais precisou ser aplicada. Curiosamente, a desdopagem não pôde ser modelada pela diminuição na densidade de carga negativa centradas nas cargas espaciais. Necessariamente, níveis de dopagem seriam tão altos que as cargas extrínsecas seriam dominantes sobre as lacunas injetadas e um expoente de tensão de quase 2 não poderia ser observado ao contrário das constatações experimentais. A $I_{\max }$ medida indica uma alteração na mobilidade.

Tomamos a diminuição da mobilidade durante desdopagem como uma indicação clara da dependência da mobilidade pela dopagem. O aumento da mobilidade no último passo de annealing não deve ser devido a dopagem, mas provavelmente, ao melhoramento na morfologia do P3HT, alcançando um maior rearranjo e alinhamento das cadeias.

Um aspecto relevante para a discussão, diz respeito a interação metal-semicondutor em função do annealing. O consenso é de que o tratamento térmico promove a formação de lamelas conjugadas auto orientadas do P3HT e a otimização do contato metal-semicondutor se faz presente, porém, trata-se de um efeito ainda pouco compreendido. Park [54] analisou o efeito do tratamento térmico sobre a resistência de contato e constatou que a orientação e ordenação dos filmes é alcançada com o annealing o que resulta numa notória diminuição na resistência de contato.

\subsubsection{Deposição do PEDOT:PSS por dip coater e spin coater}

A fim de se constatar a influência de menores espessuras da camada de PEDOT:PSS nas hipóteses sugeridas anteriormente, empregou-se as técnicas de dip coater e spin coater para a deposição do filme. O experimento consistiu em submeter um dispositivo DO-2 obtido por cada técnica, à sequencia A de annealing, descrita na seção 4.9.1. As figuras 4.23 (a)-(c) representam as curvas IV para cada técnica empregada, além de imersão (dip coating manual) para um comparativo. Os gráficos para tensões negativas encontram-se em anexo.

Em termos de baixas tensões negativas, constatou-se que apenas a técnica de imersão confere o efeito de sublinearidade, confirmando a hipótese de que tal comportamento se dá em função da maior espessura do filme, como discutido na subseção 4.8.4. Com o aumento da tensão aplicada, os métodos de spin coater e dip coater indicam inclinações maiores que 2, com corrente limitada por armadilhas, e apenas na técnica de imersão a corrente mostrou-se limitada por cargas espaciais. Interessante notar que, apenas nesse último método, o fenômeno de interação entre PSS e P3HT é 


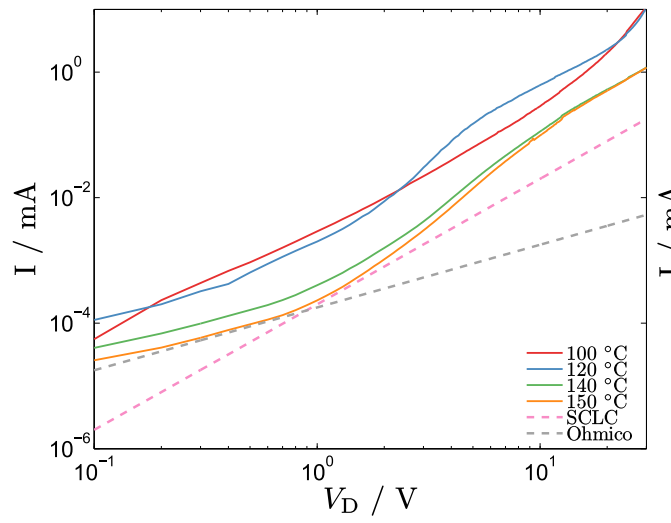

(a)

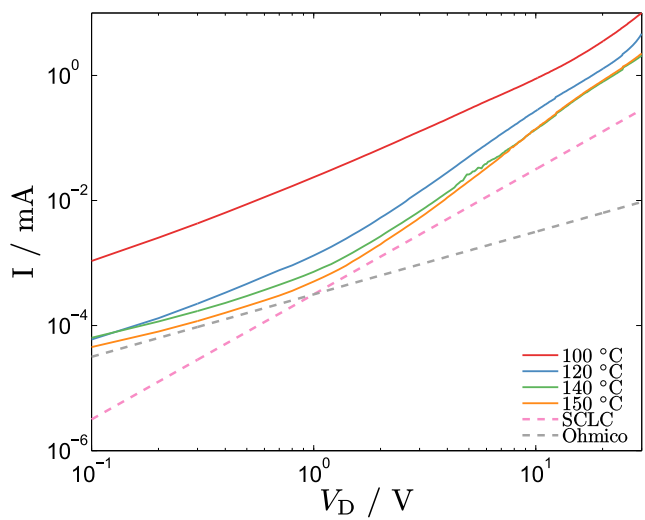

(b)

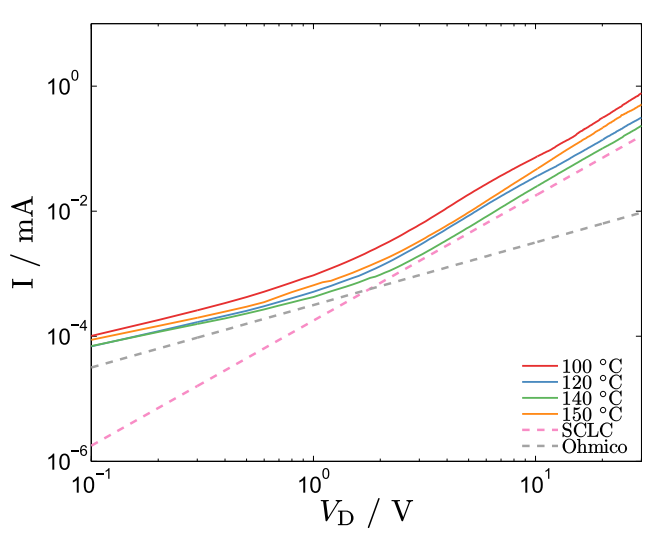

(c)

Figura 4.23: Caracterização elétrica de dispositivos submetidos à sequência de annealing A, onde a camada de PEDOT:PSS foi obtida por (a) Spin coater (b) Dip coater (c) Imersão. 
evidenciado pelo aumento da corrente entre temperaturas de 140 e $150^{\circ} \mathrm{C}$ e não pela cristalização, já que nas demais técnicas não foi observado.

No experimento realizado, diferentes técnicas de deposição conferem características distintas ao filme HTL, como por exemplo, espessura e orientação molecular, os quais refletem na segregação do PSS e na interação interfacial, respectivamente.

\subsection{Sob efeito do envelhecimento}

Algumas amostras submetidas à sequência de tratamento térmico A, foram analisadas pela óptica do envelhecimento, para tanto ficaram armazenadas sob atmosfera ambiente durante 3 dias. As figuras 4.24 (a)-(d) e a tabela 4.8 mostram a alteração das curvas I(V) durante o envelhecimento. As características elétricas se referem a última medida realizada no experimento de annealing e aos períodos de envelhecimento de um, dois e três dias.

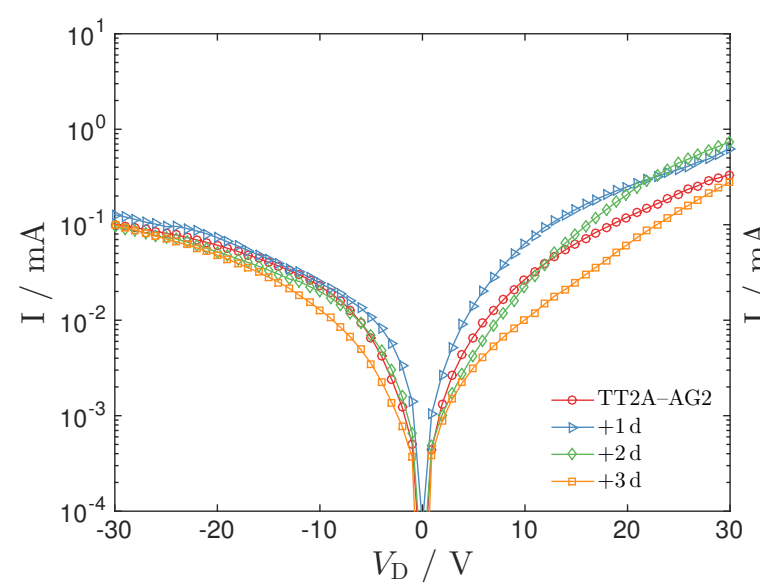

(a)

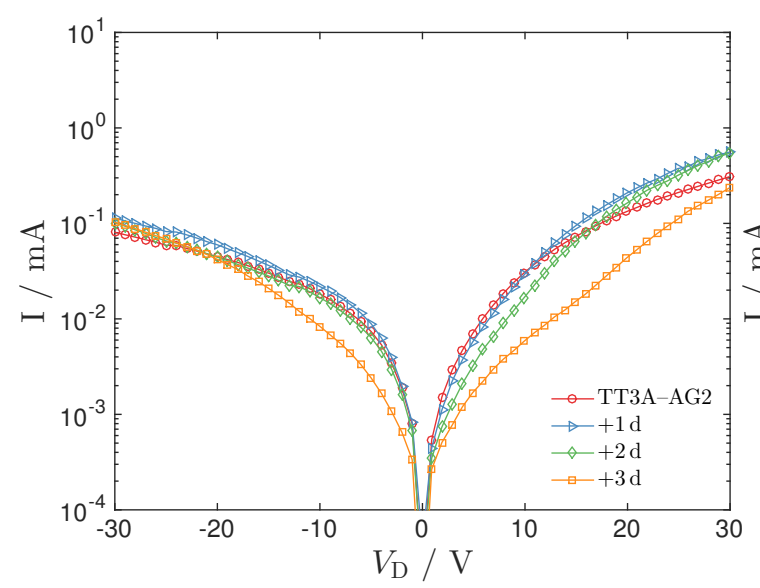

(c)

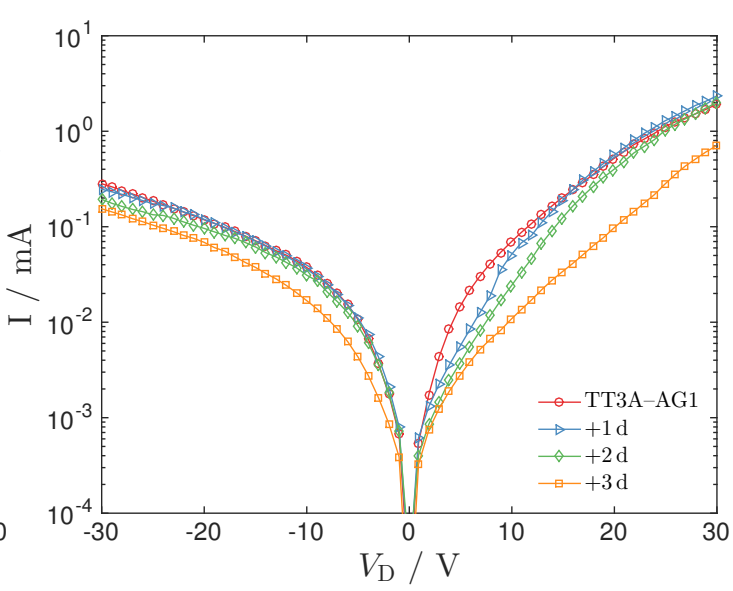

(b)

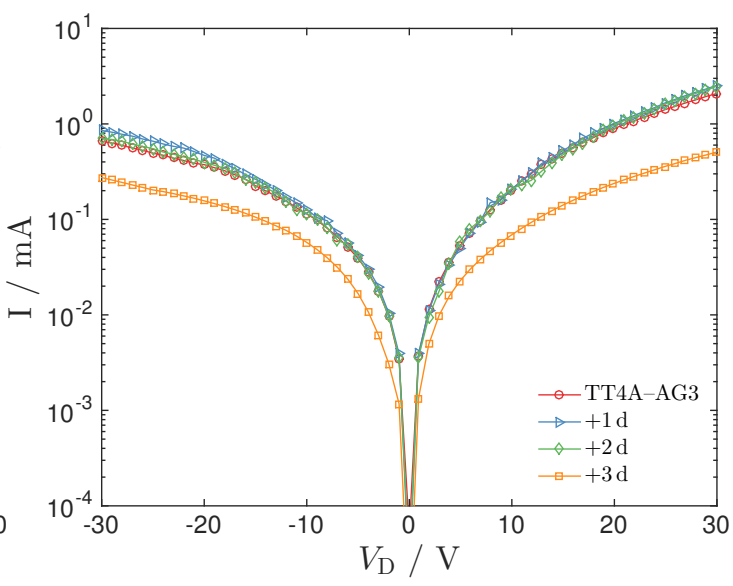

(d)

Figura 4.24: Curvas IV de amostras submetidas ao envelhecimento por 1, 2 e 3 dias

As amostras após a última medida de annealing, puderam ser modeladas por simulação difusãoderiva de maneira altamente consistentes, sem necessidade de separar dois canais de dopagem e 


\begin{tabular}{|c|c|c|c|c|}
\hline Envelhecimento & $\alpha_{\mathrm{lb}}$ & $\alpha_{\mathrm{hb}}$ & $I_{\min } / \mu A$ & $I_{\max } / \mathrm{mA}$ \\
\hline Dia 0 & 0.928 & 2.31 & 0.056 & 0.338 \\
Dia 1 & 0.981 & 1.96 & 0.124 & 0.628 \\
Dia 2 & 0.917 & 3.24 & 0.069 & 0.743 \\
Dia 3 & 0.860 & 3.12 & 0.056 & 0.279 \\
\hline
\end{tabular}

Tabela 4.8: Evolução nas características IV durante envelhecimento da amostra TT2A-Ag2 .

injeção. Essas curvas IV são similares àquelas mostradas na figura 4.16 .

Os canais de dopagem e injeção começam a se formar durante o envelhecimento devido a absorção de dopantes ou pela aplicação de repetidas rampas de tensão. Depois de um dia de envelhecimento, a densidade de dopagem aumentou de $N_{\mathrm{a}}=6 \times 10^{12} \mathrm{~cm}^{-3}$ para $N_{\mathrm{a}}=2 \times 10^{13} \mathrm{~cm}^{-3}$ e a extração de mobilidade de lacunas passou de $\mu=6.7 \times 10^{-3} \mathrm{~cm}^{2} / V s$ para $\mu=17 \times 10^{-3} \mathrm{~cm}^{2} / V s$. Depois de dois dias o expoente de tensão medido excede um valor de três implicando danos severos da amostra e uma corrente limitada pela presença de armadilhas. Como consequência $I_{\min }$ cai. $I_{\text {max }}$ continua a aumentar, provavelmente devido à absorção contínua de dopantes, como oxigênio e humidade, mas também começa a cair depois de três dias.

Ao realizar um monitoramento em tempo real das características elétricas do P3HT sob dopagem e de-dopagem de oxigênio, Liao 49 mostrou que ambos processos podem ocorrer em tempos desde minutos a até semanas. Tanto a adsorção quanto a dessorção são lentas, porém a temperatura e a luz aceleram o fenômeno. O processo de dopagem e de-dopagem é totalmente reversível, podendo ser realizado diversas vezes. Para Abdou [57, o oxigênio reage com o P3HT formando um fraco complexo de tranferência de carga. Tal complexo, tem grande influência na geração de portadores de cargas desses materiais, quando expostos ao ar, aumentando assim, a condutividade do polímero. Além disso, o grau de transferência de carga e a magnitude da formação de tais complexos, dependem do potencial de ionização e morfologia do material, assim sendo, polímeros com baixo potencial de ionização e natureza mais amorfa terão maiores chances de formar complexos de tranferência de carga na presença do ar.

Sabendo-se que esses dispositivos são sensíveis ao oxigênio e mais fortemente na presença de luz, em um processo reversível, é possível tirar proveito de tal característica, como por exemplo no desenvolvimento de fotodetectores à base de P3HT. Trabalho esse realizado por diversos pesquisadores dentre eles Ferrer [21].

\subsubsection{Análises de tendências}

No intuito de se fazer uma análise dos expoentes de todas as amostras desenvolvidas, tanto do grupo 1 quanto 2, submetidas à annealing e envelhecimento, plotou-se os gráficos relacionando expoentes em altas tensões negativas $\alpha_{\mathrm{hb}^{-}}$e baixas tensões positivas $\alpha_{\mathrm{lb}^{+}}$, bem como, altas tensões positivas $\alpha_{\mathrm{hb}^{+}}$e baixas tensões negativas $\alpha_{\mathrm{lb}^{-}}$. Os resultados para amostras de grupo $1,2 \mathrm{e}$ annealing após secagem e última etapa de tratamento térmico, encontram-se nas figuras 4.25 (a)- 
(d), ao passo que para amostras envelhecidas após secagem e ao término de 3 dias, nas figuras 4.26 (a)-(d). Os gráficos para cada etapa tanto de annealing quanto de envelhecimento encontram-se em anexo.

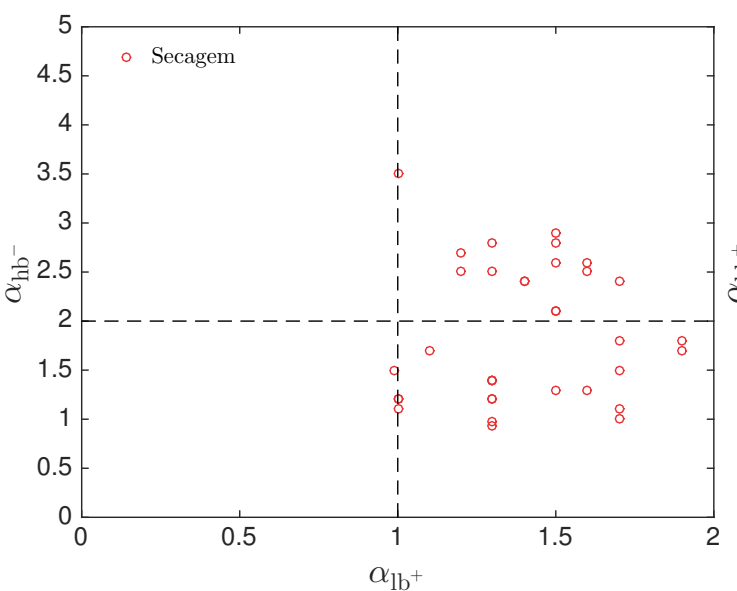

(a)

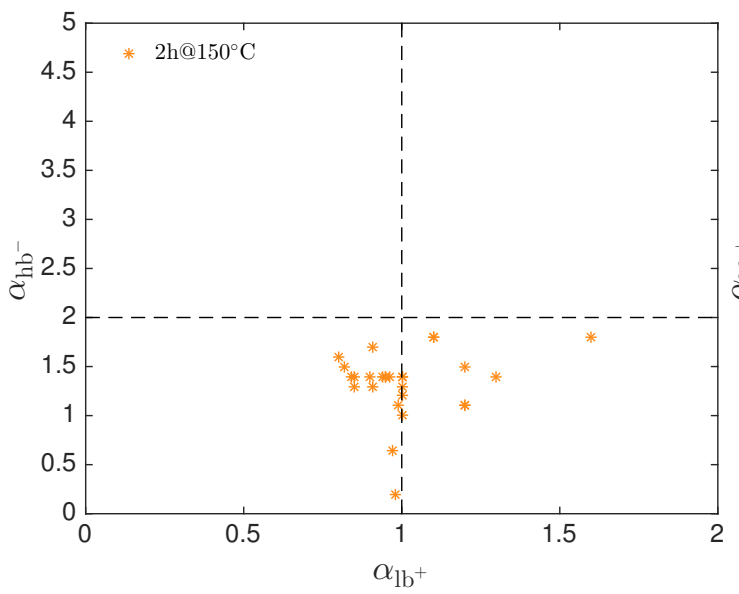

(c)

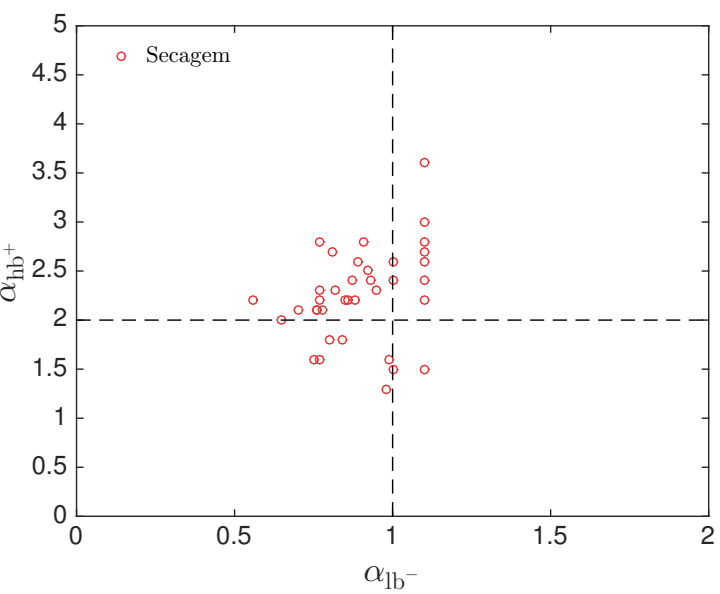

(b)

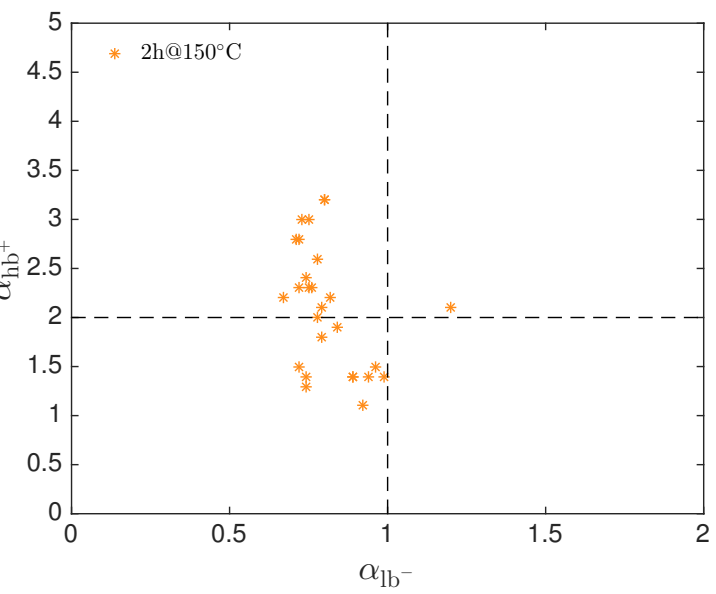

(d)

Figura 4.25: Gráficos de tendências de todas as amostras de grupo 1, 2 e annealing, relacionando expoentes obtidos para baixas e altas tensões em ambas polarizações, para amostras após secagem e após tratamento de $150^{\circ} \mathrm{C}$.

Com o aumento da temperatura, todos os expoentes em altas tensões negativas (figura ?? (c)) tornam-se menores que dois e em baixas tensões negativas (figura ?? (d)) apenas uma amostra não evidencia o comportamento sublinear. Em contrapartida, para altas tensões positivas algumas amostras com expoente em torno de dois migram para valores menores e em baixas tensões se aglomeram em torno de 1 com o annealing. Com relação ao comportamento sublinear, tais observações indicam as seguintes correlações: Polarização 1: $\mathrm{I}_{\text {Total }}=\alpha_{b t} \mathrm{I}_{\text {sublinear }}+\alpha_{a t} \mathrm{I}_{S C L C}$, onde $\alpha_{b t} \leq \alpha_{a t}$ e $\mathrm{V}_{b i}$ é menor. Ao passo que para a polarização 2: $\mathrm{I}_{\text {Total }}=\alpha_{b t} \mathrm{I}_{\text {sublinear }}+\alpha_{a t} \mathrm{I}_{S C L C}$, onde $\alpha_{b t}>\alpha_{a t}$ e $\mathrm{V}_{b i}$ é maior.

Após 3 dias sob o efeito do envelhecimento as amostras sob altas tensões negativas passam a exibir poucos expoentes de dois e em baixas tensões positivas, o efeito de sublinearidade não 


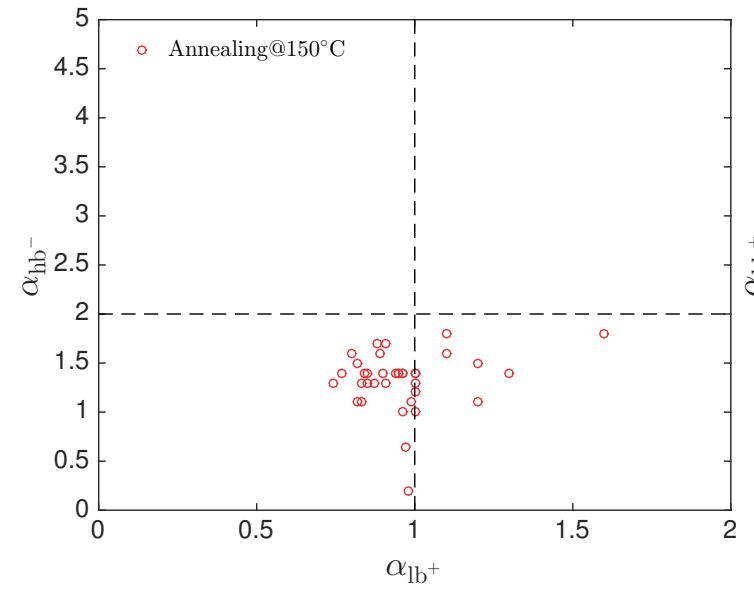

(a)

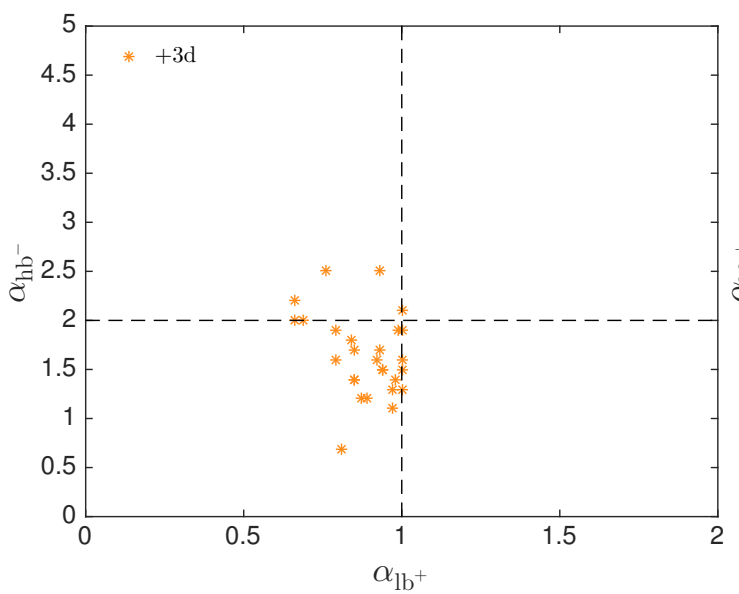

(c)

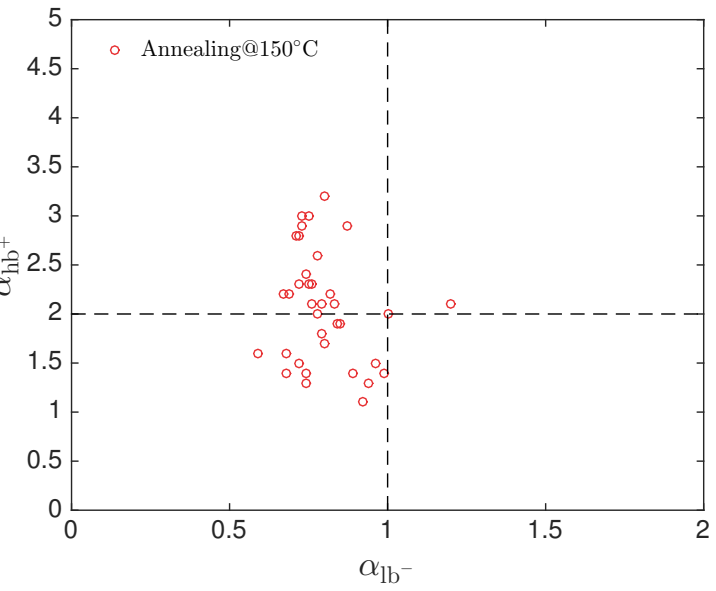

(b)

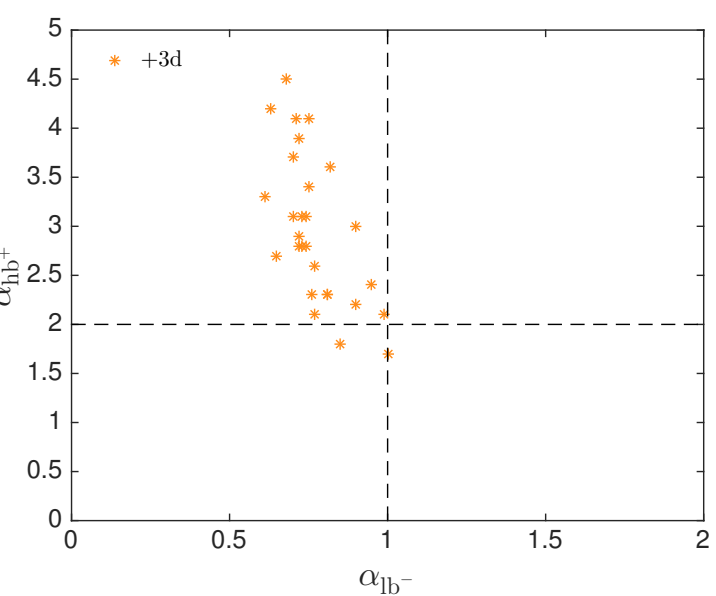

(d)

Figura 4.26: Gráficos de tendências de todas as amostras após envelhecimento, relacionando expoentes obtidos para baixas e altas tensões em ambas polarizações, para amostras após última etapa de annealing e após três dias. 
é alterado significativamente (figura ?? (c)). Porém, para altas tensões positivas notou-se um grande deslocamento de amostras com expoente maior que dois (figura ?? (d)), em consequência da profunda quantidade de armadilhas impostas pelo oxigênio, umidade, etc.

Para as tendências observadas, percebeu-se que tanto sob ação do tratamento térmico quanto sob envelhecimento, a polarização 2 de inclinações menores que 1, não sofreu mudança significativa, sugerindo um efeito de limitação pelo contato. Em contrapartida, na polarização 2 os expoentes variaram em função das condições ambientais impostas, em outras palavras, indicam limitação de injeção pelo filme polimérico.

\subsection{Dispositivos obtidos a partir de OB e OU}

No tocante aos óleos vegetais, respostas elétricas foram obtidas com filmes depositados por imersão (dip coating manual) na espessura ótima, visto que muito espessos tornam-se isolantes e muito finos acarretam curto-circuito. De posse do protocolo obtido empregando-se P3HT como camada ativa, pôde-se fazer um comparativo inicial dos óleos vegetais estudados. Para tanto, foram desenvolvidos os DO-1 e DO-2, cuja estrutura é a mesma usada para o polímero semicondutor, porém contendo os compósitos de OB/PS ou OU/PS como camada ativa. As figuras 4.27 (a) e (b), apresentam os resultados elétricos dos dispositivos contendo $47 \%$ dos óleos vegetais e a curva interna representa a mesma configuração para o diodo contendo P3HT.

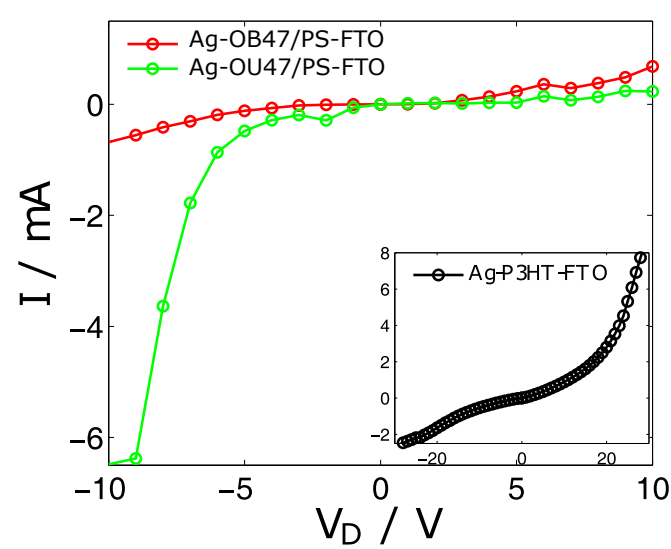

(a)

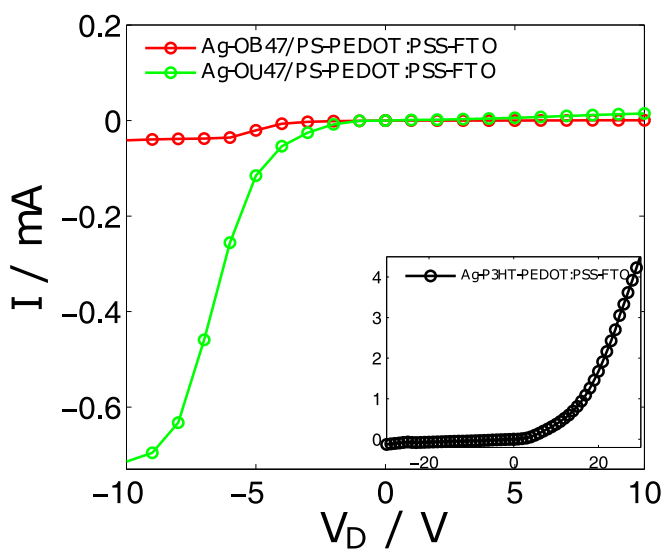

(b)

Figura 4.27: Características elétricas dos dispositivos à base de OB e OU (a) Na configuração de dispositivo tipo 1 (b) Na configuração de dispositivo tipo 2. A curva interna dos gráficos representa a resposta elétrica para a mesma configuração contendo P3HT, a título de comparação.

Em uma análise preliminar dos dispositivos à base de óleos vegetais, nota-se que os mesmos apresentam comportamentos opostos àqueles com P3HT, uma vez que têm preferência pela condução elétrica na polarização 2. Ocorreu, também, uma redução significativa nos níveis de correntes, como esperado, tendo em vista que, são materiais com elevada concentração de impurezas, portanto grande quantidade de armadilhas e baixa mobilidade. 
A observação isolada dos dispositivos tipo 1 - figura 4.27 (a) - evidencia uma maior condutividade em tensões negativas e praticamente nenhuma em tensões positivas, ao passo que, no P3HT o comportamento é exatamente o oposto. Comparando-se um óleo com relação ao outro, é nítida a maior condutividade por parte do OU. Já na configuração tipo 2, a condução elétrica para tensões positivas permanece bloqueada, e a injeção de cargas por parte do FTO-PEDOT:PSS não confere mudança significativa na condutividade, diferente do P3HT que experimenta um bloqueio de cargas com a adição do PEDOT:PSS. Uma vez que, os perfis de respostas elétricas entre DO-1 e DO-2 não diferem significativamente - ocorre apenas uma diminuição na corrente devido ao aumento da espessura com diminuição do campo elétrico - acredita-se haver uma maior barreira de injeção entre a prata e os compósitos dos óleos. Com base nos valores de LUMO e HOMO referenciados para o betacaroteno (tabela 4.9 ) e sabendo que as funções trabalho entre prata e FTO são aproximados, o transporte de cargas mais pronunciado em um sentido que em outro, não pode ser explicado pelos níveis energéticos dos compósitos, portanto, a maior corrente observada quando o FTO-PEDOT:PSS injeta cargas, pode se dar pelo surgimento de um filme adicional entre essas camadas, afetando positivamente a barreira de injeção.

\begin{tabular}{|c|c|c|c|c|c|}
\hline Substância química & HOMO $(\mathrm{eV})$ & LUMO $(\mathrm{eV})$ & Eg óptico $(\mathrm{eV})$ & $\mu_{\mathrm{h}}\left(\mathrm{cm}^{2} / \mathrm{Vs}\right)$ & $\left(\epsilon_{\mathrm{r}}\right)$ \\
\hline$\beta$ - Caroteno & 5.84 & 3.54 & 2.3 & $4 \times 10^{-} 4$ & 2.5 \\
\hline
\end{tabular}

Tabela 4.9: Níveis energéticos, mobilidade e permitividade do composto $\beta$ - Caroteno, obtidos através de fotoemissão 12 .

Tendo em vista que, o compósito de OU mostrou-se eletricamente melhor que a de OB, desenvolveu-se DO-2 com diferentes proporções daquele óleo, a saber: 28 e $34 \%$ além dos 47 já mencionados. As curvas IV encontram-se nas figuras 4.28 .

Nas amostras de $28 \%$ observou-se picos de corrente negativas, semelhantes à observadas na seção 4.6, provavelmente um efeito transiente decorrente de íons de impurezas. Comportamento interessante foi apresentado por amostras com 34\% de OU. Não apenas houve fluxo de carga na polarização 1 como também os perfis das curvas mostraram-se mais semelhantes aos obtidos com P3HT. Durães [91] acredita que, as diferentes proporções de óleo adicionam diferentes quantidades de estados dentro do gap energético da matriz, assim deve haver uma distribuição ótima do óleo dentro dos domínios da matriz polimérica, de modo a favorecer o fluxo de corrente entre os estados disponíveis ao longo do material isolante. Nesse caso, amostras com 34\% de OU parecem atingir a melhor relação dopante-matriz polimérica refletindo nas características mencionadas. De fato, a injeção de cargas pelo modelo SCLC foi observada, refletida na inclinação 2 da curva IV ( figura 4.28 e consequentemente foi possível calcular a mobilidade da ordem $10^{-} 5 \mathrm{~cm}^{2} / \mathrm{V} . \mathrm{s}$, para uma espessura de filme de $2 \mu \mathrm{m}$ medido no perfilometro. No entanto, vale salientar que essas características elétricas foram evidenciadas em poucas amostras, tornando a reprodutibilidade ainda um desafio. Ademais, a apreciação da figura 4.28 (d) evidencia elevação no expoente com aumento do óleo no compósito, em virtude de maior quantidade de armadilhas no filme.

Sendo assim, acredita-se que é necessário otimizar a preparação dos compósitos, como por exemplo, tratando termicamente os óleos para promover a transição entre a configuração cis e 


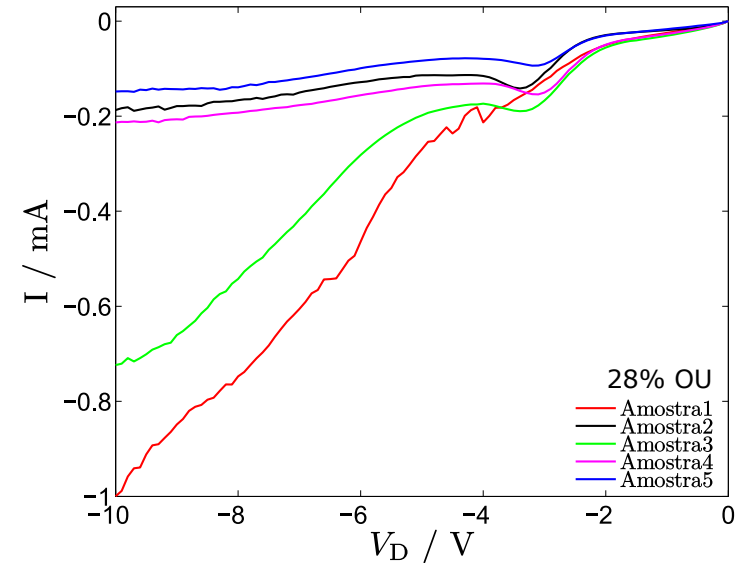

(a)

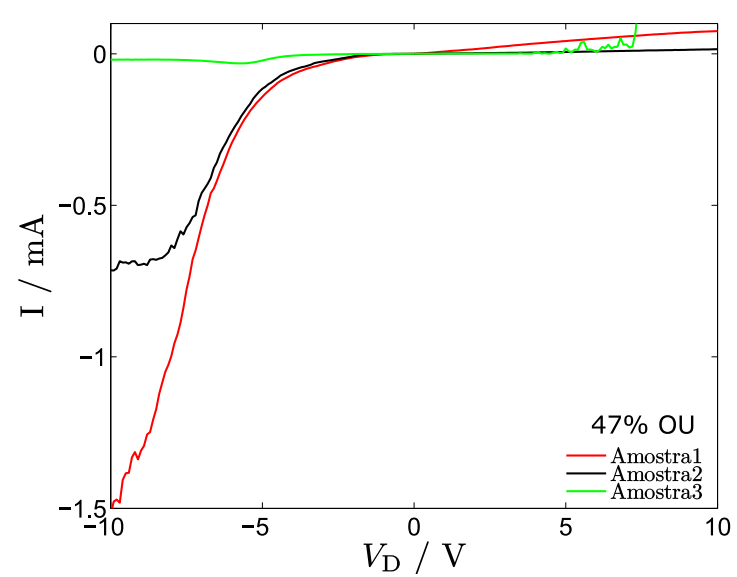

(c)

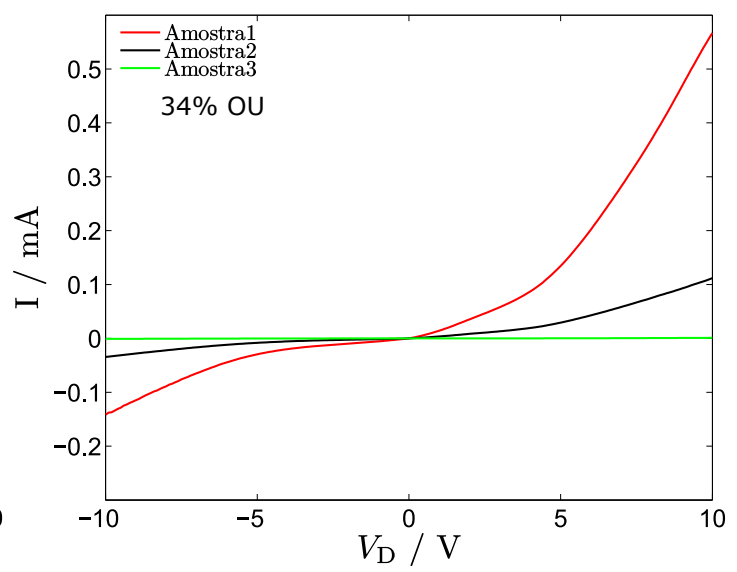

(b)

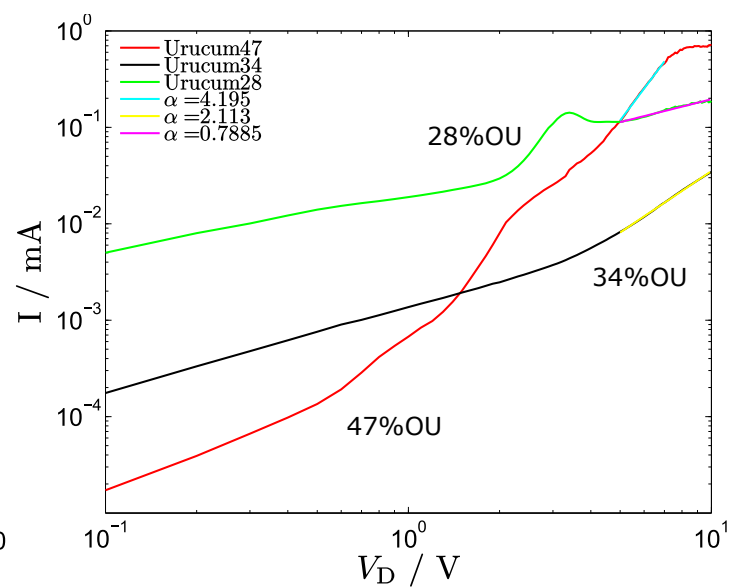

(d)

Figura 4.28: Curvas IV de amostras com diferentes proporções de OU na configuração tipo 2 (a) $28 \%$ (b) $34 \%$ (c) 47\% (d) Comparativo entre amostras 28, 34 e 47\% em escala dupla logarítmica 
trans, tornando-os mais estáveis. Além disso, a mobilidade por efeito de campo pode ser um método mais eficaz para extração de parâmetros elétricos em tais materiais.

\subsection{Resumo dos resultados alcançados}

1. Por meio de AFM verificou-se que a rugosidade do FTO é drasticamente reduzida pelo filme do PEDOT:PSS e o filme de P3HT promoveu menor diminuição na rugosidade do FTO, indicando que por si só, possui uma rugosidade razoável. Com auxílio do software ImageJ mediu-se as áreas dos contatos, cujo valor médio é de $0.014 \mathrm{~cm}^{2}$.

2. As resistências por quadrado dos filmes de FTO e ITO foram medidas com sucesso, no entanto, não foi possível obter essa característica para o filme de PEDOT:PSS.

3. Os resultados das amostras de grupo 1 indicaram:

- A investigação de diferentes substratos condutivos indicou a sequência de função trabalho da seguinte maneira: $\phi_{\mathrm{Al}}<\phi_{\mathrm{FTO}}<\phi_{\mathrm{ITO}}<\phi_{\mathrm{Au}}$, estando de acordo com a literatura. No entanto, para todos os substratos a injeção de cargas foi conseguida apenas para o dispositivo tipo 2 .

- As três interfaces identificadas no dispositivo tipo 2 correspondem à: forte depleção com barreira fina entre FTO-PEDOT:PSS, acumulação e depleção de maneira não uniforme entre FTO/PEDOT:PSS-P3HT e fraca acumulação P3HT- Prata. Porém, visto que a injeção de cargas por parte do FTO é dificultada, acredita-se que o PEDOT:PSS utilizado, não encontra-se dopado adequadamente, introduzindo uma maior barreira na polarização 2. Em consequência das funções trabalho dos eletrodos serem altos conseguindo injetar cargas apenas no HOMO dos polímeros, os portadores do dispositivo são apenas lacunas.

- Foram visualizados três perfis de histereses nas amostras. A presença de capacitância foi identificada em algumas medidas elétricas, caracterizadas por meio de picos de correntes negativas em baixas tensões positivas. Sugeriu-se duas formas para eliminá-las: aplicação de um protocolo cujo objetivo é descarregar as cargas acumuladas aplicandose $0 \mathrm{~V}$ por 5 minutos e o outro seria após aplicação de uma rampa positiva seguir com uma rampa negativa de menor valor e em seguida positiva novamente.

- Não ocorre espalhamento, significativo, no filme de P3HT quando a prata injeta cargas. Assim, o fluxo de portadores de carga atravessa os filmes poliméricos, a área ativa dos diodos estudados é aquela delimitada abaixo do contato de topo.

- Após a parametrização do SMU de medidas elétricas optou-se por utilizar o modo medium como padrão para realização das medidas elétricas, uma vez que este alia tempo de abertura nem tão curto quanto short nem tão longo quanto os OTs e ATs dos demais modos, permitindo medição de dados representativos e evitando degradação da amostra durante a aplicação da tensão. 
- A resistência de contato relacioanda à resistência por quadrado foi de $3.25 \mathrm{~K} \Omega \mathrm{cm}$ Relativamente baixa se comparada ao sílicio.

4. Os resultados das amostras de grupo 2 indicaram:

- Com a aplicação de uma maior temperatura na secagem das amostras houve eliminação de impurezas e identificação de injeção de cargas com níveis de correntes coerentes para estes dispositivos. Os resultados obtidos na polarização 1 indicam limitações de injeção pelo corpo do polímero, enquanto que na polarização 2, o contato é responsável por esse efeito. Para o modelo TCAD de simulação desenvolvido para o perfil de polarização 1, adicionou-se dopagem não intencional na tentativa de obter os níveis de correntes experimentais em baixas tensões. Os valores de densidade de dopagem não intencional pôde ser determinada e é da ordem de $10^{13} \mathrm{~cm}^{-3}$. E as mobilidades extraídas são na faixa de $10^{-3} \mathrm{~cm}^{2} / V s$ e $10^{-2} \mathrm{~cm}^{2} / V s$, como esperado para P3HT.

- Observou-se o fenômeno de sublinearidade em baixas tensões, indicando uma corrente limitada pelo contato de injeção. A característica elétrica do dispositivo pôde ser explicado como a soma de duas correntes possivelmente resultantes de dois canais de condução paralelos. Os dois caminhos de correntes seriam caracterizados por diferentes densidades e / ou mobilidades de dopagem e seriam limitados por um campo elétrico ou um gradiente de lacuna oposto, respectivamente. Contudo, a origem dos dois canais paralelos permanece obscura. Pode-se especular, que a dopagem por si só não seria uniforme, formando canais condutores sinuosos através do filme ou caminhos de fuga presentes no material que levariam a canais de elevada dopagem/mobilidade quando várias varreduras de tensão são aplicadas.

5. As sequências de annealing aplicadas indicaram diminuição dos níveis de corrente até uma temperatura de $140^{\circ} \mathrm{C}$, em virtude da eliminação de impurezas. Entre esta temperatura e a de $150^{\circ} \mathrm{C}$ houve um aumento da corrente apenas na polarização 1, cujas hipóteses sugeridas, embasadas na literatura, são: dopagem por parte do PSS segregado no P3HT ou o contato do polímero sobre metal não ocorre de maneira satisfatória. Os parâmetros de TCAD utilizaram abordagem de dois canais para as últimas quatro etapas do tratamento térmico.

6. As amostras envelhecidas foram modeladas de maneira altamente consistente, sem necessidade de separar dois canais de dopagem e injeção. Depois de dois dias o expoente de tensão medido excede um valor de três implicando danos severos da amostra e uma corrente limitada pela presença de armadilhas. Como consequência $I_{\min }$ cai. $I_{\max }$ continua a aumentar, provavelmente devido à absorção contínua de dopantes, como oxigênio e humidade, mas também começa a cair depois de três dias.

7. Os dispositivos à base de óleos vegetais apresentam comportamentos opostos àqueles com P3HT, uma vez que têm preferência pela condução elétrica na polarização 2. Existem, também, uma redução significativa nos níveis de correntes. A observação isolada das amostras tipo 1 evidenciam uma maior condutividade em tensões negativas, ao passo que, no P3HT essa polarização é dificultada. Ao compararmos as amostras contendo Buriti e Urucum, 
esta conduz, consideravelmente, mais do que aquela. Já na configuração tipo 2, a condução elétrica para tensões positivas parecem ser bloqueada, e a injeção de cargas por parte do FTO-PEDOT não confere mudança significativa na condutividade. A injeção de cargas pelo modelo SCLC foi observado nas amostras com teores de $34 \%$ de OU com mobilidade da ordem $10^{-} 5 \mathrm{~cm}^{2} / \mathrm{V} . \mathrm{s}$. 


\section{Capítulo 5}

\section{Conclusões}

As análises do presente trabalho começaram por investigar características corrente-tensão de amostras $\mathrm{M}(0) / \mathrm{P} 3 \mathrm{HT} / \mathrm{Ag}(\mathrm{V})$ empregando diferentes metais $\mathrm{M}$, no qual verificou-se que um metalon-polímero (MOP) obtido pela aplicação de pasta de prata exibe uma capacidade de injeção de carga semelhante ou até melhor que substratos de óxido de estanho dopado com índio (ITO) ou flúor (FTO). A injeção de cargas através do contato polímero-sobre-metal (POM) foi melhorado pelo emprego de uma camada de transporte lacuna de (PEDOT: PSS). Dezenas de amostras constituídas por camadas de filmes orgânicos empilhados FTO(0)/PEDOT:PSS/P3HT/Ag(V) foram fabricados no presente estudo. As amostras foram polarizadas positiva e negativamente, permitindo uma comparação direta da injeção de lacunas através da interface (Ag/P3HT) e da heterojunção orgânica (PEDOT:PSS/P3HT) em atmosfera ambiente. A resistência por quadrado dos filmes de PEDOT:PSS depositados mostrou-se muito elevada, porém, o significante espalhamento de corrente dentro do filme P3HT pode ser excluído e a área ativa do dispositivo é basicamente determinada pela área de contato MOP. As amostras fabricadas demonstraram uma alta variabilidade com relação ao comportamento elétrico.

Efeitos de histerese confirmam a presença de armadilhas de lacunas. Acredita-se que a população de cargas móveis e fixas na amostra pode ser conduzida para fora do equilíbrio por varreduras de tensão com velocidades superiores a $5 \mathrm{~V} / \mathrm{s}$. Impurezas carregadas como íons promovem efeitos de histerese adicionais e deslocamento de correntes negativas em tensões baixas. Este último pode ser removido por ligação à terra da amostra durante alguns minutos antes da medição elétrica. Amostras tratadas termicamente demonstraram correntes limitadas por cargas espaciais (SCLC) em tensões relativamente altas . Uma comparação entre as características IV medidas e as simulações numéricas, que resolveram equações diferencias não-lineares de Poisson e equações diferenciais deriva-difusão (DD), permitiu extrair a mobilidade efetiva e densidades de dopantes não intencionais. Os valores de mobilidade de lacunas foi $10^{-3}$ a $10^{-2} \mathrm{~cm}^{2} /$ Vs como esperado para P3HT. A densidade de dopantes não intencionais foi $10^{13} \mathrm{~cm}^{-3}$, bem acima da densidade de portadores de carga intrínseca, mas ainda surpreendentemente baixos. Curiosamente, o comportamento em baixas tensões não pôde ser sempre descrito como corrente de fuga causada pela corrente de deriva das lacunas intrínsecas e dopadas. Em vez disso, observou-se um aumento da corrente sublinear com a tensão. Argumentou-se que esse efeito se deve à correntes de deriva opostas a um gradiente 
positivo de lacunas no contato extrator de corrente e analisou-se a ideia por meio de simulações DD. A presença simultânea de sublinearidade e o comportamento SCLC indicam uma camada interfacial PEDOT:PSS/P3HT não uniforme, possivelmente causada por segregação do PSS. Que por sua vez, pode também explicar a inferior injeção de carga pela heterojunção orgânica em detrimento da $\mathrm{Ag} / \mathrm{P} 3 \mathrm{HT}$. Curiosamente, a característica $\mathrm{I}(\mathrm{V})$ depende da técnica de deposição de PEDOT: PSS e correntes sublineares só podem ser observados para filmes espessos.

O Annealing promoveu uma diminuição nos níveis de corrente devido a de-dopagem da amostra. Uma vez que as curvas IV foram medidas após resfriamento até à temperatura ambiente, o que leva alguns minutos, a desdopagem é provavelmente causada não pela eliminação dos contaminantes mas por elétrons desarmadilhados e sucessivas recombinações com lacunas móveis. A uma temperatura de annealing de $150^{\circ} \mathrm{C}$ observou-se um aumento de condutividade, no entanto, apenas quando a injeção de cargas se dá entre a interface Ag / P3HT. Uma melhoria geral da morfologia do semicondutor aliada ao efeito de interação PSS-P3HT é atribuído ao efeito. O envelhecimento leva a dopagem por lacunas e armadilhas. Durante os dois primeiros dias de envelhecimento os níveis de correntes aumentam devido a um aumento do número de lacunas móveis. Expoentes de tensão aumentaram indicando a presença reforçada de armadilhas profundas de lacunas, as quais alteram o comportamento em altas tensões de correntes limitadas por cargas espaciais para limitadas por armadilhas. Em amostras mais antigas a corrente diminui rapidamente.

Finalmente, injeção de cargas em filmes plastificados de Buriti e Urucum através da heterojunção com PEDOT:PSS é superior a injeção de cargas na interface com a prata. Esta descoberta é contrária ao comportamento dos filmes de P3HT, o que indica uma mudança nas funções trabalho dos contatos injetores de carga, devido à formação de camadas interfaciais.

\subsection{Trabalhos futuros}

O presente trabalho promoveu um progresso no estudo de materiais verdes com aplicação eletrônica. Porém algumas melhorias em técnicas de processamento, ainda podem ser realizados para otimizar a injeção de carga e elucidar ainda mais os efeitos degradativos observados:

- Influência de tratamentos térmicos sobre a função trabalho do PEDOT:PSS, medindo-se o gap no espectro de absorção ultravioleta e visível (UV-Vis);

- Submeter filmes de PEDOT:PSS à sputtering, verificando-se o efeito sobre a função trabalho e as características IV dos dispositivos.

- Analisar a morfologia, espessura e características ópticas dos filmes de P3HT sob ação de annealing, bem como a interação metal-semicondutor do dispositivo;

- Acompanhar os perfis de histerese de dispositivos tipo 2 em função de tratamento térmico;

- Realizar tratamento por solvente, pois acredita-se que esse método facilita o crescimento de um filme mais cristalino; 
- Obter soluções semicondutoras com solventes de diferentes pontos de ebulição investigando os efeitos de vacâncias geradas;

- Realizar medidas elétricas de amostras com e sem iluminação;

- Com relação aos óleos vegetais, promover um tratamento térmico para transição entre as configurações cis e trans, tornando-os mais estáveis e provavelmente com melhores respostas elétricas;

- Testar diferentes proporções do óleo de Urucum quanto as respostas elétricas acompanhando a morfologia e espectroscopia de absorção.

Interessante ainda, faz-se o estudo dos materiais verdes sob a óptica do efeito de campo, visto que constitui-se em um método mas eficaz para extração de parâmetros elétricos dos materiais. 


\section{REFERÊNCIAS BIBLIOGRÁFICAS}

[1] FIER, I. Estudo de propriedades elétricas em sistemas orgânicos e inorgânicos correlacionados. Tese (Doutorado) — Universidade estadual Paulista Julio de Mesquita Filho, 2012.

[2] SOUZA, J. F. P. Transporte de cargas em polímeros semicondutores para aplicacao em dispositivos fotovoltaicos. Tese (Doutorado) — Universidade Federal do Paraná, 2014.

[3] COUTINHO, D. J. Estudos sobre fotogeração, efeitos de interfaces e de transporte de portadores em células solares orgânicas. Tese (Doutorado) - Universidade de São Paulo, 2015.

[4] ROTH, S. et al. One-Dimensional Metals. [S.l.: s.n.], 2004.

[5] TONIOLO, R. Método de Encapsulamento de Dispositivos Orgânicos Usando o Polímero Poliisobuteno e Dispositivos Chaveadores Feitos em Geometria de Contatos Co-Planares. Tese (Tese de Doutorado) — Universidade de Federal do Paraná, 2005.

[6] HWANG, J.; WAN, A.; KAHAN, A. Energetics of metal-organic interfaces: New experiments and assessment of the field. Materials Science and Engineering R, v. 64, p. 1-31, 2009.

[7] KIRCHARTZ, T. Influence of diffusion on space-charge-limited current measurements in organic semiconductors. Beilstain J. Nanotechnol, v. 4, p. 180-188, 2013.

[8] LIM, J. A. et al. Polymer semiconductor crystals. Materials Today, v. 13, n. 5, p. 14-24, 2010.

[9] DIAH, A. W. M. et al. Investigation of the doping efficiency of poly(styrene sulfonic acid) in poly(3,4-ethylenedioxythiophene)/poly(styrene sulfonic acid) dispersions by capillary electrophoresis. Electrophoresis, v. 35, 2014.

[10] JORGENSEN, M.; NORRMAN, K.; KREBS, F. C. Stability / degradation of polymer solar cells. Solar Energy Materials and Solar Cells, v. 92, p. 686-714, 2008.

[11] HWANG, J.; AMY, F.; KAHN, A. Spectroscopic study on sputtered PEDOT-PSS : Role of surface PSS layer. Organic Electronics, v. 7, p. 387-396, 2006.

[12] GLOWACKI, E. et al. Natural and nature inspired semiconductors for organic electronics. The International Society for Optical Engineering, n. September, p. 0-10, 2011.

[13] RAMANA, C. V. V.; MOODLEY, M. K.; KANNAN, V. Electrical characteristics of ITO / MEH-PPV / ZnO / Al structure. Nanoscience and Nanotechnology Letters, v. 5, p. 1-5, 2014. 
[14] SAKKOPOULOS, S. et al. Thermal degradation mechanisms of PEDOT : PSS. Organic Electronics, v. 10, p. 61-66, 2009.

[15] MOIZ, S. A.; AHMED, M. M.; KARIMOV, K. S. Estimation of Electrical Parameters of OD Organic Semiconductor Diode from Measured I-V Characteristics. ETRI Journal, v. 27, n. 3, p. 319-325, 2005.

[16] PARNELL, A. J. et al. Physical Mechanisms Responsible for the Water-Induced Degradation of PCBM P3HT Photovoltaic Thin Films. Journal of polymer science, v. 54, p. 141-146, 2016.

[17] MOIZ, S. A. et al. Space charge limited current- voltage characteristics of organic semiconductor diode fabricated at various gravity conditions. Synthetic Metals, v. 159, p. 1336-1339, 2009.

[18] NASIRI, M.; ABBASI, F.; MOGHADDAM, M. K. Materials Science in Semiconductor Processing Effects of exciton blocking layer and cathode electrode work function on the performance of polymer solar cells. Materials Science in Semiconductor Processing, Elsevier, v. 40, p. 218$223,2015$.

[19] QU, S. et al. The Influence of Molecular Configuration on the Thermoelectrical Properties of Poly ( 3-hexylthiophene ). Polymer Chemistry, v. 45, n. 3, p. 1389-1396, 2016.

[20] GU, Z. et al. Annealing Effect on Performance and Morphology of Photovoltaic Devices Based on Poly ( 3-hexylthiophene )-Poly ( ethylene oxide ). Journal of Polymer Chemistry, v. 49, p. 2645-2652, 2011.

[21] FERRER, J. C. et al. Electrical Characterization of Photodetectors Based on Poly(3hexylthiophene-2,5-diyl) Layers. Sensors, v. 14, p. 4484-4494, 2014.

[22] SANTOS, J. C. B. Estudo de camadas transportadoras de cargas em diodos emissores de luz poliméricos. Tese (Doutorado) — Universidade de São Paulo, 2007.

[23] LIAO, B.-h. et al. Fluorine-doped tin oxide films grown by pulsed direct current magnetron sputtering with an Sn target. Applied Optics, v. 50, n. 9, p. 106-110, 2011.

[24] IRIMIA-VLADU, M. Green electronics: biodegradable and biocompatible materials and devices for sustainable future. Chem. Soc. Rev., v. 43, n. 2, 2014.

[25] MUHL, S.; BEYER, B. the Future. Electronics, v. 3, p. 444-461, 2014.

[26] IRIMIA-VLADU, M. et al. Green and biodegradable electronics. Materials Today, Elsevier Ltd, v. 15, n. 7-8, p. 340-346, 2012.

[27] SOUZA, E. M. P. de; FARIA, L. J. G. de. Extração e estabilidade do corante de Urucum em base cosmética. Revista Brasileira de Produtos Agroindustriais, v. 16, n. 2, p. 195-204, 2014.

[28] ALBUQUERQUE, M. L. S. et al. Infrared absorption spectra of Buriti ( Mauritia flexuosa L .) oil. Vibrational Spectroscopy, v. 33, p. 127-131, 2003. 
[29] MUSKOviCH, M.; BetTingeR, C. J. Biomaterials Based Electronics: Polymers and Interfaces for Biology and medicine. Adv. Healthc. Mater, v. 1, n. 3, p. 248-266, 2013.

[30] BURCH, R. R. et al. Electrical properties of polyunsaturated natural products : field effect mobility of carotenoid polyenes. Synthetic Metals, v. 146, p. 43-46, 2004.

[31] HARYANTO, D. A.; LANDUMA, S.; PURWANTO, A. Fabrication of Dye - sensitized Solar Cell ( DSSC ) Using Annato Seeds ( Bixa orellana Linn ). AIP Conference Proccedings, v. 104, n. February 2014, 2016.

[32] IRIMIA-VLADU, M. et al. Environmentally sustainable organic field effect transistors. Organic Electronics, Elsevier B.V., v. 11, n. 12, p. 1974-1990, 2010.

[33] DURÃES, J. A.; SALES, M. J. A. Observation of negative differential resistance and hysteretic effect on buriti oil: polystyrene organic devices. Applied Physics Letters, v. 89, p. 13-15, 2006.

[34] PRASAD, S. S.; KUMAR, C. A Green and Reliable Internet of Things. Communication and network, v. 5, p. 44-48, 2013.

[35] GRANVILle, L. Z. Computação. Revista da Sociedade Brasileira de computação, v. 29, p. $1-58,2015$.

[36] ROCHA-FILHO, R. C. Nobel 2000 Descoberta e Aplicações. Atualidades em Química, 2000.

[37] PADILlA, R. M. A. Estudo de Transporte de Carga de Polímeros de Polianilina. Tese (Dissertação de Mestrado) — Pontifícia Universidade Católica do Rio de Janeiro, 2011.

[38] CANESTRARO, C. D. Dispositivos fotovoltaicos orgânicos: estudo de camadas ativas e eletrodos. Tese (Doutorado) — Universidade Federal do Paraná, 2010.

[39] SAlVATIERRA, R. V. Filmes Finos de Polímeros Conjugados e Nanoestruturas de Carbono obtidos em Interfaces Líquido-Líquido: Síntese, caracterização e aplicação em dispositivos fotovoltaicos. Tese (Doutorado) — Universidade Federal do Paraná, 2014.

[40] CAVALlaRI, M. R. Filmes de P3HT para transistores de filmes finos orgânicos utilizados como sensores. Tese (Doutorado) - Universidade de São Paulo, 2014.

[41] SILVA, H. S. Transporte eletrônico em sistemas semicondutores orgânicos emissores de luz. Tese (Doutorado) - Universidade Federal de Uberlandia, 2012.

[42] QUEIROZ, E. L. Estudos das propriedades elétricas de diodos poliméricos com eletrodo injetor à base de óxido de zinco. Tese (Tese de Doutorado) — Universidade de São Paulo, 2008.

[43] SILVA, P. P. B. Célula fotovoltaica orgânica de heterojunção de P3HT e N2200: preparação e caracterização. Tese (Dissertação de mestrado) - Universidade de Brasília, 2016.

[44] ANTONI, L. O. Nanopartículas de Ouro Empregadas no Desenvolvimento de Célula Solar Orgânica de Alta Eficiência. Tese (Doutorado) - Universidade Federal do Rio Grande do Sul, 2012. 
[45] MARK, P.; HELFRICH, W. Space-charge-limited currents in organic crystals. Journal of Applied Physics, v. 33, n. 1, p. 205-2015, 1962.

[46] KUMAR, P. et al. Current-voltage characteristics of an organic diode: Revisited. Synthetic Metals, v. 157, p. 905-909, 2007.

[47] NICOLAI, H. et al. Unification of trap-limited electron transport in semiconducting polymers. Nature Materials, v. 11, p. 882-887, 2012.

[48] HWANG, H.; KAO, K. A unified approach to the theory of current injection in solids with traps uniformly and non-uniformly distributed in space and in energy, and size effects in anthracene films. Solid-State Electronics, v. 15, p. 523-529, 1972.

[49] LIAO, H.-h. et al. Dynamics and reversibility of oxygen doping and de-doping for conjugated polymer. Journal of Applied Physics, v. 103, p. 1-8, 2008.

[50] HO, V.; BOUdOURIS, B. W.; SEGAlman, R. A. Tuning Polythiophene Crystallization through Systematic Side Chain Functionalization. Macromolecules, v. 43, p. 7895-7899, 2010.

[51] DEROUICHE, H.; MOHAMED, A. B. Thermal Annealing Effect on Poly ( 3-hexylthiophene ): Fullerene: Copper-Phthalocyanine Ternary Photoactive Layer. The Scientific World Journal, v. 2013, p. 1-6, 2013.

[52] CHIGUVARE, Z. Influence of Thermal Annealing on the Electrical Properties of Poly (3hexylthiophene ) -Based Thin Film Diodes. p. 609-619, 2007.

[53] RODRIGUES, A. et al. Thermal stability of P3HT and P3HT : PCBM blends in the molten state. Polymer Testing, v. 32, n. 7, p. 1192-1201, 2013.

[54] PARK, Y. D. The Molecular Structures of Poly ( 3-hexylthiophene ) Films Determine the Contact Properties at the Electrode/ Semiconductor Interface. Bull. Korean Chem., v. 35, n. 8, p. 2277-2280, 2014.

[55] CHENG, H.-l. et al. Effects of solvents and vacancies on the electrical hysteresis characteristics in regioregular poly (3-hexylthiophene) organic thin-film transistors. Applied Physics Letters, v. 94 , p. $92-95,2009$.

[56] BOUdouris, B. W.; FRISBIE, C. D.; HILlmyeR, M. A. Nanoporous Poly ( 3alkylthiophene ) Thin Films Generated from Block Copolymer Templates. Mac, p. 67-75, 2008.

[57] ABDOU, M. S. A. et al. Interaction of Oxygen with Conjugated Polymers: Charge Transfer Complex Formation with Poly(3-alkylthiophenes). J. Am. Chem. Soc, v. 119, n. 7, p. 4518-4524, 1997.

[58] KIM, H.; SO, W.-w.; MOON, S.-j. Effect of Thermal Annealing on the Performance of P3HT / PCBM Polymer Photovoltaic Cells. Journal of the Korean Physical Society, v. 48, n. 3, p. 441-445, 2006. 
[59] ELSENBAUMER, R. L. et al. Poly (alkyl thiophenes) and Poly (substituted heteroaromatic vinylenes): Versatile, Highly Conductive, Processible Polymers with Tunable Properties. Electronic Properties of Conjugated Polymers, 1987.

[60] POELKING, C. et al. Morphology and Charge Transport in P3HT : A Theorist' s Perspective. Adv. Polym. Sci, 2014.

[61] MARSH, R. A. et al. Effect of Annealing on P3HT : PCBM Charge Transfer and Nanoscale Morphology Probed by Ultrafast Spectroscopy. Nanoletters, v. 10, p. 923-930, 2010.

[62] MCPHERSON, T. E. Characterizing the Morphology of Solvent Annealed PCBM- P3HT Bilayers using GIXRD and Raman Spectroscopy. Tese (Doutorado) - University of Tennessee, 2014.

[63] MACIEL, A. C. Fabricação e estudo das propriedades de transporte de transistores de filmes finos orgânicos. Tese (Doutorado) — Universidade de São Paulo, 2012.

[64] ZHAO, Y. et al. A calorimetric study of the phase transitions in poly(3-hexylthiophene). Polymer, v. 36, n. 11, p. 2211-2214, 1995.

[65] BAO, Z. Self-Assembly in Organic Thin Film Transistors for Flexible Electronic Devices. Material Matters, v. 11, p. 3-6, 2006.

[66] HUANG, D. et al. The Consequences of Interface Mixing on Organic Photovoltaic Device Characteristics. Advanced Functional Materials, 2010.

[67] YING-JIE, X. et al. Increased work function in PEDOT:PSS film under ultraviolet irradiation. Chin. Phys. B, v. 23, n. 3, 2014.

[68] MOULÉ, A. J. et al. Mixed interlayers at the interface between PEDOT : PSS and conjugated polymers provide charge transport control. Journal of Materials Chemistry C, v. 3, p. 2664$2676,2015$.

[69] WILSON, P. et al. Transverse charge transport in inkjet printed poly ( PEDOT : PSS). ORGANIC ELECTRONICS, Elsevier B.V., v. 15, n. 9, p. 2043-2051, 2014.

[70] ABDUlRAZZAQ, O. et al. Comparative Aging Study of Organic Solar Cells Utilizing Polyaniline and PEDOT:PSS as Hole Transport Layers. Applied Materials and Interfaces, v. 7, p. $27667-27675,2015$.

[71] FRIEDEL, B. et al. Effects of Layer Thickness and Annealing of PEDOT : PSS Layers in Organic Photodetectors. Macromolecules, v. 42, p. 6741-6747, 2009.

[72] UNSWORTH, N. K. et al. Comparison of dimethyl sulfoxide treated highly conductive electrodes for use in indium tin oxide-free organic electronic photovoltaic devices. Organic Electronics, Elsevier B.V., v. 15, n. 10, p. 2624-2631, 2014.

[73] ELSCHNER, A. et al. PEDOT: Principles and Applications of an Intrinsically Conductive Polymer. [S.1.]: Taylor and Francis Group, 2011. 
[74] BENHAOUA, B.; ABBAS, S.; RAHAL, A. Effect of film thickness on the structural, optical and electrical properties of FTO thin films prepared by spray ultrasonic for solar cells applications. Superlattices and Microestrutures, v. 83, p. 78-88, 2015.

[75] ABDULLAHI, S. et al. Optical Characterization of Fluorine doped Tin Oxide (FTO) thin films deposited by spray pyrolysis technique and annealed under Nitrogen atmosphere. International Journal of Innovation and Applied Studies, v. 9, n. 2, p. 947-955, 2014.

[76] RAVICHANDRAN, K. et al. Superlattices and Microstructures Effect of annealing on the transparent conducting properties of fluorine doped zinc oxide and tin oxide thin films A comparative study. Superlattices and Microestrutures, v. 83, p. 121-130, 2015.

[77] ROEHRS, M.; ROEHRS, R. Bixin and Norbixin: Chemistry, Production and Health Benefits. Center of Healthy Sciences, p. 261-270, 2000.

[78] OLSON, A.; KRINSKYT, I. Introduction : carotenoids : The colorful, important fascinating world modulators. The FASEB Journal, v. 9, p. 1547-1550, 1995.

[79] MORAIS, F. L. Carotenóides - características biológicas e químicas. Tese (Doutorado) Universidade de Brasília, 2006.

[80] OLIVEIRA, C. G. Extração e caracterização do betacaroteno produzido por Rhodotorula glutinis tendo como substrato o suco de caju. Tese (Doutorado) - Univerisidade Federal do Ceara, 2010.

[81] OLIVEIRA, M. Thermal stability of P3HT and P3HT : PCBM blends in the molten state Thermal stability of P3HT and P3HT : PCBM blends in the molten state. n. JULY, 2013.

[82] NOONAN, J. Color additives in food. p. 597-615, 1975.

[83] ARAUJO, V. F. et al. Produção não - madeireira e desenvolvimento Sustentável na Amazônia. [S.1.], 2007. 1-214 p.

[84] TAHAM, T.; CABRAL, F. A.; BARROZO, M. A. S. Extraction of bixin from annatto seeds using combined technologies. The Journal of Supercritical Fluids, Elsevier B.V., v. 100, p. 175$183,2015$.

[85] SANTOS, F. et al. Spectroscopic and photothermal characterization of annatto : Applications in functional foods. Dyes and pigments, v. 110, p. 72-79, 2014.

[86] SILVA, C. A. N.; BRAGA, S. F. P.; SILVA, A. G. da. Urucum, Bixa orellana L . ( Bixaceae) - um agente importante na regulação de dislipidemias. Natureza online, v. 4, p. 72-76, 2006.

[87] SMITH, J. Chemical and Technical Assessment First draft prepared . Annatto extracts, p. 121, 2006.

[88] MOREIRA, V. S. Atividade antioxidante e caracterização físico - química de variedades de urucueiros in natura e encapsulado. Tese (Doutorado) - Universidade Estadual do Sudoeste da Bahia, 2013. 
[89] GARCIA, C. E. R. et al. Carotenoides bixina e norbixina extraídos do urucum ( Bixa orellana L .) como antioxidantes em produtos cárneos. Ciência Rural, v. 42, p. 1510-1517, 2012.

[90] PEI, Z.; DEVI, B. P.; THIYAGU, S. Study on the Al P3HT PCBM interfaces in electrical stressed polymer solar cell by X-ray photoelectron spectroscopy. Solar Energy Materia, v. 123, p. 1-6, 2014.

[91] DURAES, J. A. Dispositivos Eletrônicos Orgânicos Baseados no Óleo de Buriti. Tese (Doutorado) - Universidade de Brasília, 2008.

[92] SEEMANN, A. et al. Reversible and irreversible degradation of organic solar cell performance by oxygen. Solar Energy, v. 85, n. 6, p. 1238-1249, 2011. ISSN 0038-092X.

[93] ZHUO, B. J.-m. et al. Direct Spectroscopic Evidence for a Photodoping Mechanism in Polythiophene and Poly (bithiophene-alt-thienothiophene ) Organic Semiconductor Thin Films Involving Oxygen and Sorbed Moisture. Advanced Materials, v. 21, p. 4747-4752, 2009.

[94] FOnTANA, J. D. et al. Cores Atraentes e Ação Biológica. Biotecnologia Ciência e Desenvolvimento, p. 40-45, 2000.

[95] AZAROVA, N. A. et al. Fabrication of organic thin-film transistors by spray-deposition for low-cost, large-area electronics. Organic Electronics, Elsevier B.V., v. 11, n. 12, p. 1960-1965, 2010.

[96] LEE, T.-w.; PARK, O. O. Effect of electrical annealing on the luminous efficiency of thermally annealed polymer light-emitting diodes Effect of electrical annealing on the luminous efficiency of thermally annealed polymer light-emitting diodes. Applied Physics Letters, v. 77, p. 11-14, 2000.

[97] LIU, F. et al. Progress in Polymer Science Characterization of the morphology of solutionprocessed bulk heterojunction organic photovoltaics. v. 38, p. 1990-2052, 2013.

[98] LUPTON, J. M.; SAMUEL, I. D. W. Temperature-dependent single carrier device model for polymeric light emitting diodes. Appl. Phys., v. 32, p. 2973-2984, 1999.

[99] SENTAURUS TCAD manuals. Disponível em: < http://www.synopsys.com>.

[100] KUMATANI, A. et al. On Practical Charge Injection at the Metal/Organic Semiconductor Interface. Scientific Reports, v. 3, 2013.

[101] GOZZI, G. Fabricação e caracterização de dispositivos poliméricos emissores de luz com camada ativa de MEH-PPV. Tese (Doutorado) - Universidade de São Paulo, 2008.

[102] SHEN, Y. et al. Bulk and contact resistance in P3HT : PCBM heterojunction solar cells. Solar Energy Materials and Solar Cells, v. 95, p. 2314-2317, 2011.

[103] SCHRODER, D. K. MATERIAL AND DEVICE SEMICONDUCTOR MATERIAL AND DEVICE. Third edit. Arizona: [s.n.], 2006. 
[104] LIU, J. et al. Solvation induced morphological effects on the polymer/metal contacts. Journal of Applied Physics, v. 89, n. 7, 2001.

[105] BANGE, S. et al. The role of poly( 3, 4-ethylenedioxythiophene): poly)(styrenesulphonate) as a hole injection layer in a blue-emitting polymer light-emitting diode. Journal of Applied Physics, v. 104, p. 1-7, 2008.

[106] NARDES, A. M. et al. Conductivity, work function, and environmental stability of PEDOT:PSS thin films treated with sorbitol. Organic Electronics: physics, materials, applications, v. 9 , n. 6 , p. $727-734,2008$.

[107] NAUJOKS, N. et al. Microscopical Investigations of PEDOT : PSS Thin Films. Advanced Functional Materials, v. 19, p. 1215-1220, 2009.

[108] DUDA, J. C. et al. Thermal transport in organic semiconducting polymers Thermal transport in organic semiconducting polymers. Applied Physics Letters, v. 102, 2013.

[109] VERPLOEGEN, B. E. et al. Effects of Thermal Annealing Upon the Morphology of Polymer Fullerene Blends. Chemistry of Materials, v. 24, p. 3923-3931, 2012.

[110] PARKER, I. D. Carrier tunneling and device characteristics in polymer light emitting diodes Carrier tunneling and device characteristics. Journal of Applied Physics, v. 75, n. 3, 1994.

[111] ALOUI, W. et al. Materials Science in Semiconductor Processing Effect of thermal annealing on the electrical properties of P3HT : PC 70 BM nanocomposites. Materials Science in Semiconductor Processing, Elsevier, v. 39, p. 575-581, 2015. 
ANEXOS 


\section{GRÁFICOS COMPLEMENTARES}

I.1 Tendências de expoentes

I.2 Técnicas de deposição PEDOT-PSS: Tensões negativas 


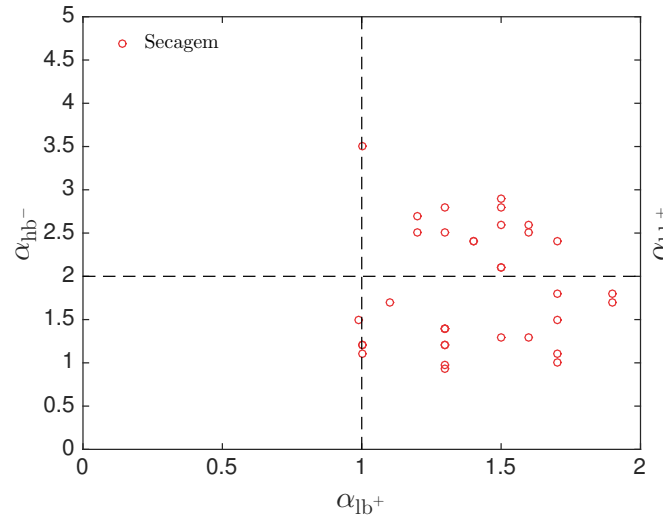

(a)

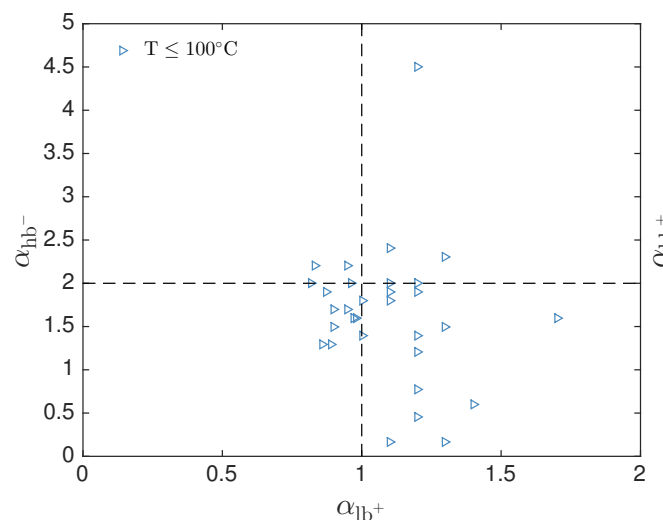

(c)

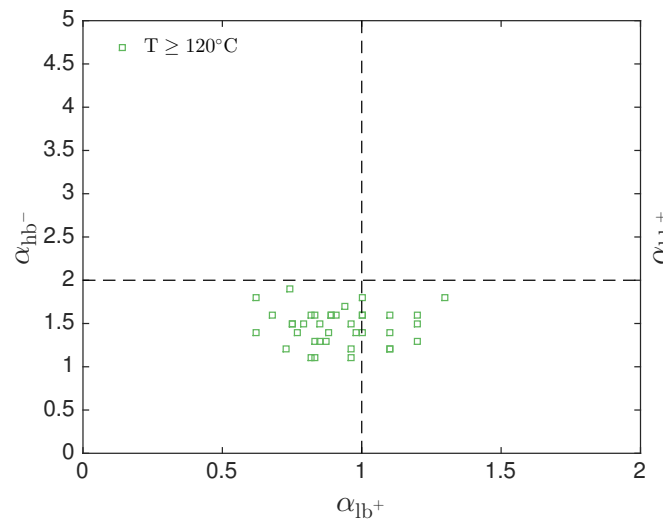

(e)

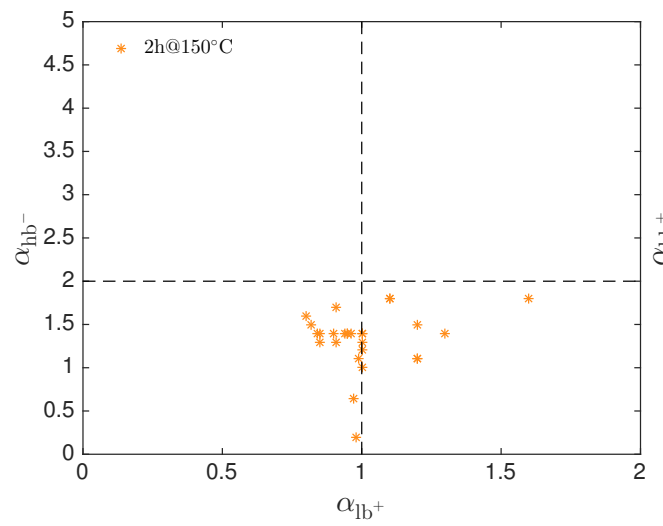

(g)

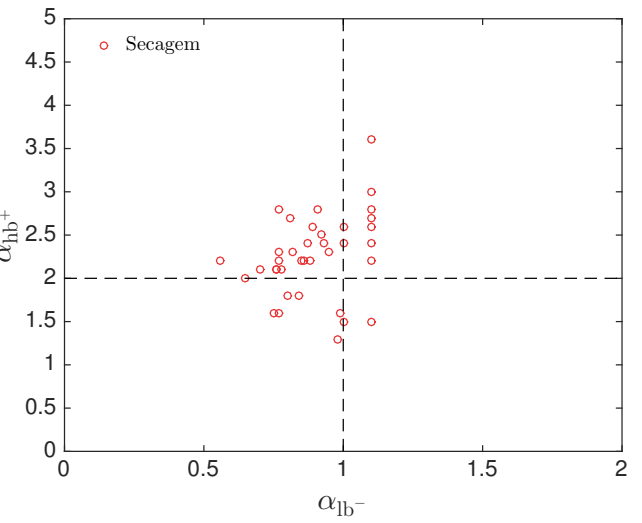

(b)

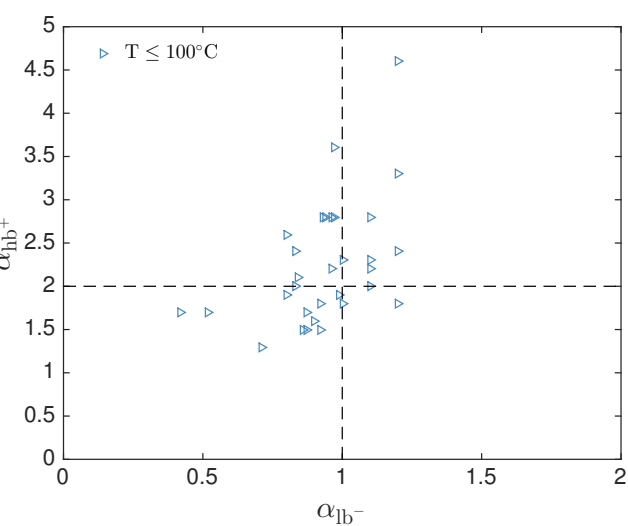

(d)

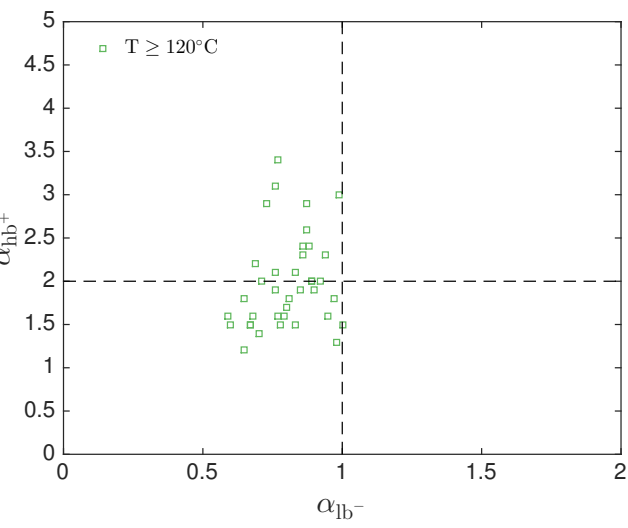

(f)

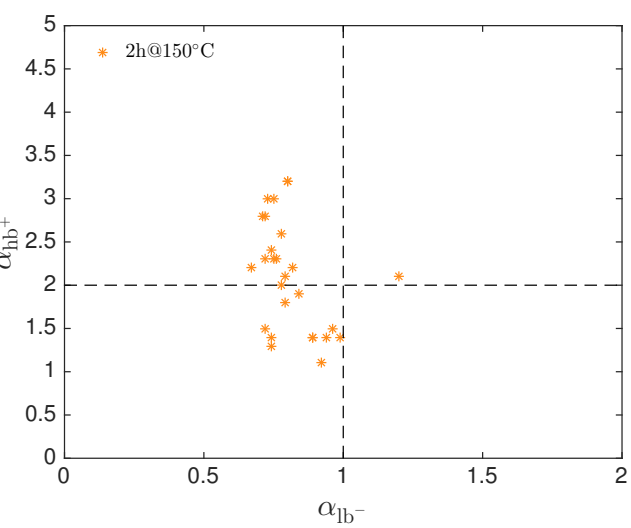

(h)

Figura I.1: Amostras de grupo 1, 2 e annealing, relacionando expoentes obtidos para baixas e altas tensões em ambas polarizações. 


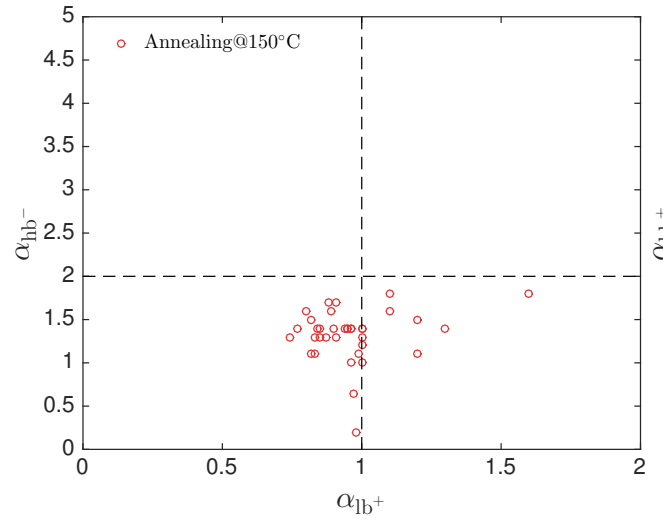

(a)

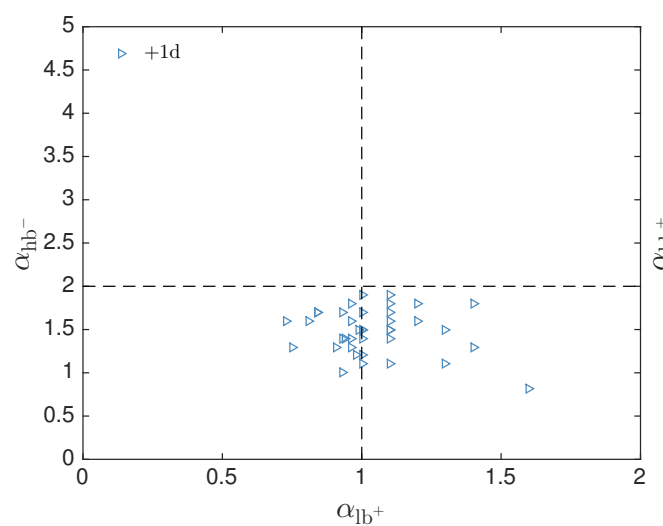

(c)

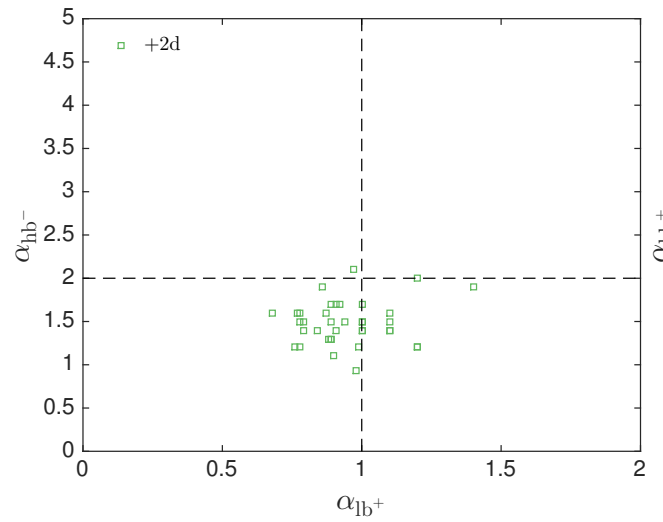

(e)

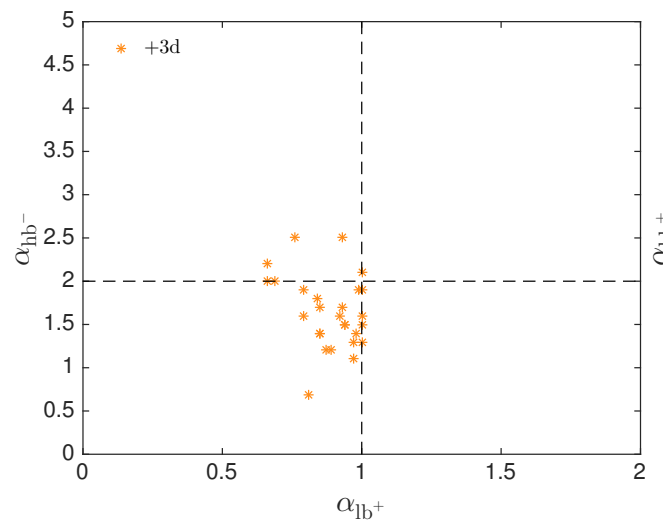

(g)

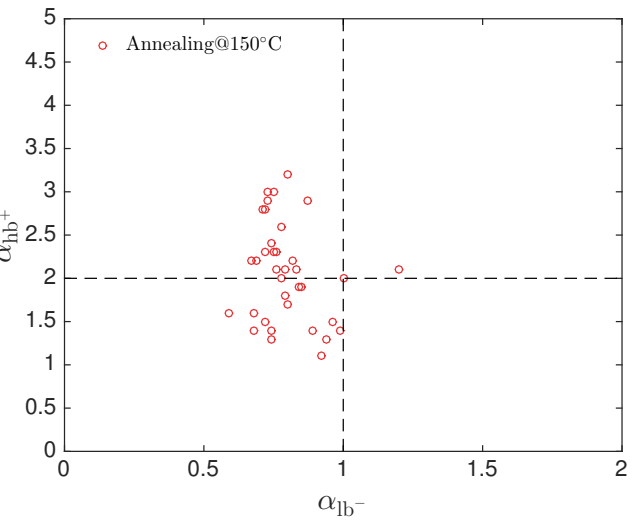

(b)

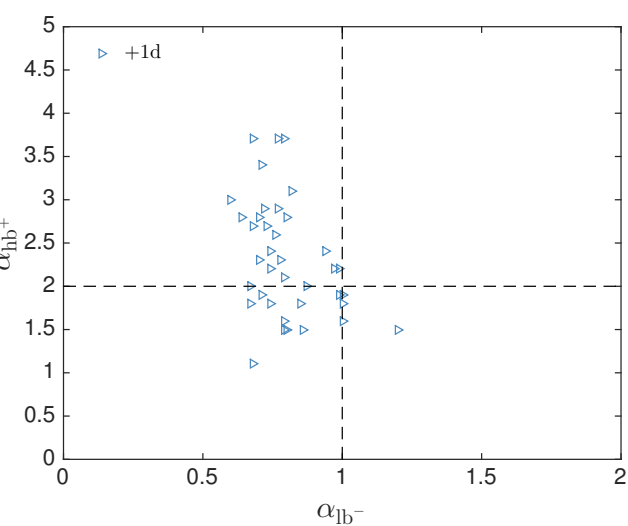

(d)

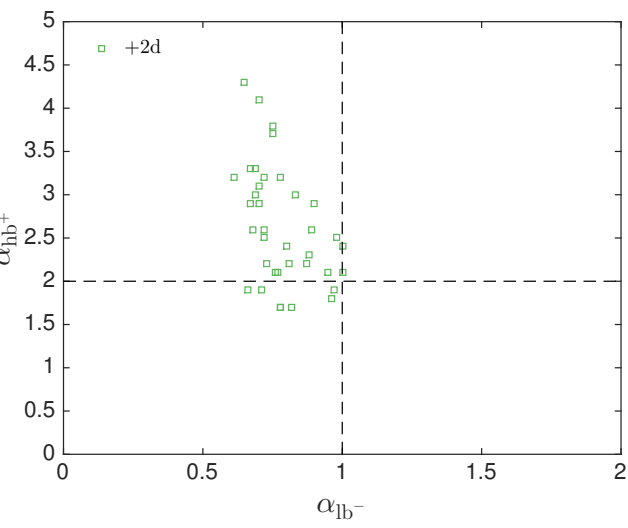

(f)

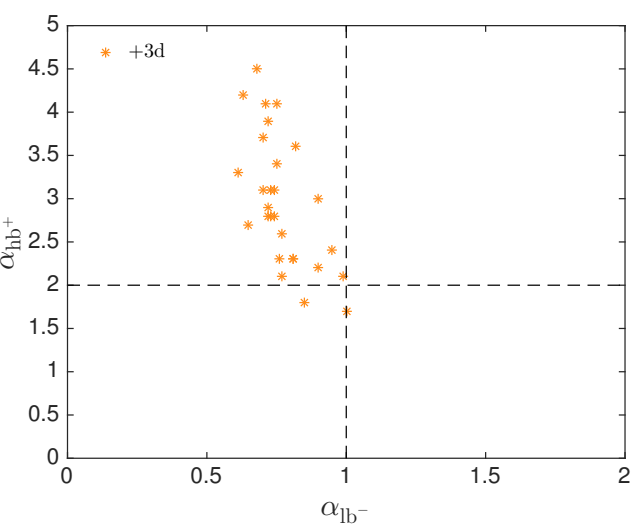

(h)

Figura I.2: Amostras após envelhecimento, relacionando expoentes obtidos para baixas e altas tensões em ambas polarizações. 


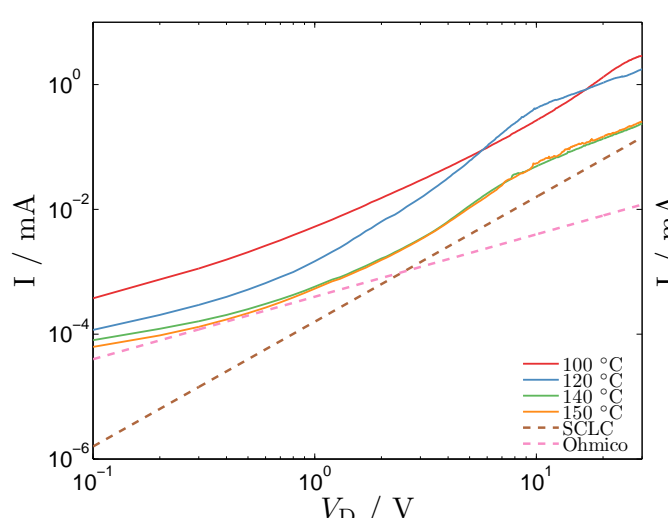

(a)

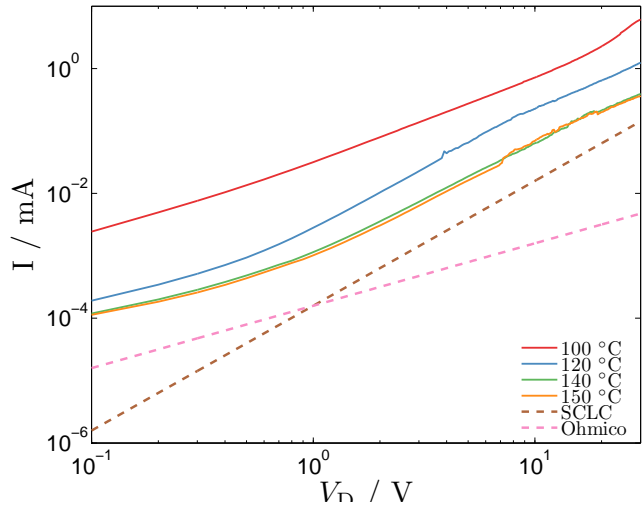

(b)

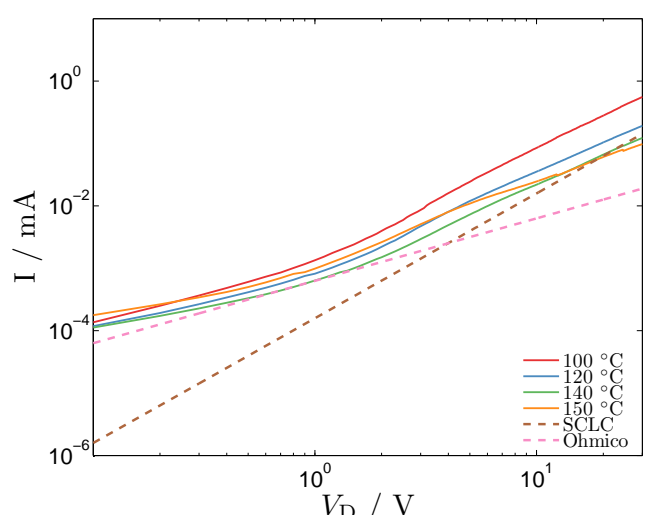

(c)

Figura I.3: Curvas para tensões negativas de dispositivos submetidos à sequência de annealing A, onde a camada de PEDOT:PSS foi obtida por (a) Spin coater (b) Dip coater (c) Imersão. 